\title{
Microglia Actively Remodel Adult Hippocampal Neurogenesis through the Phagocytosis Secretome
}

\author{
Irune Diaz-Aparicio, ${ }^{1,2}$ Iñaki Paris, ${ }^{1,2}$ Virginia Sierra-Torre, ${ }^{1,2}$ Ainhoa Plaza-Zabala, ${ }^{1}$ Noelia Rodríguez-Iglesias, ${ }^{1,2}$ \\ Mar Márquez-Ropero, ${ }^{1,2}$ Sol Beccari, ${ }^{1,2}$ Paloma Huguet, ${ }^{1,2}$ Oihane Abiega, ${ }^{1,2}$ Elena Alberdi, ${ }^{1,2}$ (Carlos Matute, ${ }^{1,2}$ \\ Irantzu Bernales, ${ }^{2}$ Angela Schulz, ${ }^{3}$ Lilla Otrokocsi, ${ }^{4}$ Beata Sperlagh, ${ }^{4}$ Kaisa E. Happonen, ${ }^{5,6}$ Greg Lemke, ${ }^{5,6}$ \\ Mirjana Maletic-Savatic, ${ }^{7,8} \oplus^{-}$Jorge Valero, ${ }^{1,2,9}$ and ${ }^{-}$Amanda Sierra ${ }^{1,2,9}$ \\ ${ }^{1}$ Achucarro Basque Center for Neuroscience, Leioa, Bizkaia 48940, Spain, ${ }^{2}$ University of the Basque Country UPV/EHU, Leioa, Bizkaia 48940, Spain, \\ ${ }^{3}$ Rudolf-Schönheimer-Institute of Biochemistry, Medical Faculty, University Leipzig 04109, Germany, ${ }^{4}$ Laboratory of Molecular Pharmacology, Institute of \\ Experimental Medicine, Hungarian Academy of Sciences, Budapest H-1083, Hungary, ${ }^{5}$ Molecular Neurobiology Laboratory, ${ }^{6}$ Immunobiology and \\ Microbial Pathogenesis Laboratory, Salk Institute for Biological Studies, La Jolla, California 92037, 7 Jan and Dan Duncan Neurological Research Institute at \\ Texas Children's Hospital, Houston, Texas 77030, ${ }^{8}$ Department of Pediatrics and Neuroscience, Program in Developmental Biology, Baylor College of \\ Medicine, Houston, Texas 77030, and ${ }^{9}$ Ikerbasque Foundation, Bilbao, Bizkaia 48013, Spain
}

During adult hippocampal neurogenesis, most newborn cells undergo apoptosis and are rapidly phagocytosed by resident microglia to prevent the spillover of intracellular contents. Here, we propose that phagocytosis is not merely passive corpse removal but has an active role in maintaining neurogenesis. First, we found that neurogenesis was disrupted in male and female mice chronically deficient for two phagocytosis pathways: the purinergic receptor P2Y12, and the tyrosine kinases of the TAM family Mer tyrosine kinase (MerTK)/Axl. In contrast, neurogenesis was transiently increased in mice in which MerTK expression was conditionally downregulated. Next, we performed a transcriptomic analysis of the changes induced by phagocytosis in microglia in vitro and identified genes involved in metabolism, chromatin remodeling, and neurogenesis-related functions. Finally, we discovered that the secretome of phagocytic microglia limits the production of new neurons both in vivo and in vitro. Our data suggest that microglia act as a sensor of local cell death, modulating the balance between proliferation and survival in the neurogenic niche through the phagocytosis secretome, thereby supporting the longterm maintenance of adult hippocampal neurogenesis.

Key words: adult neurogenesis; MerTK/Axl; microglia; P2Y12; phagocytosis; secretome

Significance Statement

Microglia are the brain professional phagocytes and, in the adult hippocampal neurogenic niche, they remove newborn cells naturally undergoing apoptosis. Here we show that phagocytosis of apoptotic cells triggers a coordinated transcriptional program that alters their secretome, limiting neurogenesis both in vivo and in vitro. In addition, chronic phagocytosis disruption in mice deficient for receptors P2Y12 and MerTK/Axl reduces adult hippocampal neurogenesis. In contrast, inducible MerTK downregulation transiently increases neurogenesis, suggesting that microglial phagocytosis provides a negative feedback loop that is necessary for the long-term maintenance of adult hippocampal neurogenesis. Therefore, we speculate that the effects of promoting engulfment/degradation of cell debris may go beyond merely removing corpses to actively promoting regeneration in development, aging, and neurodegenerative diseases.

\section{Introduction}

Neurogenesis, or the formation of new neurons, is a complex process that extends throughout adulthood in specific regions

Received May 2, 2019; revised Dec. 12, 2019; accepted Dec. 13, 2019

Author contributions: I.D.-A., I.P., J.V., and A. Sierra designed research; I.D.-A., I.P., V.S.-T., A.P.-Z., N.R.-I., M.M.-R., S.B., P.H., O.A., E.A., I.B., L.O., K.E.H., J.V., and A. Sierra performed research; I.D.-A., I.P., I.B., J.V., and A. Sierra analyzed data; C.M., B.S., G.L., and A. Sierra contributed unpublished reagents/analytic tools; I.D.-A., I.P., V.S.-T., A.P.-Z., N.R.-I., M.M.-R., S.B., A. Schulz, L.O., B.S., K.E.H., G.L., M.M.-S., J.V., and A. Sierra wrote the paper.

This work was supported by grants from the Spanish Ministry of Economy and Competitiveness (http://www. mineco.gob.es) with FEDER funds to A.S. (BFU2012-32089 and RYC-2013-12817) to A.S. and J.V. (BFU2015-66689); of the mammalian brain. Here we focus on the subgranular zone of the hippocampus, whose radial neural stem cells (rNSCs) generate newborn granule cells in rodents (Ehninger and Kemp- 
ermann, 2008) and humans (Moreno-Jimenez et al., 2019). Nowadays, newly generated neurons are strongly suggested to contribute to hippocampus-dependent learning and memory, among other functions (Deng et al., 2010). Multiple endogenous factors regulate the proliferation, survival, differentiation, and integration of the new neurons in the adult hippocampus. In the cellular niche, one key element is microglia, the resident macrophages of the nervous system that coordinate the brain inflammatory response. The detrimental effect of neuroinflammation on neurogenesis is well described, and is mediated by inflammatory cytokines such as interleukin (IL)- $1 \beta$, tumor necrosis factor $\alpha$ (TNF $\alpha$ ), and IL-6 (Ekdahl et al., 2003; Monje et al., 2003).

Microglia also beneficially affect neurogenesis, as they are capable of producing factors that modulate proliferation or survival of different cells within the neuronal lineage. In vitro studies demonstrate that cultured microglia promote differentiation of precursor cells (Aarum et al., 2003), whereas microglia-conditioned media enhances neuroblast production and neuronal survival (Morgan et al., 2004; Walton et al., 2006). Furthermore, microglia were suggested to inhibit the proliferation of hippocampal rNSCs, as their number inversely correlates with adult hippocampal neurogenesis (Gebara et al., 2013). Recently, experiments using diphtheria toxin-induced ablation of microglia propose that microglia are essential for neuroblast survival (Kreisel et al., 2019) but the mechanisms underlying the regulation of hippocampal neurogenesis by microglia are still unexplored both in vitro and especially in vivo (Sierra et al., 2014).

Here, we focus on another major role of microglia in the adult hippocampal neurogenic niche: the removal of apoptotic newborn cells through phagocytosis (Sierra et al., 2010). The majority of hippocampal newborn cells undergo apoptosis in the first few days of cells' life through adulthood (Beccari et al., 2017) and are immediately recognized and degraded by "unchallenged" microglia (Sierra et al., 2010). Microglia are the brain professional phagocytes compared with other cell types (Sierra et al., 2013) and prevent the release of toxic intracellular contents (Nagata et al., 2010), and thus, this process is essential to avoid alterations of the surrounding tissue.

In this study, we propose that microglial phagocytosis does not conclude with the physical elimination of apoptotic cells, but is followed by a coordinated transcriptional program that triggers the production of neurogenic modulatory factors, which directly contribute to the maintenance and correct regulation of the adult hippocampal neurogenic cascade. We have used constitutive and inducible knock-out (KO) mice to abolish two phagocytosisrelated receptors: the purinergic receptor P2Y12 and the Mer tyrosine kinase (MerTK) of the TAM (Tyro, Axl, and Mer) family. We discovered that chronic phagocytosis deficiency disrupts neurogenesis but acute phagocytosis impairment only transiently increases neurogenesis. In addition, using a combined in vitro

and Competitiveness; V.S.-T. and 0.A. are recipients of pre-doctoral fellowship from the Basque Government; and A.P.-Z. is the recipient of a Juan de la Cierva postdoctoral fellowship from the Spanish Ministry of Economy and Competitiveness. The funders had no role in study design, data collection and analysis, decision to publish, or preparation of the manuscript; UPV/EHU SGlker technical and human support is gratefully acknowledged. We thank Victor Sánchez Zafra for technical support, and I sabel Fariñas, María Domercq, and Ismael Galve-Roperh for thoughtful discussion of the data.

The authors declare no competing financial interests.

Correspondence should be addressed to Amanda Sierra at amanda.sierra@achucarro.org or Jorge Valero at jorge.valero@achucarro.org.

https://doi.org/10.1523/JNEUROSCI.0993-19.2019 Copyright $\odot 2020$ Diaz-Aparicio et al.

This is an open-access article distributed under the terms of the Creative Commons Attribution License Creative Commons Attribution 4.0 International, which permits unrestricted use, distribution and reproduction in any medium provided that the original work is properly attributed. and in vivo based experimental strategy, we found that the secretome of phagocytic microglia limits the production of new neurons to maintain the homeostasis of the adult hippocampal neurogenic niche.

\section{Materials and Methods}

Mice. All experiments were performed in fms-EGFP (MacGreen) mice, except where indicated, in which all microglia express the fluorescent reporter (Sasmono et al., 2003; Sierra et al., 2007). KO mice were provided by Beata Sperlagh, Institute of Experimental Medicine (P2Y12 KO) and Greg Lemke, Salk Institute (MerTK/Axl KO). Microglial-specific, inducible MerTK/Axl mice were generated using Cx3crl ${ }^{\text {CreER }}$ (Parkhurst et al., 2013) and Mertk ${ }^{f l f l}$ (Fourgeaud et al., 2016), described previously. To induce deletion of the Mertk ${ }^{f l / f l}$ allele in $C \times 3 \mathrm{crl} \mathrm{CreER} / \mathrm{H}^{\mathrm{Cert}} \mathrm{k}^{f l f l}$ mice, two doses of tamoxifen dissolved in corn oil $(75 \mathrm{mg} / \mathrm{kg})$ or corresponding volume of corn oil alone (control mice) were administered intraperitoneally at postnatal days (P)21 and P23. All mice used were in a C57BL/6 background. Mice were housed in $12 \mathrm{~h}$ light/dark cycle with ad libitum access to food and water. Mice received a single dose of 5-bromo-2' deoxyuridine (BrdU; $100-150 \mathrm{mg} / \mathrm{kg}$ ) at P28. At $24 \mathrm{~h}$ or $28 \mathrm{~d}$ after BrdU injection, mice were anesthetized with a mixture of ketamine and xylazine $(100 \mathrm{mg} / \mathrm{kg}$ and $10 \mathrm{mg} / \mathrm{kg}$, respectively), perfused with $20 \mathrm{U} / \mathrm{ml}$ heparin in PBS followed by $4 \%$ PFA in PBS. Brains were collected, immersion fixed for $4 \mathrm{~h}$ in $4 \%$ PFA in PBS, and stored in 30\% sucrose, $30 \%$ ethylene glycol at $-20^{\circ} \mathrm{C}$ until analysis. All procedures followed the European Directive 2010/63/EU and NIH guidelines, and were approved by the Ethics Committees of the University of the Basque Country EHU/ UPV (Leioa, Spain; CEBA/205/2011, CEBA/206/2011, CEIAB/82/2011, CEIAB/105/2012).

SH-SY5Y cell line. SH-SY5Y (American Type Culture Collection), a human neuroblastoma cell line derived from the bone marrow of 4-yearold female was used for phagocytic assay experiments. SH-SY5Y cells were grown as an adherent culture in non-coated culture flasks covered with $10-15 \mathrm{ml}$ of medium. The medium consisted of DMEM (Invitrogen), supplemented with $10 \%$ fetal bovine serum (FBS) and $1 \%$ antibiotic/antimycotic (all from Invitrogen). When confluency was reached, cells were trypsinized and re-plated at 1:4.

BV2 cell line. BV2 (Interlab Cell Line Collection San Martino-Instituto Scientifico Tumori-Instituto Nazionale per la Ricerca sul Cancro), a cell line derived from raf/myc-immortalized murine neonatal microglia was used to obtain LPS-induced conditioned media. BV2 cells were grown as an adherent culture in non-coated culture flasks covered with $10-15 \mathrm{ml}$ of medium. The medium consisted of DMEM (Invitrogen), supplemented with $10 \%$ FBS and $1 \%$ antibiotic/antimycotic (all from Invitrogen). When confluency was reached, cells were trypsinized and replated at $1: 4$.

Primary microglia cultures. Primary microglia cultures were performed as previously described (Abiega et al., 2016; Beccari et al., 2018). P0-P1 fms-EGFP mice pup brains were extracted and the meninges were peeled off. The olfactory bulb and cerebellum were discarded and the rest of the brain was then mechanically homogenized by careful pipetting and enzymatically digested with papain $(20 \mathrm{U} / \mathrm{ml}$; Sigma-Aldrich), a cysteine protease enzyme, and DNase $(150 \mathrm{U} / \mu \mathrm{l}$; Invitrogen $)$ for $15 \mathrm{~min}$ at $37^{\circ} \mathrm{C}$. The resulting cell suspension was then filtered through a $40 \mu \mathrm{m}$ nylon cell strainer (Fisher) and transferred to a $50 \mathrm{ml}$ Falcon tube quenched by $5 \mathrm{ml}$ of $20 \%$ FBS (Invitrogen) in HBSS. Afterward, the cell suspension was centrifuged at $200 \times g$ for $5 \mathrm{~min}$, the pellet was resuspended in $1 \mathrm{ml}$ DMEM (Invitrogen) supplemented with 10\% FBS and 1\% antibiotic/ antimycotic (Invitrogen), and seeded in T75 poly-L-lysine-coated (15 $\mu \mathrm{l} / \mathrm{ml}$; Sigma-Aldrich) culture flasks at a density of two brains per flask. Medium was changed the day after and then every 3-4 d, always enriched with granulocyte-macrophage colony stimulating factor $(5 \mathrm{ng} / \mathrm{ml} \mathrm{GM-}$ CSF; Sigma-Aldrich), which promotes microglial proliferation. After confluence (at $37^{\circ} \mathrm{C}, 5 \% \mathrm{CO}_{2}$ for $\sim 14 \mathrm{~d}$ ), microglia cells were harvested by shaking at $100-150 \mathrm{rpm}, 37^{\circ} \mathrm{C}, 4 \mathrm{~h}$. Isolated cells were counted and plated at a density of 80,000 cells/well on poly-L-lysine-coated glass coverslips in 24-well plates for immunofluorescence purposes or 1,000,000 cell/dish on coated Petri dishes for real-time quantitative PCR (qPCR). Microglia were allowed to settle for at least $24 \mathrm{~h}$ before any experiment. 
NPC culture. Neurosphere cultures were performed as previously described (Babu et al., 2011) with some modifications. Briefly, P0-P1 fmsEGFP pups were decapitated and the brains extracted and placed in cold HBSS. The homogenization process was performed as detailed in the Primary microglia cultures section, except that no FBS was used in any step to avoid undesired neurosphere adhesion and differentiation. Afterward, the cell suspension was centrifuged at $200 \times g$ for $5 \mathrm{~min}$, the pellet was resuspended in $1 \mathrm{ml}$ DMEM/F12 with GlutaMAX (Invitrogen) supplemented with $1 \%$ penicillin/streptomycin, $1 \%$ B27, EGF $(12.5 \mathrm{ng} / \mathrm{ml})$, FGF-2 (5 ng/ml; Xapelli et al., 2013). Cells were plated on uncoated Petri dishes (P60); each brain was plated in four Petri dishes with supplemented DMEM/F12. After 6 d, neurospheres were then disaggregated into a single-cell suspension of neuroprogenitor cells (NPCs) using NeuroCult chemical dissociation kit following the manufacturer's instructions and each Petri dish was plated in two 6-multiwell plates. To maintain replicability through the experiments, neurospheres were frozen until their use at $-80^{\circ} \mathrm{C}$ in $15 \%$ DMSO after the first passage.

In vitro phagocytosis assay. The protocol was detailed previously (Beccari et al., 2018). In brief, microglia were allowed to rest and settle for at least $24 \mathrm{~h}$ before phagocytosis experiments. Phagocytosis experiments were performed in DMEM $+10 \%$ FBS to ensure the presence of complement molecules, which are related to microglial phagocytosis in vivo (Diaz-Aparicio and Sierra, 2019) and whose presence determines the immunomodulatory outcome of phagocytosis (Fraser et al., 2010). Primary microglia cells were fed for different time points with SH-SY5Y. The cell line was previously labeled with the membrane marker CM-DiI (5 $\mu \mathrm{m} ; 10 \mathrm{~min}$ at $37^{\circ} \mathrm{C}, 15 \mathrm{~min}$ at $4^{\circ} \mathrm{C}$; Invitrogen) and treated with staurosporine (STP; $3 \mu \mathrm{M}, 4 \mathrm{~h}$; Sigma-Aldrich) to induce apoptosis. Only the floating dead-cell fraction was collected from the supernatant and added to the primary microglia cultures in a proportion of $\sim 1: 1$. Apoptotic cells were visualized and quantified by trypan blue in a Neubauer chamber. Because cell membrane integrity is still maintained in early induced apoptotic cells, cells not labeled with trypan blue were considered apoptotic. The media of naive and phagocytic $(24 \mathrm{~h})$ microglia was immediately stored at $-80^{\circ} \mathrm{C}$ until its use as conditioned media for NPCs.

In some experiments, control and phagocytic microglia were treated with LPS. Three different LPS paradigms were used. In the low LPS concentration paradigm, media was removed and fresh medium with $150 \mathrm{ng} / \mathrm{ml}$ LPS or vehicle (PBS) was added for $18 \mathrm{~h}$ to primary microglia (Fraser et al., 2010). In the high LPS concentration paradigm, medium was removed and fresh medium with $1 \mu \mathrm{g} / \mathrm{ml}$ LPS or vehicle (PBS) was added for $24 \mathrm{~h}$ to primary or BV2 cells (Monje et al., 2003). To control for LPS presence in the phagocytic media, a third paradigm was performed in which primary microglia was treated with $1 \mu \mathrm{g} / \mathrm{ml}$ LPS or vehicle (PBS) for $6 \mathrm{~h}$, then media was changed into fresh media for another $18 \mathrm{~h}$. All supernatants were collected and stored at $-80^{\circ} \mathrm{C}$ until its use as conditioned media for NPCs, and all of them were filter-sterilized before adding to the NPC culture.

NPC proliferation and differentiation. Neurospheres of Passage 1 were thawed and expanded for 1 week before the experiment in proliferative conditions (2 passages were performed in total).The day of the experiment Passage 3 neurospheres were dissociated into NPCs, cells were counted and plated at a 80,000 cells/well density on poly-L-lysine-coated glass coverslips in 24-well plates in supplemented (Penicillin/streptomycin, B27, EGF, and FGF2) DMEM/F12. NPCs were allowed to proliferate for $48 \mathrm{~h}$ (Babu et al., 2011) and then washed with PBS before treatment with conditioned media (CM) from control or phagocytic ( $24 \mathrm{~h}$ ) microglia. For the experimental group, DMEM was also added as a control because it is the media in which microglia were grown. NPCs were then fixed with $4 \%$ PFA for $10 \mathrm{~min}$ at $3 \mathrm{~d}$, and $5 \mathrm{~d}$ of differentiation. For multipotency experiments, NPCs treated for $3 \mathrm{~d}$ with CM (control, $24 \mathrm{~h}$ phagocytosis or DMEM) were transferred back to DMEM/F12 (without trophic factors) medium and were allowed to differentiate for 5 and $9 \mathrm{~d}$. For late survival and differentiation assay, after the $48 \mathrm{~h}$ of proliferation, NPCs were allowed to differentiate in DMEM/F12 (no trophic factors) for $10 \mathrm{~d}$ and then were treated with CM from control or phagocytic $(24 \mathrm{~h})$ microglia or DMEM for another 3 and $5 \mathrm{~d}$.
Calcium imaging. Intracellular calcium imaging experiments were performed as described previously (Alberdi et al., 2013). CM-treated NPCs were incubated and loaded with $5 \mu \mathrm{M}$ Fura-2 AM (Invitrogen) for 30 min at $37^{\circ} \mathrm{C}$ and then washed in HBSS containing 20 mM HEPES, pH 7.4, 10 $\mathrm{mm}$ glucose, and $2 \mathrm{~mm} \mathrm{CaCl}_{2}$ for $10 \mathrm{~min}$ at room temperature. The perfusion chamber was assembled on the platform of an inverted epifluorescence microscope (Zeiss Axiovert 35) equipped with a 150-W xenon lamp Polychrome IV (TILL Photonics) and a Plan Neofluar $40 \times$ oilimmersion objective (Zeiss). NPCs were treated with $50 \mathrm{~mm} \mathrm{KCl,} 10 \mu \mathrm{M}$ AMPA, $1 \mathrm{~mm}$ ATP, and $100 \mu \mathrm{m}$ histamine, sequentially. Cells were allowed to recover their baseline before adding the next compound. Cells were visualized with a digital black/white CCD camera (ORCA; Hamamatsu Photonics). Intracellular calcium signaling responses were calculated as the proportion of different cell phenotypes responding to the different stimuli. The baseline was calculated as the mean of the first $60 \mathrm{~s}$ of recording for each cell. Only peaks that increase or decrease three times the SEM of the baseline were considered as a significant response.

FACS sorting. Microglia cells were isolated from brains as described previously (Sierra et al., 2007; Abiega et al., 2016). The corresponding tissues from fms-EGFP mice were dissected and placed in enzymatic solution (in mm: $116 \mathrm{NaCl}, 5.4 \mathrm{KCl}, 26 \mathrm{NaHCO}_{3}, 1 \mathrm{NaH}_{2} \mathrm{PO}_{4}, 1.5 \mathrm{CaCl}_{2}$, $1 \mathrm{MgSO}_{4}, 0.5 \mathrm{EDTA}, 25$ glucose, $1 \mathrm{~L}$-cysteine) with papain $(20 \mathrm{U} / \mathrm{ml})$ and DNase I $\left(150 \mathrm{U} / \mu \mathrm{l}\right.$; Invitrogen) for digestion at $37^{\circ} \mathrm{C}$ for $15 \mathrm{~min}$. The homogenization process was also helped by careful pipetting. After homogenization, tissue clogs were removed by filtering the cell suspension through a $40 \mu \mathrm{m}$ nylon strainer to a $50 \mathrm{ml}$ Falcon tube quenched by $5 \mathrm{ml}$ of $20 \%$ FBS in HBSS. For further enrichment of microglia, myelin was removed by using Percoll gradients. For this purpose, cells were centrifuged at $200 \times g$ for $5 \mathrm{~min}$ and resuspended in a $20 \%$ solution of isotonic percoll (SIP; 20\% in HBSS), obtained from a previous stock of SIP (9 parts Percoll per 1 part PBS $10 \times$ ). Then, each sample was layered with HBSS poured very slowly by fire-polished pipettes. Afterward, gradients were centrifuged for $20 \mathrm{~min}$ at $200 \times g$ with minimum acceleration and no brake so the interphase was not disrupted. Then the interphase was removed, cells were washed in HBSS by centrifuging at $200 \times g$ for 5 min and pellet was resuspended in $500 \mu \mathrm{l}$ of sorting buffer $(25$ mM HEPES, 5 mM EDTA, 1\% BSA, in HBSS). Microglia cell sorting was performed by FACS Jazz (BD Biosciences), in which the population of green fluorescent cells was selected, collected in Lysis Buffer (Qiagen) containing $0.7 \%$ $\beta$-mercaptoethanol and stored at $-80^{\circ} \mathrm{C}$ until processing.

Administration of microglia $C M$ in vivo. $\mathrm{CM}$ from control and phagocytic (Ph24h) microglia was administrated via osmotic pumps for 6-d to 2 -month-old fms-EGFP mice. Briefly, osmotic pump (flow rate $1 \mu \mathrm{l} / \mathrm{h}$; Model 2001, Alzet) and infusion catheter tubes (Alzet) were filled with the conditioned media $(200 \mu \mathrm{l})$ and connected. Pumps were incubated overnight at $37^{\circ} \mathrm{C}$ in PBS before the surgery. Mice were anesthetized with ketamine/xylazine $(10 / 1 \mathrm{mg} / \mathrm{kg})$ and received a single dose of the analgesic buprenorphine $(1 \mathrm{mg} / \mathrm{kg})$ subcutaneously. The infusion cannulae were inserted at anteroposterior: $-1.7 \mathrm{~mm}$, laterolateral: $-1.6 \mathrm{~mm}$, and dorsoventral: $-1.9 \mathrm{~mm}$ from bregma. The injection site did not reach nor damage the DG in any of the mice included in the study. Afterward, a surface of dental cement was created from the cannulae to the screw to avoid any unwanted removal of the cannulae. Osmotic pumps were inserted inside the skin of the mice. After $6 \mathrm{~d}$, mice were intraperitoneally injected with $\mathrm{BrdU}$ (150 mg/kg, single injection), and transcardially perfused $2 \mathrm{~h}$ later to assess proliferation. For differentiation experiments, $\mathrm{CM}$-containing osmotic pumps were inserted for 6-d to 2-month-old fms-EGFP mice. Pumps were removed at $6 \mathrm{~d}$ and afterward, a single intraperitoneal injection of $\mathrm{BrdU}(150 \mathrm{mg} / \mathrm{kg})$ was administered, and mice were killed $28 \mathrm{~d}$ later.

Gene expression arrays. Gene arrays analysis was performed following the recommendations of the MIAME (Minimum Information About a Microarray Experiment) consortium (Brazma et al., 2001). Cell samples from control, $\mathrm{Ph} 3 \mathrm{~h}$, and $\mathrm{Ph} 24 \mathrm{~h}$ microglia $(n=3$ independent experiments) were lysed and kept at $-80^{\circ} \mathrm{C}$ until processing. Total RNA was isolated using PureLink RNA Mini kit (Ambion), following the manufacturer's instructions. RNA amount was quantified in a UV/VIS NanoDrop 1000 spectrophotometer (ThermoFisher Scientific), and its integrity was analyzed with Lab-chip technology in an Agilent 2100 Bio- 
analyzer in combination with Agilent RNA 6000 Nano Chips. Eukaryote Total RNA Nano Assay was used as type of test. In all samples, RIN $>9.3$, and $28 \mathrm{~S} / 18 \mathrm{~S}>1.3$ values were obtained. Sample labeling, hybridization, and scanning gene expression profiling were performed at the Gene Expression Unit of Genomics Core Facility of the University of the Basque Country UPV/EHU.

One-color microarray-based gene expression analysis was performed following the One-Color ( $\mathrm{p} / \mathrm{n} 5190-2305)$ protocol from Agilent Technologies (Low Input Quick Amp Labeling kit) for the labeling of the samples. First, $50 \mathrm{ng}$ of total RNA were retrotranscribed with the AffinityScript Reverse enzyme Transcriptase (AffinityScript RT), a thermostable modified enzyme derived from Moloney murine leukemia virus retrotranscriptase, using promoter-coupled T7 Oligo dT primers. The double-stranded cDNA synthesized by AffinityScript RT was transcribed in vitro by the T7 RNA pol in the presence of Cy3-CTP to generate labeled and amplified cRNA. The labeled samples were purified with columns of RNeasy Mini kit (Qiagen). Subsequently the labeled samples were quantified in the NanoDrop ND-1000 to determine the performance of the specific activity of the fluorochromes after labeling. All the hybridized samples met the following minimum requirements: yield $>0.825 \mu \mathrm{g}$ per reaction and cyanine 3 -specific activity $>6 \mathrm{pmol} / \mu \mathrm{g}$.

For the hybridization, $600 \mathrm{ng}$ of labeled cRNA were fragmented and cohybridized to SurePrint G3 Mouse GE 8X60K Microarray Design ID: 028005. Each array/slide contained 8 identical subarrays of $>60,00060-$ mer oligonucleotides of high resolution and performance. It contained probes for 55,681 sequences or transcripts (biological features or noncontrol features). Several of these biological probes were replicated 10 times for the calculations and quality control measurements (QCMetrics) of the microarrays. It also contained probes for internal positive controls (spike-ins), which were added to the RNA sample before labeling and were used for evaluation and verification of the microarray processing. Manual washing method was performed following Agilent's recommendations to prevent ozone-related problems.

Slides were scanned on a G2565CA Microarray DNA Scanner from Agilent Technologies with a resolution of $3 \mu \mathrm{m}$ and a Tiff image size of 20bit, using the Scan software v8.5.1 with default settings (Scan profile Agilent, G3_GX_1color). The scanned TIFF images were processed and the fluorescence of the probes quantified using Agilent Feature Extraction software 10.7.3.1. Feature Extraction protocol for data extraction: GE1_107_Sep09; Design File: 28005_D_F_20140728. Software extracts information of the raw fluorescence signal (mean signal) for the fluorochrome or channel (Cy3: green channel) from the spot containing the probes (positive and negative controls and no controls or biological feature) and the background, obtained from the negative controls (which contains sequences for which no hybridization is expected, nonspecific binding indicators).

Default parameters (Agilent Feature Extraction software 10.7.3.1) for one-color gene expression microarrays were used for flagging of nonuniform features, population outliers for replicated probes, and features with no significant intensities in Cy3 channel. Agilent Feature Extraction raw data were processed with software GeneSpring GX 13.0 (Agilent Technologies). Probes not present in any sample were filtered out. A list of the filtered 36,665 probes was used in the statistical analysis.

Tissue or cultured cells RNA isolation and retrotranscription. The corresponding tissue (P8 hippocampi for positive PCR controls) was rapidly isolated immediately under tribromoethanol overdose, and stored at $-80^{\circ} \mathrm{C}$. Tissue was disrupted with a roto-stator homogenizer with Lysis Buffer (Qiagen) containing 0.7\% $\beta$-mercaptoethanol and stored at $-80^{\circ} \mathrm{C}$ until processed. Cultured cells $(>500,000$ cells) were lysed and stored at $-80^{\circ} \mathrm{C}$ until processed. Total RNA was isolated using Qiagen RNeasy Mini Kit (Qiagen), following the manufacturer's instructions, including a DNase treatment step to eliminate genomic DNA residues. RNA was quantified in a NanoDrop 2000, and $1.5 \mu \mathrm{g}$ were retrotranscribed using random hexamers (Invitrogen) and Superscript III Reverse Transcriptase kit (Invitrogen), following the manufacturer's instructions in a Veriti Thermal Cycler (Applied Biosystems).

FACS-sorted cells RNA isolation and retrotranscription. RNA from FACS-sorted microglia $(<500,000$ cells $)$ was isolated by RNeasy Plus micro kit (Qiagen) according to the manufacturer's instructions, and the
RNA was retrotranscribed using an iScript Advanced cDNA Synthesis Kit (Bio-Rad) following the manufacturer's instructions in a Veriti Thermal Cycler (Applied Biosystems).

Real-time $q P C R$. Real-time qPCR was performed following MIQE guidelines (Minimal Information for Publication of Quantitative Real Time Experiments; Bustin, 2010). Three replica of $1.5 \mu$ l of a 1:3 dilution of cDNA were amplified using Power SYBR Green (Bio-Rad) for tissue or cell culture experiments or SsoFast EvaGreen Supermix (Bio-Rad) for FACS-sorted microglia experiments in a CFX96 Touch Real-Time PCR Detection System (Bio-Rad). The amplification protocol for both enzymes was $3 \min 95^{\circ} \mathrm{C}$, and 40 cycles of $10 \mathrm{~s}$ at $95^{\circ} \mathrm{C}, 30 \mathrm{~s}$ at $60^{\circ} \mathrm{C}$.

Primers. Primers were designed to amplify exon-exon junctions using PrimerBlast (NIH) to avoid amplification of contaminating genomic DNA, and their specificity was assessed using melting curves and electrophoresis in $2 \%$ agarose gels. Primer sequences are listed in Table 1 . For each set of primers, the amplification efficiency was calculated using the software LinRegPCR (Ramakers et al., 2003) or standard curve of 1:2 consecutive dilutions, and was used to calculate the relative amount using the following formula:

$$
\Delta \Delta C t=\frac{(1+\text { eff } \cdot \text { target gene })^{(C t \text { sample }- \text { Ct control })}}{(1+\text { eff } \cdot \text { reference gene })^{(C t \text { sample }- \text { Ct control })}} .
$$

Up to three independent reference genes were compared: L27A, which encodes a ribosomal protein of the 60S subunit (Sierra et al., 2007); OAZ-1, which encodes ornithine decarboxylase antizyme, a rate-limiting enzyme in the biosynthesis of polyamines and recently validated as reference gene in rat and human (Kwon et al., 2009); and HPRT, which encodes hypoxanthine guanine phosphoribosyl transferase (van de Moosdijk and van Amerongen, 2016). The expression of L27A, OAZ-1, and HPRT remained constant independently of time and treatments, validating their use as reference genes. In all experiments, the pattern of mRNA expression was similar using the assigned couple of reference genes, and in each experiment the reference gene that rendered lower intragroup variability was used for statistical analysis.

Immunofluorescence. Six series of 50- $\mu$ m-thick coronal sections of mouse brains were cut using a Leica VT 1200 S vibrating blade microtome (Leica Microsystems). Fluorescent immunostaining was performed following standard procedures (Sierra et al., 2010; Beccari et al., 2018). Free-floating vibratome sections were blocked in permeabilization solution $(0.3 \%$ Triton X-100, 0.5\% BSA in PBS; all from Sigma-Aldrich) for $3 \mathrm{~h}$ at room temperature (RT), and then incubated overnight with the primary antibodies diluted in the permeabilization solution at $4^{\circ} \mathrm{C}$. For BrdU labeling an antigen retrieval procedure was performed by incubating in $2 \mathrm{M} \mathrm{HCl}$ for $30 \mathrm{~min}$ at $37^{\circ} \mathrm{C}$ and then washing with $0.1 \mathrm{M}$ sodium tetraborate for $10 \mathrm{~min}$ at RT before the blockade of the sections. After overnight incubation with primary antibodies, brain sections were thoroughly washed with $0.3 \%$ Triton in PBS. Next, the sections were incubated with fluorochrome-conjugated secondary antibodies and DAPI ( 5 $\mathrm{mg} / \mathrm{ml}$; Sigma-Aldrich) diluted in the permeabilization solution for $3 \mathrm{~h}$ at RT. After washing with PBS, the sections were mounted on glass slides with Dako Cytomation Fluorescent Mounting Medium.

Primary microglial cultures were fixed for $10 \mathrm{~min}$ in $4 \%$ PFA and then transferred to PBS. Fluorescent immunostaining was performed following standard procedures (Abiega et al., 2016; Beccari et al., 2018). Coverslips with primary microglial cultures were blocked in $0.1 \%$ Triton X-100, 0.5\% BSA in PBS for 30 min at RT. The cells were then incubated with primary antibodies in permeabilization solution $(0.2 \%$ Triton $\mathrm{X}-100,0.5 \%$ BSA in PBS) for $1 \mathrm{~h}$ at RT, rinsed in PBS and incubated in the secondary antibodies containing DAPI $(5 \mathrm{mg} / \mathrm{ml})$ in the permeabilization solution for $1 \mathrm{~h}$ at RT. After washing with PBS, primary cultures were mounted on glass slides with Dako Cytomation Fluorescent Mounting Medium.

For fluorouridine labeling, SH-SY5Y were treated with $2 \mathrm{~mm} 5^{\prime}$ fluorouridine (Sigma-Aldrich) for $30 \mathrm{~min}$. Afterward, cells were fixed in $4 \%$ PFA with $0.5 \%$ Triton X-100. The immunofluorescence was performed as described with primary microglial cultures and anti-BrdU primary antibody was used to detect fluorouridine. 
Table 1. qPCR primer sequences

\begin{tabular}{|c|c|c|c|c|}
\hline & Gene & Gene Bank & Amplicon size & Sequence $5^{\prime}-3^{\prime}$ \\
\hline \multirow[t]{4}{*}{ Reference genes } & OAZ1 & NM_008753 & 51 & Fwd AGCGAGAGTTCTAGGGTTGCC \\
\hline & & & & $\operatorname{Rev}$ CCCCGGACCCAGGTTACTAC \\
\hline & L27A & BC086939 & 101 & $\begin{array}{l}\text { Fwd TGTTGGAGGTGCCTGTGTTCT } \\
\text { Rev CATGCAGACAAGGAAGGATGC }\end{array}$ \\
\hline & HPRT & NM_013556.2 & 150 & $\begin{array}{l}\text { Fwd ACAGGCCAGACTTTGTTGGA } \\
\text { Rev ACTTGCGCTCATCTTAGGCT }\end{array}$ \\
\hline \multirow[t]{3}{*}{ Phagocytosis receptors } & P2Y12 & NM_027571 & 88 & $\begin{array}{l}\text { Fwd GCAGAACCAGGACCATGGAT } \\
\text { Rev CTGACGCACAGGGTGCTG }\end{array}$ \\
\hline & MerTK & NM_008587.1 & 131 & $\begin{array}{l}\text { Fwd AAGGTCCCCGTCTGTCCTAA } \\
\text { Rev GCGGGGAGGGGATTACTTTG }\end{array}$ \\
\hline & Axl & NM_009465.4 & 86 & $\begin{array}{l}\text { Fwd GTTGGTGTCTGGAGGATGGG } \\
\text { Rev TGTGTGTCCTTATGGGCTGC }\end{array}$ \\
\hline \multirow[t]{3}{*}{ Peptides and hormones } & VGF & NM_001039385.1 & 74 & $\begin{array}{l}\text { Fwd CACCGGCTGTCTCTGGC } \\
\text { Rev AAGGAAGCAGAAGAGGACGG }\end{array}$ \\
\hline & Cartpt & NM_013732.7 & 106 & $\begin{array}{l}\text { Fwd GCGCTATGTTGCAGATCGAAG } \\
\text { Rev GCGTCACACATGGGGACTTG }\end{array}$ \\
\hline & FGF2 & NM_008006.2 & 113 & $\begin{array}{l}\text { Fwd CGGCTGCTGGCTTCTAAGTG } \\
\text { Rev AGTGCCACATACCAACTGGAG }\end{array}$ \\
\hline \multirow[t]{5}{*}{ Trophic factors } & VEGFA & NM_001025250.3 & 88 & $\begin{array}{l}\text { Fwd GGCCTCCGAAACCATGAACT } \\
\text { Rev CTGGGACCACTTGGCATGG }\end{array}$ \\
\hline & $\operatorname{PDGF} \alpha$ & NM_008808.3 & 94 & $\begin{array}{l}\text { Fwd TACCCCGGGAGTTGATCGAG } \\
\text { Rev TCAGCCCCTACGGAGTCTATC }\end{array}$ \\
\hline & IGF-1 & $\begin{array}{l}\text { NM_010512.4 } \\
\text { NM_184052.3 } \\
\text { NM_001111274.1 } \\
\text { NM_001111275.1 } \\
\text { NM_001111276.1 }\end{array}$ & 122 & $\begin{array}{l}\text { Fwd TTACTTCAACAAGCCCACAGG } \\
\text { Rev GTGGGGCACAGTACATCTCC }\end{array}$ \\
\hline & EGF & NM_010113.3 & 136 & $\begin{array}{l}\text { Fwd GGACTGAGTTGCCCTGACTC } \\
\text { Rev CAATATGCATGCACACGCCA }\end{array}$ \\
\hline & GDNF & NM_010275.2 & 145 & $\begin{array}{l}\text { Fwd CGCTGACCAGTGACTCCAA } \\
\text { Rev TGCCGATTCCTCTCTCTTCG }\end{array}$ \\
\hline Matrix protein & Mmp3 & NM_010809.2 & 88 & $\begin{array}{l}\text { Fwd ACCCAGTCTACAAGTCCTCCA } \\
\text { Rev GGAGTTCCATAGAGGGACTGA }\end{array}$ \\
\hline \multirow[t]{2}{*}{ Surface ligands } & Jag1 & NM_013822.5 & 119 & $\begin{array}{l}\text { Fwd TTCAGGGGGATCTTGCATCA } \\
\text { Rev CACACCAGACCTTGGAGCAG }\end{array}$ \\
\hline & D\|l4 & NM_019454.3 & 113 & $\begin{array}{l}\text { Fwd GGTTACACAGTGAGAAGCCAGA } \\
\text { Rev GGCAATCACACACTCGTTCC }\end{array}$ \\
\hline \multirow[t]{5}{*}{ Cytokines } & Csf3 & NM_009971.1 & 70 & $\begin{array}{l}\text { Fwd GCAGCCCAGATCACCCAGAAT } \\
\text { Rev TGCAGGGCCATTAGCTTCAT }\end{array}$ \\
\hline & IL1 $\beta$ & NM_000576.2 & 72 & $\begin{array}{l}\text { Fwd AGATGAAGTGCTCCTTCCAGG } \\
\text { Rev GGTCGGAGATTCGTAGCTGG }\end{array}$ \\
\hline & IL6 & NM_000600.3 & 107 & $\begin{array}{l}\text { Fwd GAAAGCAGCAAAGAGGCACTG } \\
\text { Rev TTCACCAGGCAAGTCTCCTCAT }\end{array}$ \\
\hline & $\operatorname{TNF} \alpha$ & NM_000594.3 & 142 & $\begin{array}{l}\text { Fwd TGCACTTTGGAGTGATCGGC } \\
\text { Rev GCTTGAGGGTTTGCTACAACA }\end{array}$ \\
\hline & $\operatorname{TGF} \beta$ & NM_000660.5 & 112 & $\begin{array}{l}\text { Fwd TCCTGGCGATACCTCAGCAA } \\
\text { Rev CAATTTCCCCTCCACGGCTC }\end{array}$ \\
\hline
\end{tabular}

List of primers used to amplify reference genes, phagocytosis receptors, peptides and hormones, trophic factors, matrix protein, surface ligands, and cytokines. The gene name, Gene Bank accession number, amplicon size, and sequence are listed.

NPC cultures were fixed for $10 \mathrm{~min}$ in 4\% PFA and then transferred to PBS. Coverslips containing the cells were blocked in blocking solution $(0.5 \%$ Triton X-100, 3\% BSA in PBS) for $1 \mathrm{~h}$ at RT, and then incubated overnight with the primary antibodies diluted in the permeabilization solution $(0.2 \%$ Triton X-100, 3\% BSA in PBS) at $4^{\circ} \mathrm{C}$. After overnight incubation, coverslips were allowed to warm at RT and were thoroughly rinsed in PBS. Next, the coverslips were incubated with fluorochrome-conjugated secondary antibodies and DAPI ( $5 \mathrm{mg} / \mathrm{ml}$; Sigma-Aldrich) diluted in the permeabilization solution for $2 \mathrm{~h}$ at RT. After washing with PBS, the coverslips were mounted on glass slides with Dako Cytomation Fluorescent Mounting Medium.

Western blot. CM-treated NPCs were directly lysed in RIPA buffer containing protease and phosphatase inhibitor cocktail (100×; ThermoFisher Scientific). Cells were sonicated for $5 \mathrm{~s}$ and then centrifuged $(10,000 \times g, 10 \mathrm{~min})$. Solubilized protein was quantified in triplicates by BCA Assay Kit (ThermoFisher Scientific) at $590 \mathrm{~nm}$ using a microplate reader (Synergy HT, BioTek). Ten to $15 \mu \mathrm{g}$ of protein (denatured with $\beta$-mercaptoethanol) were loaded onto Tris-glycine gradient polyacrylamide gels (8-16\%; ThermoFisher Scientific) and run at $120 \mathrm{~V}$ for 90 min. Protein samples were then blotted to nitrocellulose membranes $(0.45 \mu \mathrm{m}$ pore size; ThermoFisher Scientific) at $220 \mathrm{~mA}$ for $2 \mathrm{~h}$. Transfer efficiency was verified by Ponceau S (Sigma-Aldrich) staining. For immunoblotting, membranes were rinsed in Tris-Buffered Saline containing $0.1 \%$ Tween 20 (TBS-T; Sigma-Aldrich) and then blocked for $1 \mathrm{~h}$ in TBS-T containing $5 \%$ powder milk. Membranes were afterward incubated with rabbit primary antibodies for REST (1:500; EMD, Millipore), and phosphorylated Smad 1/5/9 (1:500; Cell Signaling Technology), and mouse primary antibodies for Smad 1 (1:500; Santa Cruz Biotechnology), Ascl1 (1:500; BD Biosciences), and $\beta$-actin (1:5000; SigmaAldrich), in TBS-T containing $4 \%$ BSA overnight $\left(4^{\circ} \mathrm{C}\right.$, shaker). Next day, membranes were rinsed and incubated with horseradish peroxidaseconjugated anti-rabbit (1:5000) and anti-mouse (1:5000) secondary antibodies (Cell Signaling Technology) in TBS-T containing 5\% powder 
Table 2. Statistics for Figures 1 and 2

\begin{tabular}{|c|c|c|c|c|c|}
\hline Figure & Parameter & Groups & Statistical test & Statistic & $p$ \\
\hline \multirow[t]{4}{*}{$1 B$} & Ph index & \multirow[t]{4}{*}{ WT vs P2Y12 K0 (1 m + 1d) } & Unpaired $t$ test & $t_{(6)}=13.5$ & $p<0.001$ \\
\hline & Ph capacity & & Unpaired $t$ test & $t_{(6)}=5.08$ & $p=0.002$ \\
\hline & Apoptosis & & Unpaired $t$ test & $t_{(6)}=1.17$ & $p=0.287$ \\
\hline & Microglia & & Unpaired $t$ test & $t_{(6)}=-0.05$ & $p=0.964$ \\
\hline \multirow[t]{4}{*}{$1 C$} & Ph index & \multirow[t]{4}{*}{ WT vs MerTK/AxI KO (1 m) } & Unpaired $t$ test & $t_{(4)}=-3.97$ & $p<0.001$ \\
\hline & Ph capacity & & Unpaired $t$ test & $t_{(4)}=2.90$ & $p=0.044$ \\
\hline & Apoptosis & & Unpaired $t$ test & $t_{(4)}=-3.97$ & $p=0.017$ \\
\hline & Microglia & & Unpaired $t$ test & $t_{(4)}=0.98$ & $p=0.382$ \\
\hline \multirow[t]{2}{*}{$1 E$} & Neuroblasts & \multirow[t]{2}{*}{ WT vs P2Y12 K0 (1 m + 1d) } & Unpaired $t$ test & $t_{(6)}^{(4)}=10.83$ & $p<0.001$ \\
\hline & Proliferating Neuroblasts & & Unpaired $t$ test & $t_{(6)}=3.51$ & $p=0.013$ \\
\hline \multirow[t]{2}{*}{$1 F$} & Neuroblasts & \multirow[t]{2}{*}{ WT vs MerTK/AxI KO (1 m) } & Unpaired $t$ test & $t_{(4)}=2.97$ & $p=0.041$ \\
\hline & Proliferating Neuroblasts & & Unpaired $t$ test & $t_{(4)}=0.38$ & $p=0.723$ \\
\hline \multirow[t]{2}{*}{$2 B$} & Newborn cells & \multirow[t]{2}{*}{ WT vs P2Y12 K0 (1 m $+4 \mathrm{w})$} & Unpaired $t$ test & $t_{(8)}^{(4)}=2.72$ & $p=0.026$ \\
\hline & Newborn neurons & & Unpaired $t$ test & $t_{(8)}=2.68$ & $p=0.028$ \\
\hline \multirow[t]{4}{*}{$2 C$} & Ph index & \multirow[t]{4}{*}{ WT vs P2Y12 K0 (1 m $+4 \mathrm{w})$} & Unpaired $t$ test & $t_{(6)}^{(1)}=7.45$ & $p<0.001$ \\
\hline & Ph capacity & & Unpaired $t$ test & $t_{(6)}=9.93$ & $p<0.001$ \\
\hline & Apoptosis & & Unpaired $t$ test & $t_{(6)}=1.17$ & $p=0.287$ \\
\hline & Microglia & & Unpaired $t$ test & $t_{(6)}=-0.05$ & $p=0.964$ \\
\hline \multirow[t]{3}{*}{$2 E$} & Ph index & \multirow[t]{4}{*}{ WT vs P2Y12 K0 (7 m) } & Unpaired $t$ test & $t_{(8)}=4.21$ & $p=0.003$ \\
\hline & Apoptosis & & Unpaired $t$ test & $t_{(8)}=-0.18$ & $p=0.863$ \\
\hline & Microglia & & Unpaired $t$ test & $t_{(8)}^{(8)}=-0.95$ & $p=0.375$ \\
\hline $2 G$ & Neuroblasts & & Unpaired $t$ test & $t_{(8)}=3.14$ & $p=0.014$ \\
\hline \multirow[t]{3}{*}{21} & $\mathrm{P} 2 \mathrm{Y} 12$ & \multirow{3}{*}{ GFP + vs GFP - } & Unpaired $t$ test & $t_{(4)}^{(0)}=552,3$ & $p<0.001$ \\
\hline & MerTK & & Unpaired $t$ test & $t_{(4)}=14.91$ & $p<0.001$ \\
\hline & Axl & & Unpaired $t$ test & $t_{(4)}^{(4)}=1.82$ & $p=0.144$ \\
\hline
\end{tabular}

Table 3. Statistics for Figure 3

\begin{tabular}{|c|c|c|c|c|c|}
\hline Figure & Parameter & Groups & Statistical test & Statistic & $p$ value \\
\hline \multirow[t]{4}{*}{$3 E$} & Ph index & \multirow[t]{4}{*}{ Control vs iKO (1 m + 1d) } & Unpaired $t$ test & $t_{(4)}=18.40$ & $p<0.001$ \\
\hline & Ph capacity & & Unpaired $t$ test & $t_{(4)}=3.40$ & $p=0.027$ \\
\hline & Apoptosis & & Unpaired $t$ test & $t_{(4)}=-2.17$ & $p=0.096$ \\
\hline & Microglia & & Unpaired $t$ test & $t_{(4)}=1.17$ & $p=0.308$ \\
\hline \multirow[t]{4}{*}{$3 F$} & Ph index & \multirow[t]{4}{*}{ Control vsiKO (1 m + 4 w) } & Unpaired $t$ test & $t_{(5)}=19.56$ & $p<0.001$ \\
\hline & Ph capacity & & Unpaired $t$ test & $t_{(5)}=4.53$ & $p=0.006$ \\
\hline & Apoptosis & & Unpaired $t$ test & $t_{(5)}=-2.40$ & $p=0.062$ \\
\hline & Microglia & & Unpaired $t$ test & $t_{(5)}=1.33$ & $p=0.240$ \\
\hline \multirow[t]{2}{*}{$3 H$} & Proliferating cells & \multirow[t]{2}{*}{ Control vs iKO (1 m + 1d) } & Unpaired $t$ test & $t_{(4)}=-3.79$ & $p=0.019$ \\
\hline & Proliferating neuroblasts & & Unpaired $t$ test & $t_{(4)}=-3.30$ & $p=0.030$ \\
\hline 31 & Neuroblasts & Control vsiK0 $(1 \mathrm{~m}+1 \mathrm{~d})$ & Unpaired $t$ test & $t_{(4)}=-0.54$ & $p=0.616$ \\
\hline \multirow[t]{2}{*}{$3 K$} & Newborn cells & \multirow[t]{2}{*}{ Control vs iKO (1 m + 4w) } & Unpaired $t$ test & $t_{(8)}=1.77$ & $p=0.114$ \\
\hline & Newborn neurons & & Unpaired $t$ test & $t_{(8)}=0.63$ & $p=0.547$ \\
\hline $3 L$ & $\mathrm{BrdU}^{+}$yield & Control vsiKO $(1 \mathrm{~m}+4 \mathrm{w})$ & Unpaired $t$ test & $t_{(8)}=5.95$ & $p<0.001$ \\
\hline
\end{tabular}

milk. After rinsing membranes, protein was visualized by enhanced chemiluminescence using Supersignal West Femto Maximum Sensitivity Substrate (ThermoFisher Scientific) in a ChemiDoc imaging system (Bio-Rad). Band intensity was quantified using the Gel Analyzer method of Fiji software. Phospho-Smad 1/5/9 levels were normalized to total levels of Smad 1. $\beta$-actin was used as loading control.

Image analysis. All fluorescence immunostaining images were collected using an Olympus FluoView or a Leica SP8 laser-scanning microscope using a $40 \times$ oil-immersion objective and a $z$-step of $0.7 \mu \mathrm{m}$. All images were imported into Adobe Photoshop 7.0 in Tiff format. Brightness, contrast, and background were adjusted equally for the entire image using the "brightness and contrast" and "levels" controls from the "image/adjustment" set of options without any further modification. For tissue sections, two to three 20 - $\mu$ m-thick $z$-stacks of the sections containing the septal hippocampus from one vibratome series was analyzed (usually 6 slices, spanning from -1 to $-2.5 \mathrm{~mm}$ in the AP axes, from bregma), to avoid variability due to the differential regulation of neurogenesis in the septal and temporal regions of the hippocampus. For primary cultures, over $4-5 z$-stacks were obtained per coverslip.

Phagocytosis analysis in vivo and in vitro. The analysis of phagocytosis in vivo was performed as described in a series containing the six most septal sections (Abiega et al., 2016; Beccari et al., 2018). Apoptotic cells were defined based on their nuclear morphology after DAPI staining as cells in which the chromatin structure (euchromatin and heterochromatin) was lost and appeared condensed and/or fragmented (pyknosis/ karyorrhexis). Phagocytosis was defined as the formation of an enclosed, three-dimensional pouch of microglial processes surrounding an apoptotic cell. In tissue sections, the number of apoptotic cells, phagocytosed cells, BrdU + cells, and microglia were estimated using unbiased stereology in the volume of the DG contained in the $z$-stack (determined by multiplying the thickness of the stack by the area of the DG at the center of the stack using ImageJ, Fiji). To obtain the absolute numbers, this density value was then multiplied by the volume of the septal hippocampus (spanning from -1 to $-2.5 \mathrm{~mm}$ in the AP axes, from bregma; $\sim 6$ slices in each of the 6 series), which was calculated using Fiji from a Zeiss Axiovert epifluorescent microscope images collected at $20 \times$. In vitro, the percentage of phagocytic microglia was defined as cells with pouches containing apoptotic SH-SY5Y nuclei and/or CM-DiI particles (Beccari et al., 2018).

Neurogenesis analysis in vivo and in vitro. The analysis of neurogenesis in vivo was performed as described previously (Encinas and Enikolopov, 2008; Abiega et al., 2016; Beccari et al., 2018). Six sections from one series 
Table 4. Statistics for Figure 8

\begin{tabular}{|c|c|c|c|c|c|}
\hline Figure & Parameter & Groups & Statistical test & Statistic & $p$ \\
\hline \multirow[t]{15}{*}{$8 C$} & VGF $(\log 10)$ & Cvs $\mathrm{Ph} 3 \mathrm{~h}$ vs $\mathrm{Ph} 24 \mathrm{~h}$ & One-way ANOVA & $F_{(2,9)}=527.4$ & $p<0.001$ \\
\hline & Cartpt $(\log 10)$ & & One-way ANOVA & $F_{(2,8)}^{(2,9)}=19.37$ & $p<0.001$ \\
\hline & FGF2 & & One-way ANOVA & $F_{(2,9)}^{(2,8)}=5.55$ & $p=0.027$ \\
\hline & VEGF $(\log 10)$ & & One-way ANOVA & $F_{(2,9)}^{(2,9)}=89.23$ & $p<0.001$ \\
\hline & PDGFa $(\log 10)$ & & One-way ANOVA & $F_{(2,9)}^{(2,3)}=5.57$ & $p=0.027$ \\
\hline & IGF1 $(\log 10)$ & & One-way ANOVA & $F_{(2,9)}^{(2,9)}=153.2$ & $p<0.001$ \\
\hline & EGF $(\log 10)$ & & One-way ANOVA & $F_{(2,9)}^{(2,9)}=4.99$ & $p=0.035$ \\
\hline & GDNF $(\log 10)$ & & One-way ANOVA & $F_{(2,9)}^{(2,9)}=128.8$ & $p<0.001$ \\
\hline & Mmp3 $(\log 10)$ & & One-way ANOVA & $F_{(2,9)}^{(2,9)}=147.9$ & $p<0.001$ \\
\hline & Jag1 & & One-way ANOVA & $F_{(2,9)}^{(2,9)}=15.26$ & $p=0.001$ \\
\hline & Csf3 $(\log 10)$ & & One-way ANOVA & $F_{(2,9)}=242.7$ & $p<0.001$ \\
\hline & IL-1 $\beta(\log 10)$ & & One-way ANOVA & $F_{(2,9)}^{(1,7)}=86.82$ & $p<0.001$ \\
\hline & IL-6 & & Kruskal-Wallis & $H_{(2)}=0.20$ & $p=0.011$ \\
\hline & $\operatorname{TNF} \alpha(\log 10)$ & & One-way ANOVA & $F_{(2,9)}=25.50$ & $p<0.001$ \\
\hline & TFG $\beta(\log 10)$ & & One-way ANOVA & $F_{(2,9)}^{(2,9)}=29.04$ & $p<0.001$ \\
\hline
\end{tabular}

Table 5. Statistics for Figure 9

\begin{tabular}{|c|c|c|c|c|c|}
\hline Figure & Parameter & Groups & Statistical test & Statistic & $p$ \\
\hline 96 & Proliferation & MicroC vs MicroPh vs DMEM & One-way ANOVA & $F_{(2,6)}=14.94$ & $p=0.005$ \\
\hline \multirow[t]{4}{*}{90} & Proliferation & Treatment $\times$ cell types & Two-way ANOVA & $\begin{array}{l}F_{\text {treat }} \times \text { cell }(4,18) \\
F_{\text {treat }(2,18)}=0.00 \\
F_{\text {cell }(2,18)}=34.60\end{array}$ & $\begin{array}{l}p<0.001 \\
p=1 \\
p<0.001\end{array}$ \\
\hline & Proliferation MicroC & & & $F_{(2,6)}=8.43$ & $p=0.018$ \\
\hline & Proliferation MicroPH & & & $F_{(2,6)}=35.90$ & $p<0.001$ \\
\hline & Proliferation MicroDMEM & GFAP only vs nestin ${ }^{+}$vs unlabelled & One-way ANOVA & $F_{(2,6)}=46.23$ & $p<0.001$ \\
\hline \multirow[t]{6}{*}{$9 F$} & Differentiation & Treatment $\times$ cell types $\times$ time & Three-way ANOVA & $\begin{array}{l}F_{\text {treat }} \times \text { cell } \times \text { time }(6,48)=0.245 \\
F_{\text {treat }} \times \text { cell }(6,48)=138.69 \\
F_{\text {treat }} \times \text { time }(2,48)=0.14 \\
F_{\text {cell } \times \text { time }(2,48)}=1.26 \\
F_{\text {treat }(2,48)}=4.77 \\
F_{\text {cell }(3,48)}=194.79 \\
F_{\text {time }(1,48)}=0.44\end{array}$ & $\begin{array}{l}p=0.959 \\
p<0.001 \\
p=0.870 \\
p=0.300 \\
p=0.013 \\
p<0.001 \\
p=0.510\end{array}$ \\
\hline & Bipolar & & One-way ANOVA & $\begin{array}{l}3 \mathrm{~d} F_{(2,8)}=336.60 \\
5 \mathrm{~d} F_{(2,8)}=70.58\end{array}$ & $\begin{array}{l}p<0.001 \\
p<0.001\end{array}$ \\
\hline & Stellate & & One-way ANOVA & $\begin{array}{l}3 \mathrm{~d} F_{(2,8)}=35.29 \\
5 \mathrm{~d} F_{(2,8)}=29.17\end{array}$ & $\begin{array}{l}p<0.001 \\
p<0.001\end{array}$ \\
\hline & Early ramified & & One-way ANOVA & $\begin{array}{l}3 \mathrm{~d} F_{(2,8)}=3.06 \\
5 \mathrm{~d} F_{(2,8)}=0.86\end{array}$ & $\begin{array}{l}p=0.121 \\
p=0.471\end{array}$ \\
\hline & Late ramified & & One-way ANOVA & $3 \mathrm{~d} F_{(2,8)}=2.18$ & $p=0.194$ \\
\hline & & MicroC vs MicroPh vs DMEM & & $5 \mathrm{~d} F_{(2,8)}=1.54$ & $p=0.288$ \\
\hline \multirow[t]{4}{*}{$9 H$} & Dead and live cells & Treatment $\times$ life $\times$ time & Three-way ANOVA & $\begin{array}{l}F_{\text {treat }} \times \text { life } \times \text { time }(2,24)=0.589 \\
F_{\text {treat }} \times \text { life }(2,24)=37.22 \\
F_{\text {treat }} \times \text { time }(2,24)=4.54 \\
F_{\text {life } \times \text { time }(1,24)}=1.92 \\
F_{\text {treat }(2,24)}=20.24 \\
F_{\text {life }(1,24)}=128.33 \\
F_{\text {time }(1,24)}=0.15\end{array}$ & $\begin{array}{l}p=0.563 \\
p<0.001 \\
p=0.021 \\
p=0.179 \\
p<0.001 \\
p<0.001 \\
p=0.702\end{array}$ \\
\hline & & & One-way ANOVA & $3 \mathrm{~d} F_{(2,8)}=8.93$ & $p=0.016$ \\
\hline & Live & & & $5 \mathrm{~d} F_{(2,8)}=24.86$ & $p=0.001$ \\
\hline & Dead & MicroC vs MicroPh vs DMEM & One-way ANOVA & $\begin{array}{l}3 \mathrm{~d} F_{(2,8)}=16.85 \\
5 \mathrm{~d} F_{(2,8)}=1.54\end{array}$ & $\begin{array}{l}p=0.003 \\
p=0.306\end{array}$ \\
\hline
\end{tabular}

containing the septal hippocampus were analyzed in all experiments except in mice injected with microglia CM, in which only the three tissue sections closest to the injection site were analyzed. Proliferation was assessed by $\mathrm{BrdU}^{+}$cell quantification; neural stem cells were identified by the expression of the markers Nestin and glial fibrillary acidic protein (GFAP) and their radial morphology for cell quantification; neuroblast were assessed by doublecortin (DCX) ${ }^{+}$cell quantification and morphology to classify them in $\mathrm{AB}, \mathrm{CD}$, or EF neuroblasts (Plümpe et al., 2006); neurons were assessed by $\mathrm{NeuN}^{+}$cell quantification. The proliferation of either of these populations was assessed by their mentioned staining combined with BrdU. Numbers of cells were estimated using unbiased stereology in the volume of the DG of the $z$-stack, which was determined by multiplying the thickness of the $z$-stack $(12 \mu \mathrm{m})$ by the area of the DG at the center of the stack using the software ImageJ (Fiji). In vitro, the effect of microglia-derived conditioned media on neuroprogenitor cells was analyzed considering both their morphology and the expression of cell-specific markers. Percentages of the different morphologies present in the population were obtained as well as the percentages of the different cell markers (nestin, GFAP, DCX, S100 $\beta$ ) per morphology.

Statistical analysis. SigmaPlot (Systat Software) was used for statistical analysis. Data were tested for normality and homoscedasticity. When the data did not comply with these assumptions, a logarithmic transformation was performed and the data were analyzed using parametric tests. In the case of IL-6 mRNA expression, normality was not achieved with the 


\begin{tabular}{|c|c|c|c|c|}
\hline $\begin{array}{l}\text { Gene } \\
\text { symbol }\end{array}$ & $\begin{array}{l}\mathrm{FC} \\
\mathrm{Ph} 3 \mathrm{~h}\end{array}$ & $\begin{array}{l}\mathrm{FC} \\
\mathrm{Ph} 24 \mathrm{~h}\end{array}$ & Location & $\begin{array}{l}\text { Effect on } \\
\text { apoptosis }\end{array}$ \\
\hline PRDX1 & 1,1 & 2 & Autologous & Anti-apoptotic \\
\hline SIRT1 & 2 & 1,6 & Autologous & Anti-apoptotic \\
\hline SMO & 1 & 3,6 & Autologous & Anti-apoptotic \\
\hline SOD2 & 1,2 & 2 & Autologous & Anti-apoptotic \\
\hline SPHK1 & 4,4 & 1,6 & Autologous & Anti-apoptotic \\
\hline UBE2B & 1,4 & 1,5 & Autologous & Anti-apoptotic \\
\hline XRCC5 & 2,1 & 3,8 & Autologous & Anti-apoptotic \\
\hline PRNP & 1,8 & 1,3 & Auto/Hetero & Anti-apoptotic \\
\hline TGM2 & 5,5 & 4,5 & Auto/Hetero & Anti-apoptotic \\
\hline CNTF & 1,5 & 2,6 & Heterologous & Anti-apoptotic \\
\hline FGF2 & 4,2 & 3,7 & Heterologous & Anti-apoptotic \\
\hline FGF8 & 1,7 & 1,6 & Heterologous & Anti-apoptotic \\
\hline VEGFA & 4,5 & 1,8 & Heterologous & Anti-apoptotic \\
\hline RARG & 1,3 & 3 & Autologous & Pleiotropic \\
\hline IL6 & 18,7 & 15,8 & Heterologous & Pleiotropic \\
\hline BAD & 1,8 & 2,2 & Autologous & Proapoptotic \\
\hline FAS & 1,5 & 1,5 & Autologous & Proapoptotic \\
\hline F0X03 & 21 & 38 & Autologous & Proapoptotic \\
\hline GAS1 & 2,7 & 3 & Autologous & Proapoptotic \\
\hline NLRP3 & 12 & 19 & Autologous & Proapoptotic \\
\hline PPP2CB & 1,5 & 1,6 & Autologous & Proapoptotic \\
\hline PTEN & 1,1 & 1,6 & Autologous & Proapoptotic \\
\hline RHOA & 1 & 1,7 & Autologous & Proapoptotic \\
\hline SCRIB & 1,9 & 2,4 & Autologous & Proapoptotic \\
\hline STK3 & 1 & 1,5 & Autologous & Proapoptotic \\
\hline TFPT & 2,4 & 3 & Autologous & Proapoptotic \\
\hline GAL & 1,2 & 1,8 & Heterologous & Proapoptotic \\
\hline $\operatorname{IL} 1 \beta$ & 8,9 & 30,7 & Heterologous & Proapoptotic \\
\hline
\end{tabular}

Classification of the genes related to cell death obtained from DAVID analysis. The genes were classified according to their FC, to the effects on microglia (autologous), or on the surrounding cells (heterologous) and to the positive or negative effect on apoptosis.

logarithmic transformation and the data were analyzed using a KruskalWallis ranks test, followed by Tukey test as a post hoc. In the rest of the cases, two-sample experiments were analyzed by Student's $t$ test and more than two-sample experiments by ANOVA. In two-way and threeway ANOVA, when interactions between factors were found, the analysis of the relevant variable was split into several one-way ANOVAs and Holm-Sidak method was used as a post hoc. The transformation used (if any), the test used, the comparison performed, the value of the statistical and the $p$ values are shown in Tables $2-5$ and 7-9. Only $p<0.05$ is reported to be significant. Data are shown as mean \pm SEM.

Statistical analysis of gene expression arrays. To analyze the differential expression between naive $(t=0)$ and phagocytic $(t=3 \mathrm{~h}$ and $t=24 \mathrm{~h})$ microglia groups over time the statistical analysis the maSigPro package of R/Bioconductor was used ( $\mathrm{R}$ v3.0.3, Bioconductor release v2.13, maSigPro v1.34.1; Conesa et al., 2006). This method is based on a general regression approximation for the modeling and adjustment of the parameters required according to the type of analysis. The parameter "Time" is considered as a continuous variable, and creates a regression model of the gene response. The analysis was performed in three steps. First, genes that exhibited changes in expression over time were selected based on a $p$-corrected Benjamini-Hochberg (FDR) value. Next, for each of the genes that presented a significant change in their expression over time a regression was applied to determine their model $\left(R^{2}>0.7\right)$ to identify patterns or models of change based on time variables, obtaining 20,800 probes. Finally, the probes were selected according to their fit to the regression model. Next, the number of genes with a very high differential pattern was reduced by applying a more restrictive criterion $\left(R^{2}>\right.$ $0.9)$, obtaining 13,146 . The $R^{2}>0.7$ list was used for the identification of neurogenesis related genes and the $R^{2}>0.9$ list was used for the study of transcriptional profile of phagocytic microglia.

DAVID. The database for annotation, visualization, and integrated discovery (DAVID; https://david.ncifcrf.gov/) v6.8 provides a compre- hensive set of functional annotation tools to understand biological meaning behind large list of genes. DAVID was used to generate a gene-GO term enrichment analysis that identified enriched biological themes and to highlight the most relevant GO terms associated with the array gene list. The array gene list of $R^{2}>0.9$ was used for this gene profile analysis. The analysis of each expression pattern was performed separately and only terms with an adjusted $p$ value (Benjamini-Hochberg) $>0.05$ were considered significant.

ClueGO. ClueGO was used to generate protein pathways and to constitute the network of pathways based on the Gene Ontology and KEGG database (Bindea et al., 2013). ClueGO is a plugin of Cytoscape (http:// www.cytoscape.org/) that visualizes the non-redundant biological terms for large clusters of genes in a functionally grouped network. A ClueGO network is created with $\kappa$ statistics and reflects the relationships between the terms based on the similarity of their associated genes (Mlecnik et al., 2018). Gene ontology (GO) analysis of mouse array data were performed with ClueGO v1.4 (Bindea et al., 2013) using the following parameters: enrichment/depletion two-sided hypergeometric statistical test; correction method: Benjamini-Hochberg; GO term range levels: 3-8; minimal number of genes for term selection: 10; minimal percentage of genes for term selection: $10 \%$; $\kappa$-score threshold: 0.8 ; general term selection method: smallest $p$ value; group method: $\kappa$; minimal number of subgroups included in a group: 3; minimal percentage of shared genes between subgroups: $50 \%$.

\section{Results}

\section{Chronic impairment of microglial phagocytosis reduces adult hippocampal neurogenesis}

To examine the impact of microglial phagocytosis on adult hippocampal neurogenesis in vivo, we focused on two signaling pathways involved on phagocytosis: P2Y12 (purinergic receptor type Y12), which mediates chemotaxis toward the "find-me" signal ADP (Haynes et al., 2006); and the TAM family tyrosine kinases MerTK and Axl, which bind to phosphatidylserine adapter/bridging molecules: growth arrest specific factor 6 and protein S (Elliott et al., 2009; Fourgeaud et al., 2016). We used two transgenic mouse models in which these proteins are constitutively knocked out (P2Y12 KO and MerTK/Axl KO). We decided to study the impact of phagocytosis in young mice ( 1 month old), as neurogenesis and apoptosis of newborn cells and subsequent phagocytosis by microglia rapidly declines with age (Sierra et al., 2010; Beccari et al., 2017). Apoptotic cells were defined as pyknotic/karyorrhectic nuclei labeled with the DNA dye DAPI, which we have previously characterized to express other apoptosis markers such as activated caspase 3 and fractin (Sierra et al., 2010). First, we assessed phagocytosis in the hippocampus of the two KO models by quantifying the $\mathrm{Ph}$ index (the percentage of apoptotic cells engulfed by microglia), which is 90\% in physiological conditions (Abiega et al., 2016), and found significantly lower $\mathrm{Ph}$ index in the two KO models $(74.8 \pm 0.9 \%$ for P2Y12, $61.5 \pm 1.6 \%$ for MerTK/Axl; Fig. $1 A-C)$. In addition, the microglial $\mathrm{Ph}$ capacity (weighted average of the number of pouches containing apoptotic cells per microglia, i.e., the average number of phagocytic pouches per microglia) was significantly reduced in both KO models (Fig. 1A-C). Nonetheless, we found no changes in the number of microglia and the phagocytosis reduction was small, possibly because of compensatory mechanisms resulting from the chronic depletion, and we only detected the expected increase of apoptotic cells in MerTK/Axl KO mice (Fig. 1A-C), possibly indicating not a complete dysfunction but a slowdown of phagocytosis.

Next, we examined hippocampal neurogenesis in these phagocytosis impaired KO models and observed that the two showed a significant decrease in the population of neuroblasts and immature neurons, labeled with DCX, compared to wild- 
Table 7. Statistics for Figure 10

\begin{tabular}{|c|c|c|c|c|c|}
\hline$\overline{10 F}$ & Dead and live cells $(\log 10)$ & Treatment $\times$ life $\times$ time & Three-way ANOVA & $\begin{array}{l}F_{\text {treat }} \times \text { life } \times \text { time }(4,18)=0.595 \\
F_{\text {treat }} \times \text { life }(4,18)=4.656 \\
F_{\text {treat }} \times \text { time }(2,18)=0.265 \\
F_{\text {life }} \times \text { time }(2,18)=1.481 \\
F_{\text {treat }(2,18)}=0.544 \\
F_{\text {life }(2,18)}=50.494 \\
F_{\text {time }(1,18)}=0.695\end{array}$ & $\begin{array}{l}p=0.671 \\
p<0.009 \\
p=0.770 \\
p=0.254 \\
p=0.590 \\
p<0.001 \\
p=0.415\end{array}$ \\
\hline & Live & MicroC vs MicroPh vs DMEM & One-way ANOVA & $\begin{array}{l}5 \mathrm{~d}(\log 10) F_{(2,6)}=8.774 \\
9 \mathrm{~d} F_{(2,6)}=14.103\end{array}$ & $\begin{array}{l}p=0.017 \\
p=0.005\end{array}$ \\
\hline & Dead & & One-way ANOVA & $\begin{array}{l}5 \mathrm{~d} F_{(2,6)}=1.476 \\
9 \mathrm{~d} F_{(2,6)}=8.563\end{array}$ & $\begin{array}{l}p=0.301 \\
p=0.017\end{array}$ \\
\hline $10 G$ & Bipolar & MicroC vs MicroPh vs DMEM & Kruskal Wallis & $\begin{array}{l}5 \mathrm{~d} H_{(2)}=7.624 \\
9 \mathrm{~d} H_{(2)}=7.624\end{array}$ & $\begin{array}{l}p=0.071 \\
p=0.071\end{array}$ \\
\hline & $\begin{array}{l}\text { Stellate } \\
\text { One-way ANOVA }\end{array}$ & & Kruskal Wallis & $\begin{array}{l}5 \mathrm{~d} H_{(2)}=5.956 \\
9 \mathrm{~d} F_{(2,6)}=15.331\end{array}$ & $\begin{array}{l}p=0.025 \\
p=0.004\end{array}$ \\
\hline & Early ramified & & One-way ANOVA & $5 \mathrm{~d} F_{(2,6)}=1.469$ & $p=0.303$ \\
\hline & Kruskal Wallis & & & $\begin{array}{l}9 \mathrm{dH}_{(2)}=2.000 \\
5 \mathrm{dF} F_{(2.6)}=7.249\end{array}$ & $\begin{array}{l}p=0.829 \\
p=0.025\end{array}$ \\
\hline & Late ramified & & One-way ANOVA & $9 \mathrm{~d} F_{(2,6)}^{(2,0)}=1.880$ & $p=0.232$ \\
\hline
\end{tabular}

Table 8. Statistics for Figures 11-13

\begin{tabular}{|c|c|c|c|c|c|}
\hline Figure & Parameter & Groups & Statistical test & Statistic & $p$ value \\
\hline \multirow[t]{3}{*}{$11 F$} & REST & \multirow[t]{3}{*}{ MicroC vs MicroPh vs DMEM } & One-way ANOVA & $F_{(3,11)}=0.688$ & $p=0.594$ \\
\hline & Ascl & & One-way ANOVA & $F_{(3,11)}=3.53$ & $p=0.068$ \\
\hline & pSMAD/SMAD & & One-way ANOVA & $F_{(3,11)}=27.30$ & $p<0.001$ \\
\hline \multirow[t]{7}{*}{$12 C$} & Differentiation & \multirow[t]{7}{*}{ Treatment $\times$ cell types $\times$ time } & Three-way ANOVA & $F_{\text {treat }} \times$ cell $\times$ time $(2,24)=0.24$ & $p=0.787$ \\
\hline & & & & $F_{\text {treat }} \times$ cell $(2,24)=0.46$ & $p=0.636$ \\
\hline & & & & $F_{\text {treat }} \times$ time $(2,24)=0.156$ & $p=0.856$ \\
\hline & & & & $F_{\text {cell }} \times$ time $(1,24)=1.052$ & $p=0.315$ \\
\hline & & & & $F_{\text {treat }(2,24)}=6.42$ & $p=0.006$ \\
\hline & & & & $F_{\text {cell(1,24) }}=1235.66$ & $p<0.001$ \\
\hline & & & & $F_{\text {time }(1,24)}=0.361$ & $p=0.554$ \\
\hline \multirow[t]{5}{*}{$12 D$} & CSF3 $(\log 10)$ & \multirow[t]{5}{*}{ MicroC vs MicroPH vs LPS vs MicroPH + LPS } & One-way ANOVA & $F_{(3,12)}=44.56$ & $p<0.001$ \\
\hline & IL-1 $\beta(\log 10)$ & & One-way ANOVA & $F_{(3,12)}=19.44$ & $p<0.001$ \\
\hline & IL-6 & & Kruskal-Wallis & $H_{(3)}=11.43$ & $p=0.010$ \\
\hline & $\operatorname{TNF} \alpha(\log 10)$ & & One-way ANOVA & $F_{(3,12)}=52.539$ & $p<0.001$ \\
\hline & TGF $\beta(\log 10)$ & & One-way ANOVA & $F_{(3,12)}=3.57$ & $p=0.047$ \\
\hline \multirow[t]{7}{*}{$13 B$} & Dead and live cells & \multirow[t]{7}{*}{ Treatment $\times$ life $\times$ time } & Three-way ANOVA & $F_{\text {treat }} \times$ life $\times$ time $(2,24)=0.512$ & $p=0.606$ \\
\hline & & & & $F_{\text {treat }} \times$ life $(2,24)=4.79$ & $p=0.018$ \\
\hline & & & & $F_{\text {treat } \times \text { time }(2,24)}=0.14$ & $p=0.872$ \\
\hline & & & & $F_{\text {life }} \times \operatorname{time}(1,24)=0.90$ & $p=0.757$ \\
\hline & & & & $F_{\text {treat }(2,24)}=1.33$ & $p=0.283$ \\
\hline & & & & $F_{\text {life }(1,24)}=309.10$ & $p<0.001$ \\
\hline & & & & $F_{\text {time }(1,24)}=0.01$ & $p=0.912$ \\
\hline
\end{tabular}

type (WT) controls. In addition, we assessed proliferation by quantifying the number of dividing cells using either BrdU, an analog of thymidine that gets incorporated into the DNA during $S$ phase of dividing cells (mice were injected with $150 \mathrm{mg} / \mathrm{kg}$ and killed $24 \mathrm{~h}$ later); or the proliferation marker Ki67 ${ }^{+}$(Scholzen and Gerdes, 2000). P2Y12 KO mice had a decrease in both neuroblasts (reduction of $31.7 \pm 2.7 \%$ ) and neuroblast proliferation (reduction of $39.3 \pm 9.8 \%$ ), and MerTK/Axl KO mice showed a reduction in neuroblasts (reduction of $26.2 \pm 9.4 \%$ ) compared to WT mice (Fig. $1 D-F$ ). We further studied the formation of newborn neurons using BrdU pulse-and-chase in the most robust model, the P2Y12 KO. Four weeks after the BrdU injection, when the mice were 2 months old, both total $\mathrm{BrdU}^{+}$cells and newborn neurons $\left(\mathrm{NeuN}^{+} / \mathrm{BrdU}^{+}\right)$were reduced in $\mathrm{P} 2 \mathrm{Y} 12 \mathrm{KO}$ mice compared to WT mice (reduction of $24.6 \pm 9.7 \%$; Fig. $2 A, B$ ), in parallel to a decrease in phagocytosis ( $\mathrm{Ph}$ index and $\mathrm{Ph}$ capacity) and no changes in apoptosis nor microglia (Fig. 2C). The defect in neurogenesis was maintained later in life, because at 7 months,
P2Y12 KO mice still showed a significant reduction in phagocytosis (Ph index) without alterations in apoptosis nor microglia (Fig. $2 D, E$ ), in parallel to a reduction in neuroblasts compared to WT mice (Fig. $2 F, G$ ).

To confirm the specificity of these results, we analyzed the expression of P2Y12, MerTK, and Axl in FACS-sorted cells from 1-month-old fms-EGFP mice, in which microglia is labeled with EGFP. We found that, P2Y12 and MerTK, but not Axl, were highly expressed in microglia compared with other cells of the hippocampal parenchyma (Fig. $2 H, I$ ), suggesting that the disruption of neurogenesis in the $\mathrm{KO}$ models might be attributable to the lack of these receptors in microglia. These receptors regulate multiple features of microglial physiology (Elliott et al., 2009; Fourgeaud et al., 2016). In addition, constitutive MerTK/Axl KO mice show autoimmune diseases (Rothlin and Lemke, 2010), as both MerTK and Axl are highly expressed in peripheral macrophages (http://rstats.immgen.org/Skyline/skyline.html). In addition, in the brain Axl is also expressed in astrocytes (http:// 
Table 9. Statistics for Figure 14

\begin{tabular}{|c|c|c|c|c|c|}
\hline Figure & Parameter & Groups & Statistical test & Statistic & $p$ \\
\hline $14 C$ & $\mathrm{BrdU}_{2 \mathrm{~h}}(\log 10)$ & MicroC vs MicroPh & Unpaired $t$ test & $t_{(18)}=-0.003$ & $p=0.998$ \\
\hline 140 & Apoptosis & MicroC vs MicroPh & Unpaired $t$ test & $t_{(12)}=-0.867$ & $p=0.403$ \\
\hline $14 F$ & Stem cells & MicroC vs MicroPh & Unpaired $t$ test & $t_{(18)}=0.42$ & $p=0.677$ \\
\hline $14 G$ & Stem cell proliferation & MicroC vs MicroPh & Unpaired $t$ test & $t_{(18)}=1.97$ & $p=0.065$ \\
\hline \multirow[t]{4}{*}{141} & Neuroblasts (total) & \multirow[t]{4}{*}{ MicroC vs MicroPh } & Unpaired $t$ test & $t_{(12)}=0.02$ & $p=0.984$ \\
\hline & $A B$ & & Unpaired $t$ test & $t_{(12)}=-0.18$ & $p=0.862$ \\
\hline & $C D$ & & Unpaired $t$ test & $t_{(12)}=-0.42$ & $p=0.679$ \\
\hline & EF & & Unpaired $t$ test & $t_{(12)}=0.293$ & $p=0.774$ \\
\hline 14J & BrdU neuroblasts $(\log 10)$ & MicroC vs MicroPh & Unpaired $t$ test & $t_{(12)}=-0.47$ & $p=0.650$ \\
\hline $14 M$ & $\mathrm{BrdU}_{4 \mathrm{w}}(\log 10)$ & MicroC vs MicroPh & Unpaired $t$ test & $t_{(17)}=2.41$ & $p=0.031$ \\
\hline $14 N$ & Apoptosis & MicroC vs MicroPh & Unpaired $t$ test & $t_{(11)}=0.12$ & $p=0.908$ \\
\hline $14 P$ & Neuroblasts & Treatment $\times$ distance & Two-way ANOVA ${ }_{\text {rep }}$ & $\begin{array}{l}F_{\text {treat }} \times \text { dist }(1,11)=0.20 \\
F_{\text {dist }(1,11)}=0.852 \\
F_{\text {treat }(1,11)}=14.19\end{array}$ & $\begin{array}{l}p=0.664 \\
p=0.376 \\
p=0.003\end{array}$ \\
\hline \multirow[t]{4}{*}{$14 R$} & Neuroblasts (total) & \multirow[t]{4}{*}{ MicroC vs MicroPh } & Unpaired $t$ test & $t_{(18)}=3.38$ & $p=0.003$ \\
\hline & $A B$ & & Unpaired $t$ test & $t_{(18)}=1.80$ & $p=0.099$ \\
\hline & $C D$ & & Unpaired $t$ test & $t_{(18)}=2.09$ & $p=0.035$ \\
\hline & EF & & Unpaired $t$ test & $t_{(18)}=4.62$ & $p<0.001$ \\
\hline 145 & New neurons & MicroC vs MicroPh & Unpaired $t$ test & $t_{(17)}=2.28$ & $p=0.036$ \\
\hline
\end{tabular}

www.brainrnaseq.org/). Nonetheless, P2Y12 is largely specific to microglia (http://www.brainrnaseq.org/) and P2Y12 KO mice show an impairment of microglial phagocytosis and concomitant decrease in neurogenesis up to 7 months. Thus, the similar phagocytosis impairment and neurogenesis reduction in the two KO models suggests that an intact microglial phagocytosis is necessary for the long-term maintenance of hippocampal neurogenesis.

\section{Acute microglial phagocytosis impairment transiently increases adult hippocampal neurogenesis}

We then studied the effect of acute phagocytosis blockage on neurogenesis using an inducible MerTK KO model (generated by crossing Mertk ${ }^{f l / f l}$ to $C \times 3 c r 1^{C r e E R /+}$ mice; Fourgeaud et al., 2016). Mice received tamoxifen (two $75 \mathrm{mg} / \mathrm{kg}$ i.p. injections) or vehicle (corn oil) at P21 and P23 to induce microglial-specific Cremediated depletion of Mertk, and one injection of BrdU at P28 to label dividing cells. Phagocytosis and neurogenesis were analyzed at $1 \mathrm{~d}$ and 4 weeks after BrdU administration (i.e., when mice were 1 and 2 months old, respectively; Fig. $3 A, B$ ). Phagocytosis was strongly reduced in the inducible $\mathrm{KO}$ mice injected with tamoxifen (iKO) compared to control mice injected with vehicle, as shown by the $\mathrm{Ph}$ index $(73.0 \pm 3.7 \%$ and $72.9 \pm 2.6 \%$ reduction at $1 \mathrm{~d}$ and 4 weeks, respectively) and the $\mathrm{Ph}$ capacity (54.5 \pm $3.1 \%$ and $65.6 \pm 11.0 \%$ reduction at $1 \mathrm{~d}$ and 4 weeks, respectively), together with an accumulation of apoptotic cells (Fig. $3 C-F)$. iKO mice showed no significant changes in the number of microglia but a trend toward increased apoptotic cells compared to control mice (Fig. $3 E, F$ ). Concomitantly, $1 \mathrm{~d}$ after the BrdU injection the number of proliferating $\mathrm{BrdU}^{+}$cells and the number of $\mathrm{DCX}^{+}, \mathrm{BrdU}^{+}$, proliferating neuroblasts increased $(51.8 \pm 10.2 \%$ and $55.4 \pm 12.2 \%$ increase, respectively), whereas there was no change in the total number of neuroblasts in MerTK iKO compared to control mice injected with oil (Fig. 3G-I). However, at 4 weeks after BrdU injection there were no significant changes in the total number of newborn cells nor newborn neurons $\left(\mathrm{BrdU}^{+}, \mathrm{NeuN}^{+}\right.$; Fig. $\left.3 \mathrm{~J}, \mathrm{~K}\right)$. Thus, the excess of BrdU cells formed at $1 \mathrm{~d}$ were lost at 4 weeks, and indeed the net yield of newborn cells, calculated as a ratio of the cells at 4 weeks over the cells at $1 \mathrm{~d}$, was significantly lower in $\mathrm{iKO}$ compared to control mice $(43.1 \pm 4.5 \%$ reduction; Fig. $3 L)$.
This transient increase in neurogenesis in the MerTK iKO model (Fig. 3) is in apparent disagreement with the reduction of neurogenesis in the constitutive P2Y12 and MerTK/Axl KO models (Figs. 1, 2). It is important to note that in the iKO model, phagocytosis is acutely and strongly impaired in the adult hippocampus, whereas in the constitutive $\mathrm{KO}$ models the effect on phagocytosis is low, chronic and from embryonic development. In addition, other differences could explain the contrast between the models, including targeting peripheral immune cells in MerTK/Axl KO mice, but not in the P2Y12 KO mice or the MerTK iKO mice; or the fact that iKO mice were generated in a heterozygous CX3CR1 background, which reduces basal neurogenesis (Rogers et al., 2011). Importantly, the administration of tamoxifen, used to activate the Cre recombinase, does not affect neurogenesis (Rotheneichner et al., 2017). Nonetheless, the data from the three models altogether suggests that microglial phagocytosis participates in the regulation of adult hippocampal neurogenesis.

\section{Phagocytosis of apoptotic cells triggers the expression of neurogenic modulatory factors by microglia in vitro}

To study the mechanism by which microglial phagocytosis regulates neurogenesis, we developed a xenogenic in vitro model of phagocytosis of apoptotic cells (Beccari et al., 2018), in which mouse primary microglia were fed for different lengths of time (1-24 h) with a human neuronal line (SH-SY5Y), previously labeled with CM-DiI and treated with STP $(4 \mathrm{~h}, 3 \mu \mathrm{M})$ to induce apoptosis (Fig. $4 A, B$ ). In this model, pooled telencephalic microglia were used in the cultures, disregarding possible specific effects of hippocampal microglia. When fed with apoptotic human cells, microglia were phagocytic as early as $1 \mathrm{~h}(30.2 \pm 5.8 \%)$, a percentage that kept increasing until $24 \mathrm{~h}(83.8 \pm 3.6 \%$; Fig. $4 C)$. We then performed a mouse-specific genome-wide transcriptomic analysis using gene expression mouse-specific arrays to compare naive versus phagocytic microglia.

Hence, we compared the genome-wide transcriptome naive versus phagocytic microglia ( 3 and $24 \mathrm{~h}$ ) using gene expression arrays. Hierarchical clustering and principal component analysis (PCA) of the transcriptome of control, Ph3h and Ph24h microglia showed strong differences in the clustering of the expression profile of three groups (Fig. $4 D, E$ ). To analyze which particular 
A
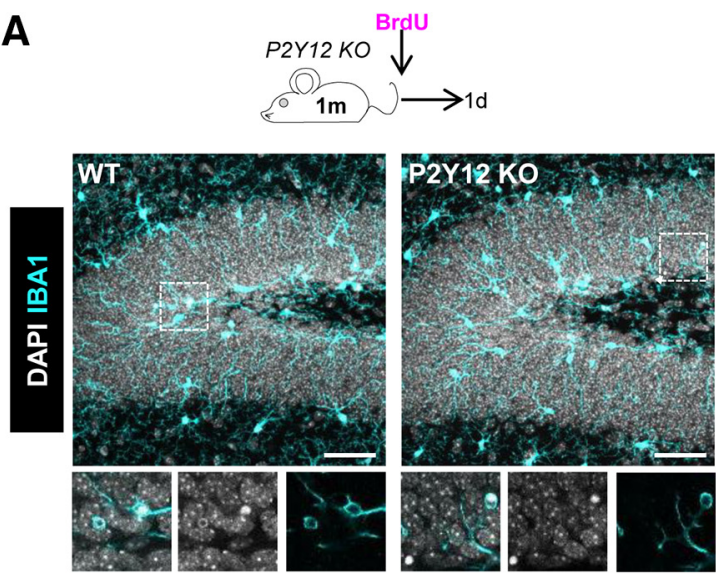

B
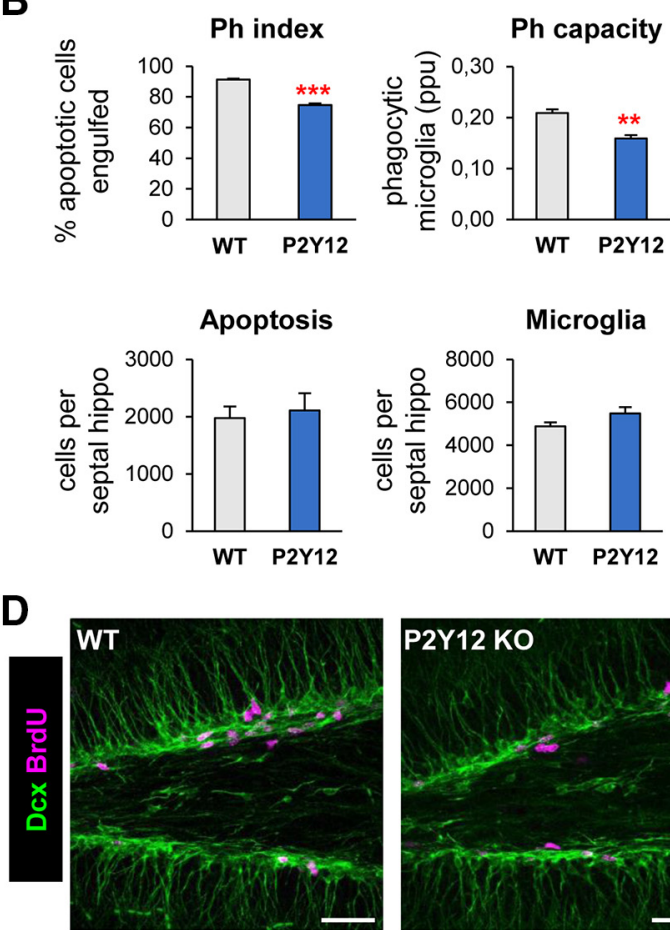

E

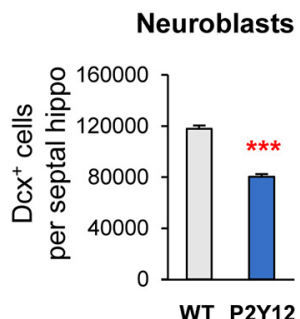

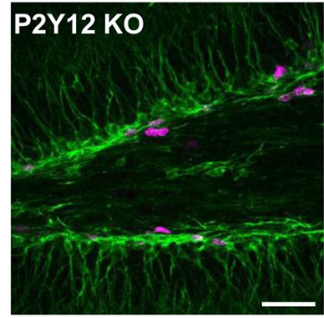

Proliferating neuroblasts

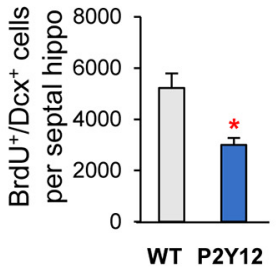

MerTK/AxIKO (O) $1 \mathrm{~m}$
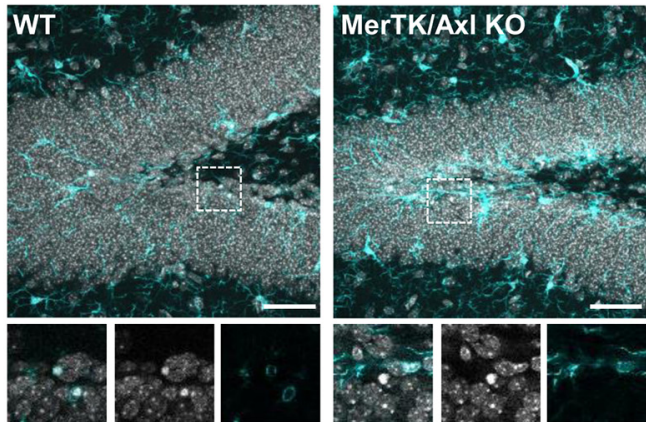

C
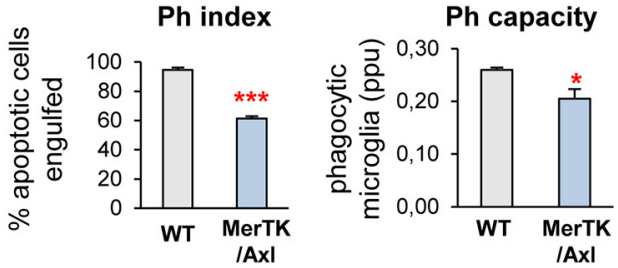

Apoptosis
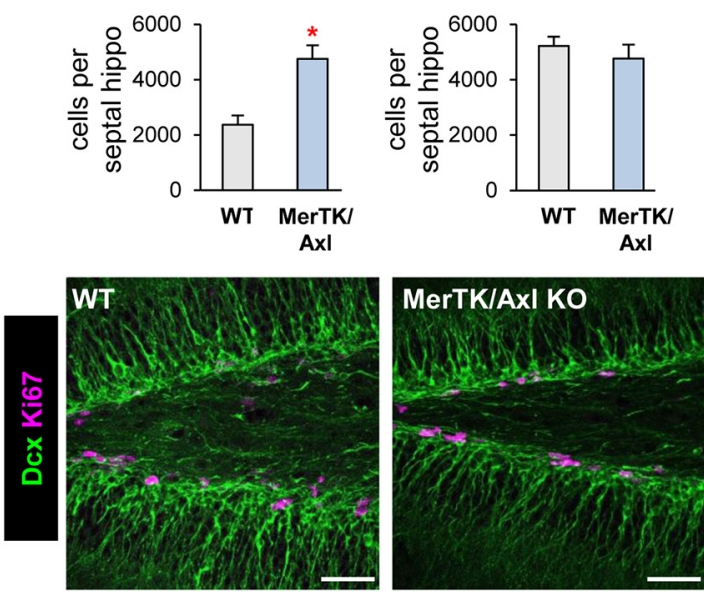

F

Neuroblasts

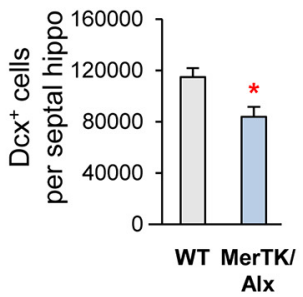

Proliferating neuroblasts

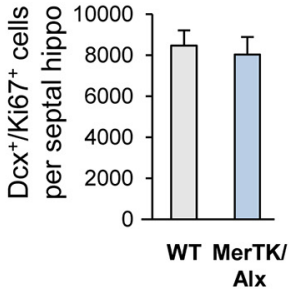

Figure 1. Chronic microglial phagocytosis impairment reduces adult hippocampal neurogenesis. $A$, Representative maximum projection of confocal $z$-stack of P2Y12 and MerTK/Axl K0 mice immunofluorescence in the mouse hippocampal DG at 1 month $(1 \mathrm{~m})$. Microglia were labeled with lba1 (cyan) and apoptotic nuclei were detected by pyknosis/karyorrhexis (white, DAPI). $\boldsymbol{B}, \boldsymbol{C}$, Percentage of apoptotic cells engulfed (Ph index), weighted average of the percentage of microglia with phagocytic pouches (Ph capacity), apoptotic cells and microglia per septal hippocampus in P2Y12 K0 mice (B) and MerTK/Axl K0 mice (C). D, Representative confocal z-stack of P2Y12 and MerTK/Axl K0 mice immunofluorescence in the mouse hippocampal DG at $1 \mathrm{~m}$. Neuroblasts were labeled with DCX (green) and proliferation was labeled with either BrdU $(150 \mathrm{mg} / \mathrm{kg}, 24 \mathrm{~h}$ ) or Ki67 (magenta). E, Neuroblast and neuroblast proliferation in 1-month-old P2Y12 K0 mice. F, Neuroblast and neuroblast proliferation in 1-month-old MerTK/Axl KO mice. Scale bars: $\boldsymbol{A}, \boldsymbol{D}, 50 \mu \mathrm{m}$ (inserts, $10 \mu \mathrm{m}$ ); $\boldsymbol{A}$, left, $z=20 \mu \mathrm{m} ; \boldsymbol{A}$, right, $z=17 \mu \mathrm{m} ; \boldsymbol{D}$, left, $z=7 \mu \mathrm{m} ; \mathbf{D}$, right, $z=10 \mu \mathrm{m}$. $N=$ 3- 4 mice $(\boldsymbol{B}, \boldsymbol{C}, \boldsymbol{E}, \boldsymbol{F})$. Error bars represent mean \pm SEM. ${ }^{*} p<0.05,{ }^{* *} p<0.01,{ }^{* * *} p<0.001$ by Student's $t$ test. Only significant effects are shown. Values of statistics used are shown in Table 2 .

genes were different among the three experimental groups, we searched for array probes with significant changes over time using a $p$-corrected Benjamini-Hochberg value and a polynomial regression model to identify time patterns (Conesa et al., 2006).
We obtained 10,000 significantly regulated probes with a restrictive criterion of $R^{2}>0.9$ and a fold-change (FC) $>1.5$ or $<-1.5$, eventually obtaining 6585 genes that presented significant changes over time (Fig. $4 F$ ). 
A
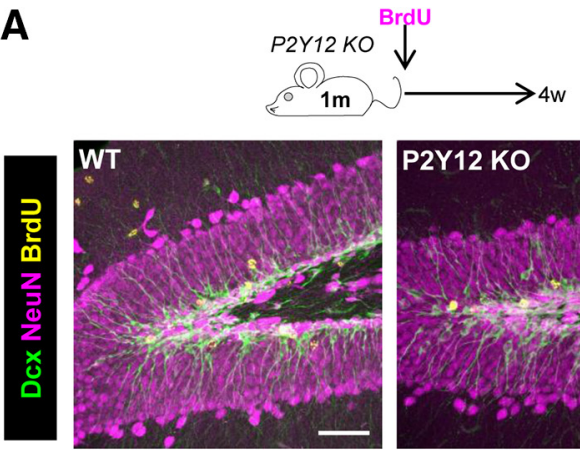

C

Ph index

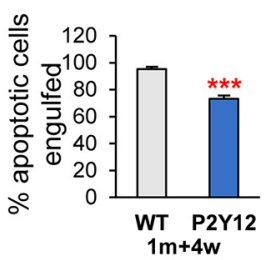

D
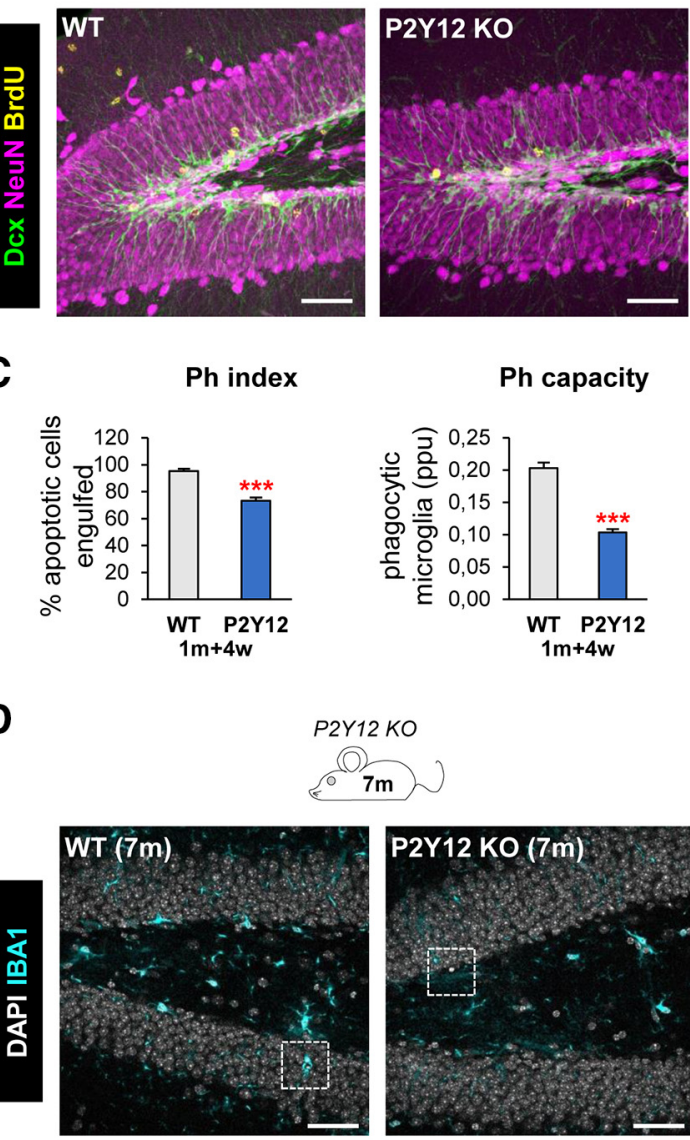

Ph capacity

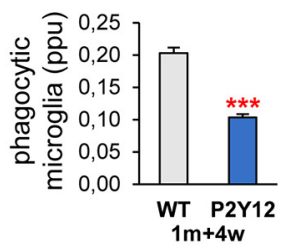

$P 2 Y 12 \mathrm{KO}$

$7 \mathrm{~m}$

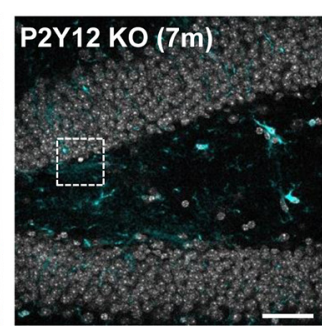

$\mathbf{F}$

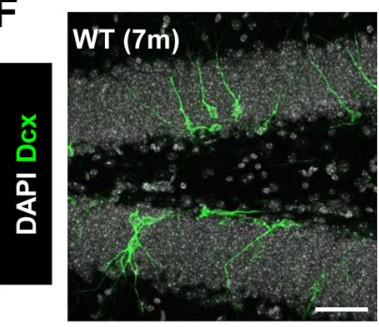

H

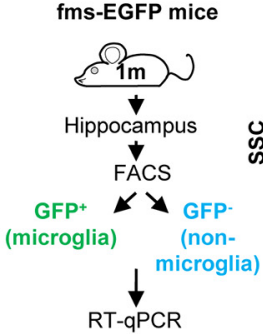

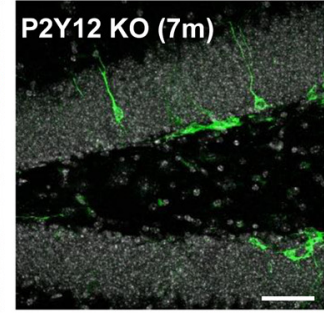

B

Newborn cells

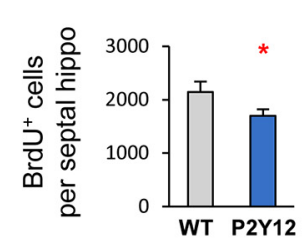

Newborn neurons

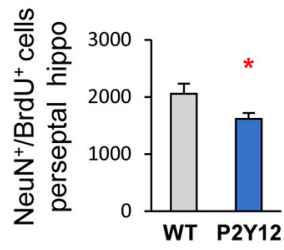

Microglia
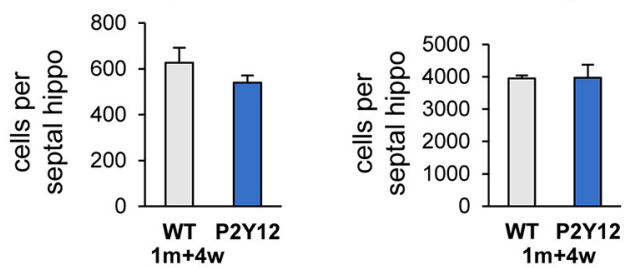

E
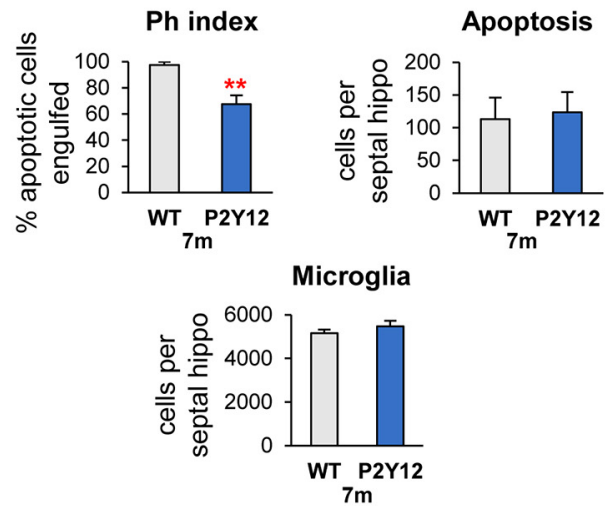

G

Neuroblasts

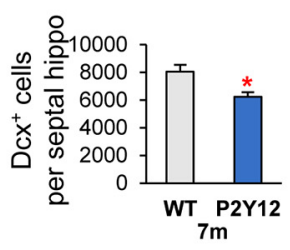

I

Expression of receptors related to phagocytosis
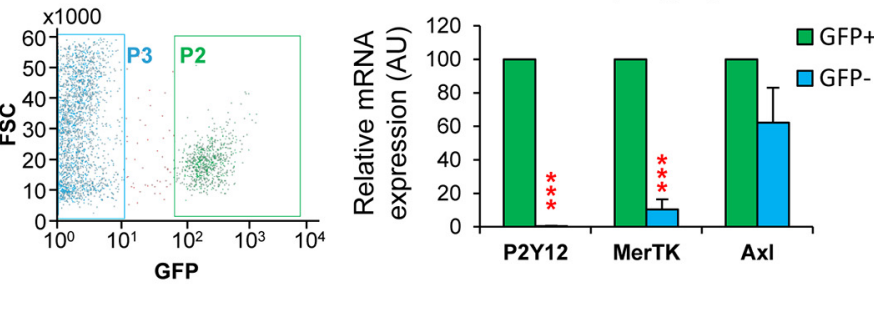

Figure 2. Chronic microglial phagocytosis impairment reduces adult hippocampal neurogenesis in the long term. $A$, Representative confocal $z$-stack of P2Y12 K0 mice immunofluorescence in the mouse hippocampal DG at 2 months. Neuroblasts were labeled with DCX (green), neurons were labeled with NeuN (magenta) and proliferation was labeled with BrdU (yellow; 4 weeks after BrdU injection). $\boldsymbol{B}$, New cells and new neurons ( NeuN ${ }^{+}$, BrdU $^{+}$) in 2-month-old P2Y12 KO mice, 4 weeks after the BrdU injection. C, Percentage of apoptotic cells engulfed (Ph index), weighted average of the percentage of microglia with phagocytic pouches (Ph capacity), apoptotic cells and microglia per septal hippocampus in P2Y12 KO mice 4 weeks after BrdU injection (2m). D, Representative maximum projection of confocal z-stack of P2Y12 K0 mice immunofluorescence in the mouse hippocampal DG at 7 months (7 m). Microglia were labeled with Iba1 (cyan) and apoptotic nuclei were detected by pyknosis/karyorrhexis (white, DAPI). $\boldsymbol{E}$, Percentage of apoptotic cells engulfed (Ph index), number of apoptotic cells and microglia per septal hippocampus in 7-month-old P2Y12 K0 mice. $\boldsymbol{F}$, Representative confocal $z$-stack of P2Y12 K0 mice immunofluorescence in the mouse hippocampal DG at 7 months. Neuroblasts were labeled with DCX (green). $\mathbf{G}$, Number of neuroblasts per septal hippocampus in 7-month-old P2Y12 KO mice. $\boldsymbol{H}$, Experimental design used to isolate microglia (GFP ${ }^{+}$) versus non-microglial cells (GFP ${ }^{-}$) from 1-month-old fms-EGFP mice using flow cytometry. First, debris was excluded using the P1 gate in FSC versus SSC (left). Next, gates for GFP ${ }^{+}$microglia cells (P2) (Figure legend continues.) 
We classified these genes according to four main expression patterns (Fig. 4G): UP (upregulation both at 3 and $24 \mathrm{~h}$ ), DOWN (downregulation in both time points), transient UP (upregulation at $3 \mathrm{~h}$ and downregulation at $24 \mathrm{~h}$ ), and transient DOWN (downregulation at $3 \mathrm{~h}$ and upregulation at $24 \mathrm{~h}$ ). Genes in the UP expression pattern showed the largest average FC changes among all patterns, some of them even reaching $8000 \mathrm{FC}$ at $24 \mathrm{~h}$. The rest of the patterns had on average more modest changes.

Next, we performed a functional analysis of the phagocytic microglia transcriptome using the ClueGO network (Fig. 5) and DAVID (Fig. 6A). These analyses revealed a number of functional biological pathways associated with each of the four main expression patterns of phagocytic microglia including downregulation in pathways related to DNA and chromosomes and upregulation of different functions associated with metabolism and chromatin remodeling. Interestingly, different studies suggesting metabolic changes in phagocytes upon the uptake of apoptotic cells have recently emerged (Morioka et al., 2018). Importantly, for many upregulated genes, ClueGO revealed specific terms like "generation of neurons", "neuron differentiation" or "neuron development" that were grouped under the term "neurogenesis" and had a direct interrelation with "neuron projection development" group.

We then focused on the identity of the neurogenesis-related genes using the following strategy (Fig. 6B). To identify phagocytosis-related potential regulators of neurogenesis, we used MANGO (The Mammalian Adult Neurogenesis Gene Ontology), a database of 259 genes already described to be involved in the regulation of adult hippocampal neurogenesis (Overall et al., 2012). Of the MANGO genes, 213 were found significantly regulated in our arrays. We then filtered those MANGO genes by disregarding those encoding for autologous proteins (i.e., acting on the same cell, such as transcription factors) and focusing on those encoding heterologous proteins (i.e., acting on neighbor cells, such as secreted molecules). We first applied this criterion to MANGO, and found 26 heterologous genes that had been previously identified to regulate adult hippocampal neurogenesis. To further extend the list of heterologous genes outside MANGO that could be potential regulators of neurogenesis, we looked into the filtered gene array list $\left(R^{2}>0.9\right.$ and $-1.5>\mathrm{FC}>$ $1.5)$, searched the GO terms associated with each MANGO heterologous gene, and selected those terms that could be related to different steps of the neurogenic process (proliferation, differentiation, migration, chemotaxis, survival, and development). MANGO heterologous genes encompassed 57 different neurogenesis-related GO terms, such as growth factor activity (GO: 0008083), nervous system development (GO:0007399), learning (GO:0007612), memory (GO:0007613), cell proliferation (GO: 0008283), cell differentiation (GO:0030154), and neuron development (GO:0048666).

We then searched for heterologous genes belonging to each of these 57 categories in our arrays, using a less-restrictive list of 20,800 probes $\left(R^{2}>0.7\right.$, no screening of FC). We finally obtained

\footnotetext{
(Figure legend continued.) and GFP ${ }^{-}$non-microglial cells (P3) were defined based on the distribution of the fms-EGFP ${ }^{+}$cells in EGFP versus FSC (right). I, Expression of P2Y12, MerTK, and Axl in microglia $\left(\mathrm{GFP}^{+}\right)$versus non-microglial cells $\left(\mathrm{GFP}^{-}\right)$by real-time $\mathrm{qPCR}$ in FACSsorted cells from fms-EGFP mice hippocampi. OAZ1 (ornithine decarboxylase antizyme 1) was selected as a reference gene. Scale bars: $\boldsymbol{A}, \boldsymbol{D}, \boldsymbol{F}, 50 \mu \mathrm{m} ; \boldsymbol{A}, Z=20 \mu \mathrm{m} ; \boldsymbol{D}, \boldsymbol{F}, Z=17.5 \mu \mathrm{m} . N=$ 5 mice $(\boldsymbol{A}) . N=4-6$ mice $(\boldsymbol{E}, \boldsymbol{G}), N=3$ independent experiments $(\boldsymbol{H}$; each from 8 pooled hippocampi), ${ }^{*} p<0.05,{ }^{* *} p<0.01,{ }^{* * *} p<0.001$ by Student's $t$ test. Values of statistics used are shown in Table 2.
}

224 genes with differential expression between naive and phagocytic microglia, which were heterologous and whose function had been previously involved in neurogenesis (based on the GO terms). The 224 candidate genes were classified according to their main regulatory expression patterns: 94 UP, 73 DOWN, 28 transient-UP, and 29 transient-DOWN genes (Fig. 6B). In the four regulation patterns, the majority of the genes were categorized as trophic factors (between 23 and $29 \%$ in all regulatory patterns; Fig. $7 A, B$ ). We also found cytokines, chemokines, peptides, and hormones as the main gene types of the candidates. Despite the fact that trophic factors were the largest percentage in each regulation pattern, they showed a similar and rather low mean FC compared to the other categories. Only the upregulated peptides and hormones revealed a large mean of $800 \mathrm{FC}$ at both 3 and $24 \mathrm{~h}$ of phagocytosis. These data suggest that peptides and hormones were the most likely molecules to perform modulatory functions in the neurogenic niche by phagocytic microglia.

To disregard the possible detection of residual mRNA from the (human) apoptotic cells, we checked the sequence of the 60,000 array probes against the human transcriptome by BLAST . We found that $96 \%$ of the probes had low homology to the human transcriptome (MegaBlast homology $<5 \%$ ). In addition, we analyzed the RNA integrity in apoptotic cells using a bioanalyzer, and found that whereas naive and phagocytic $(24 \mathrm{~h})$ microglia had the expected $18 \mathrm{~S}$ and $28 \mathrm{~S}$ rRNAs profile, apoptotic SH-SY5Y cells $(24 \mathrm{~h})$ showed a smear typical of RNA degradation (Fig. 8A). Finally, we analyzed whether apoptotic cells could synthesize new $\mathrm{mRNA}$ using $5^{\prime}$-fluorouridine (FU; a uridine analog that integrates at transcription sites; Fig. 8B). Apoptotic SHSY5Y, unlike live cells, did not exhibit nuclear FU labeling, evidencing that they were not transcriptionally active. Altogether, the RNA profiling and analysis of transcription in apoptotic cells strongly suggests that although the gene arrays used could virtually detect up to $4 \%$ of mRNAs from human apoptotic cells, their lack of residual RNA would result solely in the detection of microglial-specific transcriptional changes after phagocytosis.

Finally, we validated the mRNA expression of the candidates in naive and phagocytic microglia by real-time qPCR. We selected a subset of genes for validation based both on their high FC in the array and/or the well known neurogenesis modulatory potential described in the literature. We found that the expression pattern of the selected candidates determined by real-time qPCR was largely in agreement with that obtained in the arrays. Among the genes with the largest mRNA expression were the neuropeptide VGF, the matrix metalloprotease 3 , and the cytokine colony stimulating factor 3 (Fig. $8 \mathrm{C}$ ), reinforcing the notion that phagocytosis promotes the production of neurogenic modulators by microglia.

\section{The secretome from phagocytic and naive microglia drives neuroprogenitor cells toward different fates in vitro}

Of the 224 heterologous candidates, $83.5 \%$ belonged to the secretome, suggesting an important role of the phagocytic microglial secretome on the modulation of neurogenesis. We thus directly tested the effect of the phagocytic microglial secretome on neurogenesis in vitro. To model neurogenesis, we used a monolayer of NPC cultures derived from disaggregated neurospheres, obtained from whole $\mathrm{P} 0-\mathrm{P} 1$ brains and allowed them to proliferate $48 \mathrm{~h}$ in DMEM/F12 with trophic factors EGF/FGF2 (Babu et al., 2011). We first performed a neurogenesis differentiation assay in which NPCs were allowed to differentiate during a time course $(1-5 d)$ in the presence of conditioned media from control [naive 

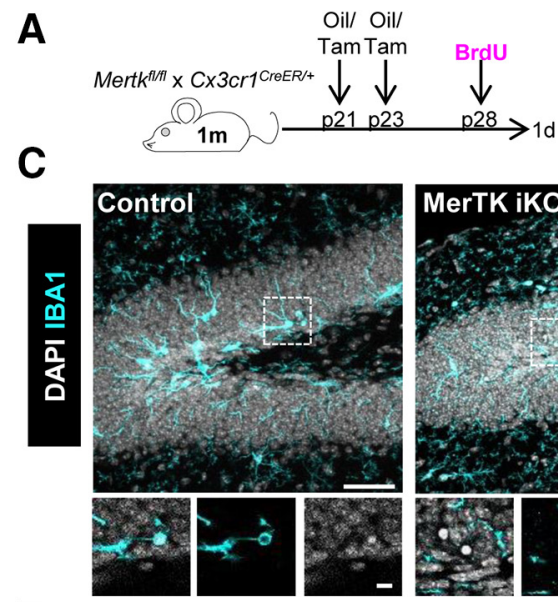

E

$\mathrm{Ph}$ index
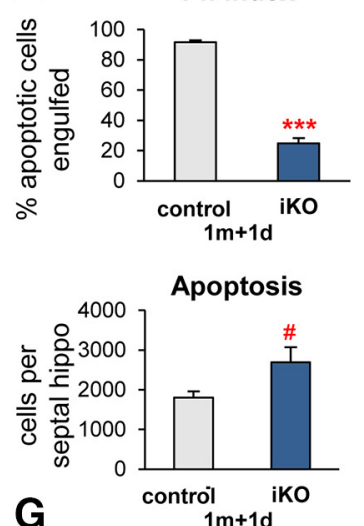

G

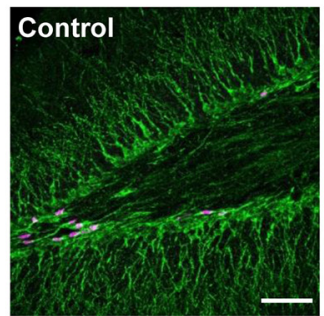

H Proliferating cells
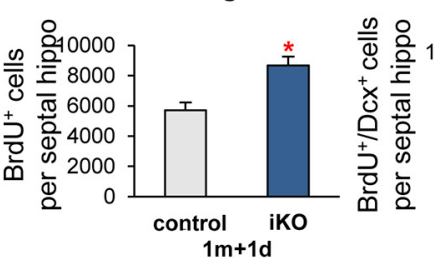

Proliferating neuroblasts

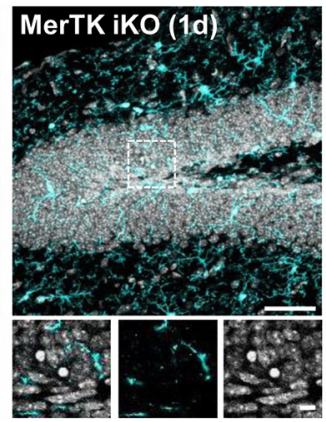

Ph capacity

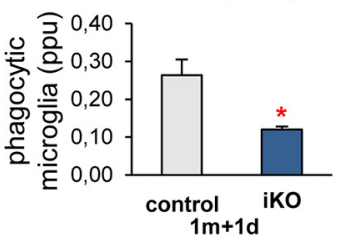

Microglia
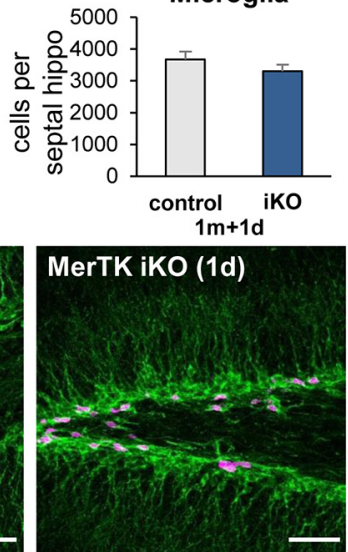

B

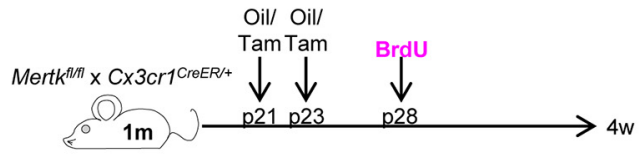

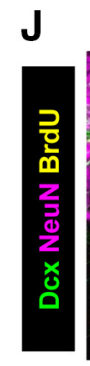

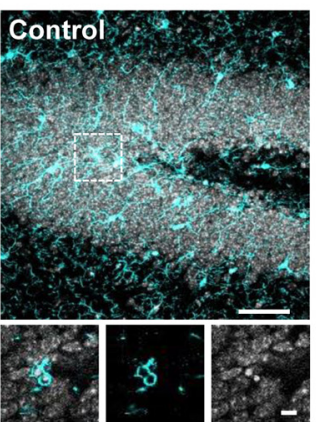

$\mathrm{Ph}$ index

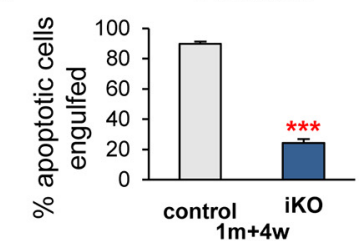

Apoptosis

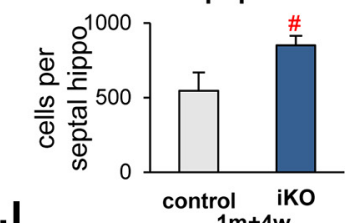

K
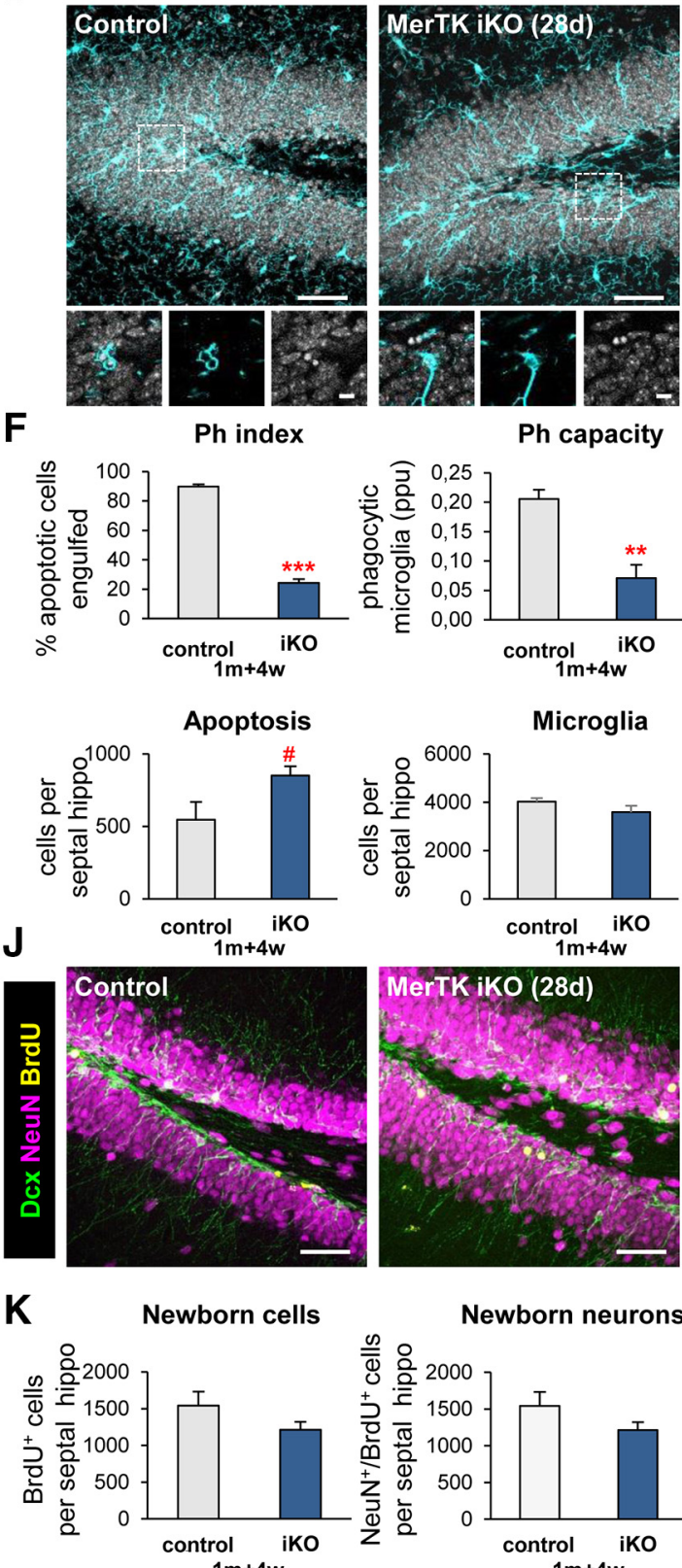

Ph capacity

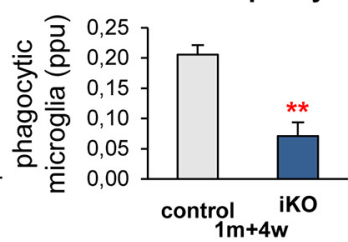

Microglia
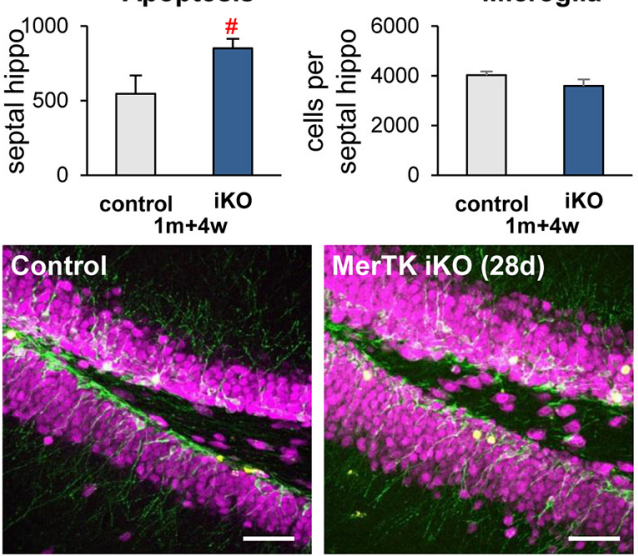

Newborn neurons

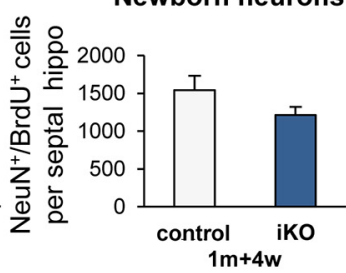

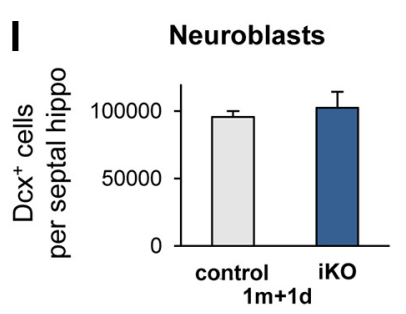

L $\quad \mathrm{BrdU}^{+}$yield

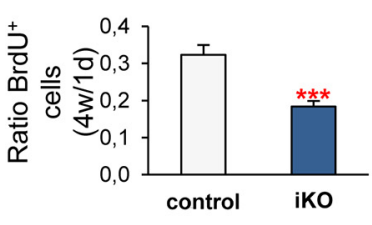

Figure 3. Acute microglial phagocytosis impairment transiently increases adult hippocampal neurogenesis. $\boldsymbol{A}, \boldsymbol{B}$, Experimental design in microglial-specific MerTK inducible K0 mice, generated

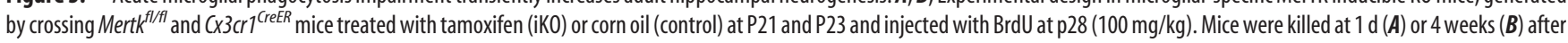
the BrdU injection. $\boldsymbol{C}, \boldsymbol{D}$, Representative maximum projection of confocal z-stack of MerTK iKO mice immunofluorescence in the mouse hippocampal DG at $1 \mathrm{~d}(\boldsymbol{C})$ and 4 weeks $(\boldsymbol{D})$. Microglia were labeled with Iba1 (cyan) and apoptotic nuclei were detected by pyknosis/karyorrhexis (white, DAPI). $\boldsymbol{E}, \boldsymbol{F}$, Percentage of apoptotic cells engulfed (Ph index), weighted average of the percentage of microglia with phagocytic pouches (Ph capacity), apoptotic cells and microglia per septal hippocampus in MerTK iKO mice at $1 \mathrm{~d}(\boldsymbol{E})$ and 4 weeks (F). $\boldsymbol{G}$, Representative confocal $z$-stack of MerTK iKO mice immunofluorescence in the mouse hippocampal DG at $1 \mathrm{~d}$. Neuroblasts were labeled with DCX (green) and proliferation was detected with BrdU (magenta). $\boldsymbol{H}$, Newborn cells (BrdU ${ }^{+}$) and newborn neuroblasts $\left(\mathrm{DCX}^{+}, \mathrm{BrdU}^{+}\right)$in MerTK iKO mice at $1 \mathrm{~d}$ post-BrdU. $I$, Neuroblasts $\left(\mathrm{DCX}{ }^{+}\right)$in MerTK iKO mice at $1 \mathrm{~d}$ post-BrdU. J, Representative confocal $z$-stack of MerTK iKO mice immunofluorescence in the mouse hippocampal DG at 4 weeks post-BrdU. Neuroblasts were labeled with DCX (green), neurons were labeled with NeuN (magenta) (Figure legend continues.) 
microglia (CM microC)] and phagocytic [24 h phagocytic microglia (CM microPH)] microglia (Fig. 9A). DMEM was used as an internal control, because microglia were cultured in this media. After $1 \mathrm{~d}$ of differentiation, cultures in $\mathrm{CM}$ microPH maintained higher levels of proliferation than $\mathrm{CM}$ microC as observed by a higher proportion of cells labeled with the proliferation marker $\mathrm{Ki}^{+}$(Fig. 9B,C). Most of the proliferating cells in microPH cultures expressed nestin, a marker of progenitor cells, stem cells, and reactive astrocytes (Encinas and Sierra, 2012; Lopez-Atalaya et al., 2018; Fig. 9D). We then followed the progeny of those populations at 3 and $5 \mathrm{~d}$ and labeled them with cell identity markers: nestin, GFAP, a marker of astrocytes (Encinas and Sierra, 2012) and DCX, a marker of neuroblasts (Brown et al., 2003; Fig. 9E). We found that $\mathrm{CM}$ microC treatment mainly produced GFAP $^{\text {high }}$, nestin ${ }^{+/-}$, stellate cells both at 3 and $5 \mathrm{~d}$, as well as a small percentage of DCX ramified cells. In contrast, in CM microPH cultures the majority of the cells were nestin ${ }^{\text {high }}$, GFAP ${ }^{+}$, with a bipolar morphology (Fig. 9F,G). Cell death (apoptosis) was observed in all conditions, as has been noted before in this type of cultures upon growth factor withdrawal-induced differentiation (Babu et al., 2011). However, higher rates of apoptosis were found in NPCs cultured in $\mathrm{CM}$ microPH, which resulted in a lower cell density (Fig. 9H). Importantly, the majority (57\%) of cell death-related upregulated heterologous genes were antiapoptotic (Table 6), suggesting that the phagocytic microglia secretome did not directly induce NPCs apoptosis. Together, the above results (Fig. 9) results indicate that naive microglia led to the production of stellate cells, resembling astrocytes in culture, and a small proportion of ramified $\mathrm{DCX}^{+}$-expressing cells, corresponding to an immature stage of the neuronal lineage. In contrast, phagocytic microglia drove NPCs toward a unique bipolar cell type, expressing nestin and GFAP but never DCX, which is characteristic of both astrocytes and undifferentiated progenitor cells (Encinas and Sierra, 2012).

\section{The secretome from phagocytic microglia drives neuroprogenitor cells toward an astrocytic phenotype in vitro} To precisely identify bipolar cells produced by $\mathrm{CM}$ microPH, we performed several studies to characterize their phenotype: labeling with the mature astrocytic marker (S100 $\beta$; Raponi et al., 2007), a multipotency assay, response to stimuli by calcium imaging, and Western blot analysis of neural and astrocytecommitted transcription factors.

First, we tested whether bipolar cells could be mature astrocytes and stained the CM-treated cultures with $\mathrm{S} 100 \beta$, a marker of mature astrocytes (Raponi et al., 2007; Fig. 10A). In CM microC few stellate cells were $S 100 \beta^{+}$and exhibited rather dim labeling, suggesting that they were still immature astrocytes (Fig. $10 B, C$ ). In addition, in CM microC cultures, we observed a small percentage of cells that did not express GFAP, expressed high levels of $S 100 \beta$ and had several branched processes, that may possibly be oligodendrocytes (Hachem et al., 2005). On the other hand, in CM microPH cultures the majority of both bipolar and

\footnotetext{
(Figure legend continued.) and proliferation was labeled with BrdU (yellow). $\boldsymbol{K}$, Newborn cells $\left(\mathrm{BrdU}^{+}\right)$and newborn neurons ( $\left.\mathrm{NeuN}^{+}, \mathrm{BrdU}^{+}\right)$in MerTK iKO mice at 4 weeks postBrdU. $L$, BrdU + yield was calculated as a ratio of the BrdU ${ }^{+}$cells at 4 weeks over the average $\mathrm{BrdU}^{+}$cells of each group at $1 \mathrm{~d}$ after injection. Scale bars: $\boldsymbol{C}, \boldsymbol{D}, \boldsymbol{G}, J, 50 \mu \mathrm{m}$ (insets, $10 \mu \mathrm{m}$ ); $C$, $\boldsymbol{D}, Z=16.1 \mu \mathrm{m} ; \boldsymbol{G}, Z=7 \mathrm{~mm} ; J, Z=23.1 \mu \mathrm{m} . N=3$ mice $(\boldsymbol{E}, \boldsymbol{H}, \boldsymbol{I}), N=4-6$ mice $(\boldsymbol{F}, \boldsymbol{K}, \boldsymbol{L})$. Error bars represent mean \pm SEM. $\# p=0.096(\boldsymbol{E}), \# p=0.062(\boldsymbol{F}),{ }^{*} p<0.05,{ }^{* *} p<0.01$, ${ }^{* * *} p<0.001$ by Student's $t$ test. Only significant effects are shown. Values of statistics used are shown in Table 3.
}

stellate cells had a very $\operatorname{dim} S 100 \beta$ staining and oligodendrocytelike cells were not found. Therefore, the faint $S 100 \beta$ expression in bipolar cells triggered by conditioned media from phagocytic microglia suggested that they could be immature astrocytes.

Second, we analyzed the multipotency of bipolar cells. After $3 \mathrm{~d}$ of differentiation into stellate, ramified, and bipolar cells in $\mathrm{CM}$ microC and microPH, we switched the culture media to DMEM/F12 culture media (the regular media to grow neurospheres) without trophic factors and allowed cells to differentiate for another 5-9 d (Fig. 10D-G). We found that after 5-9 d in DMEM/F12, cells derived from microPH CM had lower rates of cell death than cultures derived from microC and DMEM treatments, calculated as a ratio over the number of cells at $3 \mathrm{~d}$ in each culture (Fig. 10F). We then analyzed the multipotency of the cultures by calculating the ratio of change of each cell type after DMEM/F12. CM microC-derived cultures presented similar ratios of stellate cells and ramified cells after 5-9 d in DMEM/F12 (Fig. 10G). In contrast, cultures derived from microPH CM had a strong increase in the ratio of differentiation into stellate cells while neuroblasts were not found (Fig. 10G). These data strongly suggest that bipolar cells produced after treatment with the phagocytic microglia secretome were unlikely to be prototypical neuroprogenitors because they only gave rise to astrocytes but not to neuron-committed cells.

Third, we used calcium responses to different cell-specific stimuli to characterize bipolar cells triggered by microPH medium. We used Fura-2 AM, a cell permeant calcium indicator: $\mathrm{KCl}$, which triggers an intracellular $\mathrm{Ca}^{+2}$ response in excitable cells (De Melo Reis et al., 2011); AMPA, which depolarizes neurons expressing the corresponding glutamate receptors (Bloodgood and Sabatini, 2008); ATP, which activates purinergic receptors in astrocytes and neurons (De Melo Reis et al., 2011); histamine, which triggers intracellular $\mathrm{Ca}^{+2}$ response in immature cells through histamine receptor, highly expressed on immature/stem cells and embryonic stem cells (Eiriz et al., 2011); and NMDA (Fig. 11A-D). We examined the calcium response to these stimuli of bipolar and stellate cells, as well as freshly dissociated NPCs as control. We found that $69 \%$ of the freshly dissociated NPCs depolarized in response to ATP and histamine, and became hyperpolarized in response to $\mathrm{KCl}$. The majority of stellate cells depolarized in response to $\mathrm{KCl}$, AMPA, and ATP, and the majority of ramified cells responded to all stimuli except NMDA, most likely because they were still immature neuroblasts. On the other hand, in $\mathrm{CM}$ microPH-treated cultures, the majority of bipolar cells highly depolarized when incubated with ATP and hyperpolarized when incubated with $\mathrm{KCl}$ (Fig. 11C,D). These data show that bipolar cells have similar features as both NPCs and astrocytes, suggesting an intermediate phenotype.

Finally, we performed Western blot analysis of NPCs as well as $\mathrm{CM}$ microC and $\mathrm{CM}$ microPH cultures of different fatecommitting transcription factors: REST (RE1 silencing transcription factor 1), a repressor of neuronal genes that is highly expressed in astrocytes (Kohyama et al., 2010); Ascl (ASC1-like protein), which is related to neuronal fate commitment (Liu et al., 2015); and SMAD1, which is highly phosphorylated in differentiating astrocytes (Kohyama et al., 2010). In the CM-treated NPC cultures, we found no differences for REST and Ascl, but the pSMAD/SMAD ratio was significantly increased in $\mathrm{CM}$ microPH-treated cells compared to CM microC (Fig. 11E,F), suggesting that $\mathrm{CM}$ microPH bipolar cells were committed to the astrocytic lineage. All together, these in vitro data demonstrate that at the cellular level, the microglial phagocytosis secretome 
A

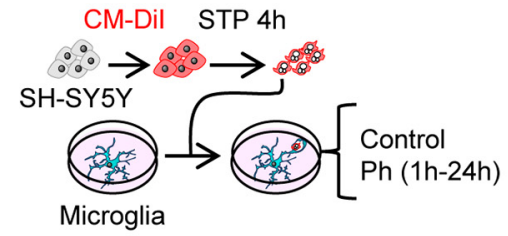

C

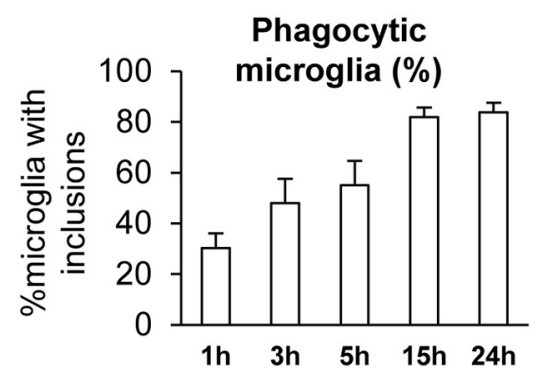

D

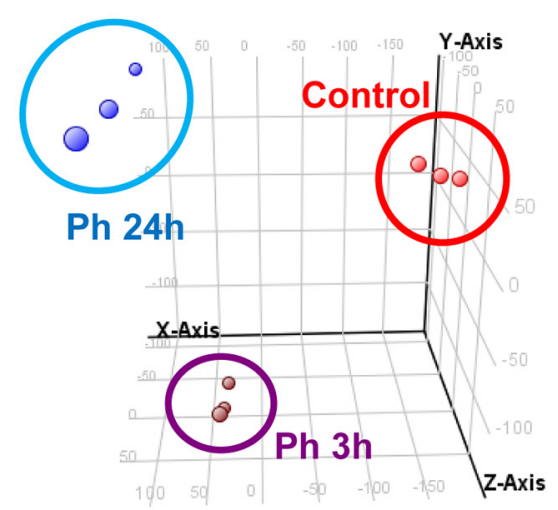

B

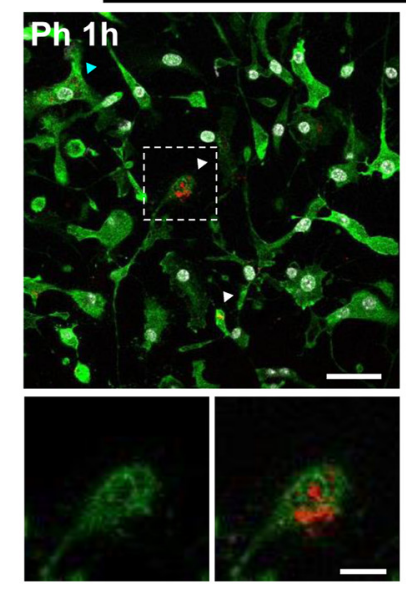

E

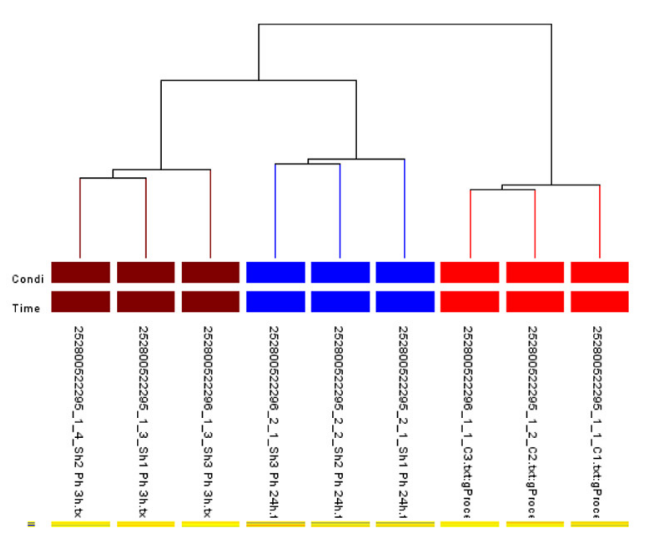

F
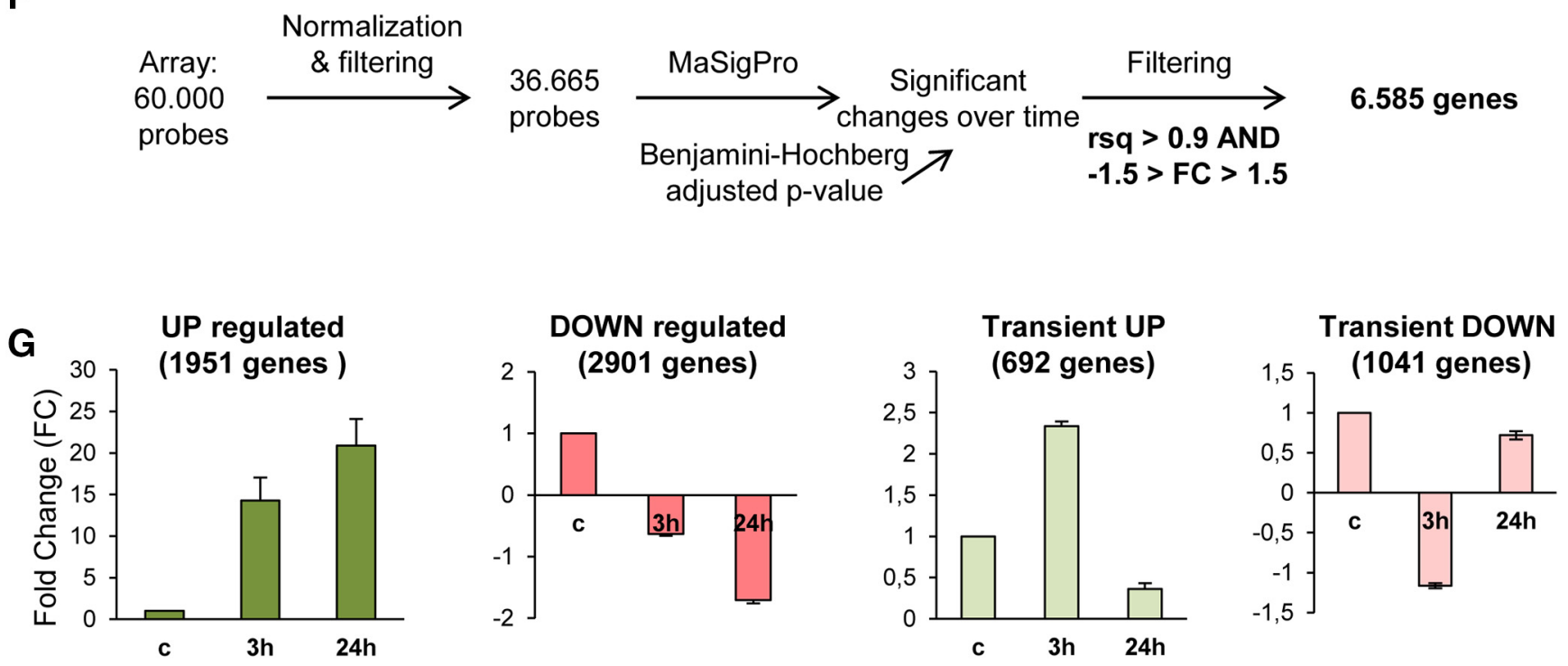

Figure 4. Phagocytosis assay with a human neural cell line (SH-SY5Y). $\boldsymbol{A}$, Experimental design of the phagocytosis assay. $\boldsymbol{B}$, Representative confocal microscopy images of primary microglia (GFP; green) fed with SH-SY5Y, which were previously labeled with CM-Dil (red) and treated with STP ( $4 \mathrm{~h}, 3 \mu \mathrm{M})$ for the induction of apoptosis (pyknosis/karyorrhexis; DAPI, white). Arrowheads, phagocytosed apoptotic SH-SY5Y cells. C, Percentage of microglia with CM-Dil and/or DAPI inclusions along a time course. Only fully closed pouches with particles within were identified as phagocytosis. D, PCA of the different replica of the samples: Control microglia, Ph3h, and Ph24h. E, Hierarchical clustering (HCL) of the different replica of the samples control microglia (blue), Ph3h (brown), and Ph24h (red). F, Representation of the strategy followed to screen genes from the gene array. G, FC mean of the genes classified under the UP, DOWN, transient UP, and transient DOWN regulation patterns. Scale bars: $\boldsymbol{B}, 30 \mu \mathrm{m}$ (inserts, $10 \mu \mathrm{m}) . N=3$ independent experiments $(\boldsymbol{C}-\boldsymbol{G})$. 

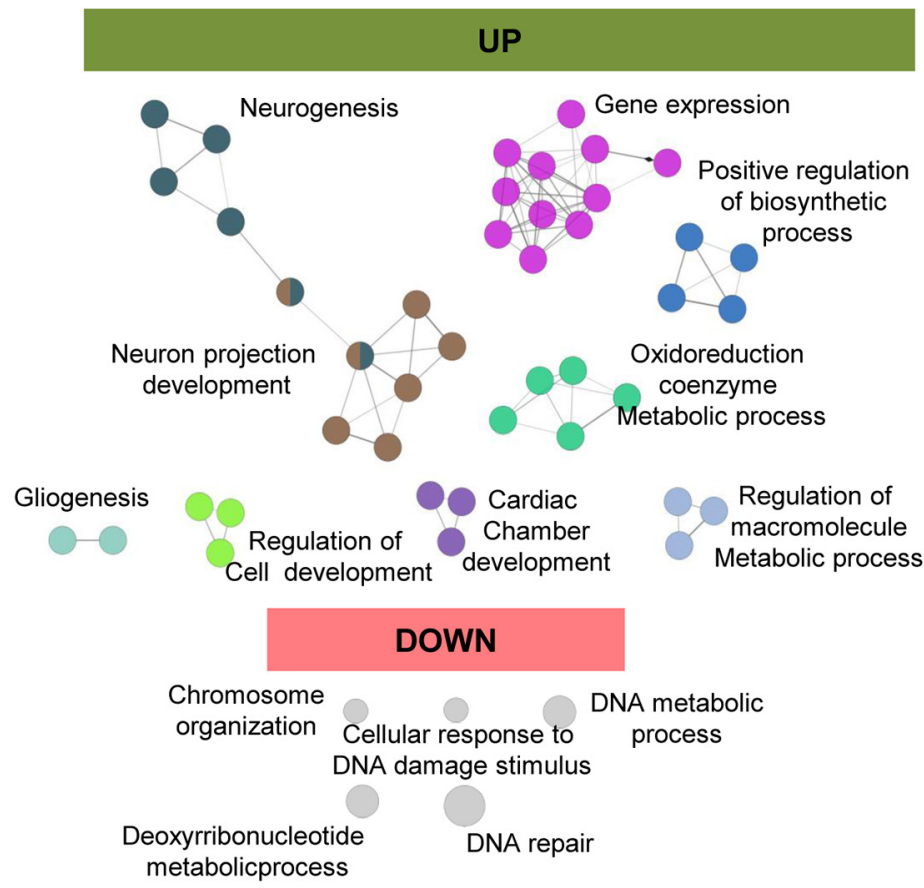

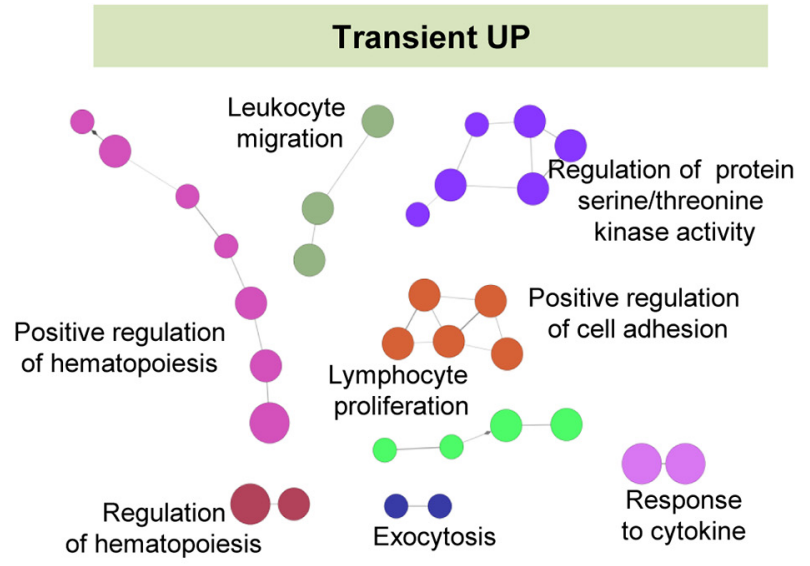

Transient DOWN

Glycoprotein

Metabolic process

Figure 5. Functional analysis of phagocytic microglia using ClueGO. Charts show the interactions among the significantly different functions for the four main expression patterns. Biological functions are visualized as colored nodes linked to related groups based on their $\kappa$ score level. The node size reflects the enrichment significance of the term and functionally related groups are linked. Non-grouped terms are shown in gray.

promotes the inhibition of neural-committed cells and resulted in the differentiation of NPCs into astrocytes.

\section{Cytokines are unlikely to drive the bipolar phenotype} triggered by phagocytic microglia conditioned media We next focused on characterizing the nature of the phagocytosis secretome. As observed in the arrays (Figs. 7, 8), phagocytic microglia expressed the mRNA of several cytokines, such as Csf3, IL- $1 \beta$, IL- 6 , TNF- $\alpha$, or TGF- $\beta$ among others. In addition to phagocytosis, these molecules are also released by microglia upon inflammatory stimuli and some have already been reported to impair neurogenesis (Ekdahl et al., 2003; Monje et al., 2003). To directly compare cytokine expression induced by phagocytosis and by a classical inflammatory stimulus such as LPSs (bacterial lipopolysaccharides) we treated NPCs with the CM of primary microglia that had been pretreated with LPSs $(1 \mu \mathrm{g} / \mathrm{ml}$; Monje et al., 2003) for $6 \mathrm{~h}$ to trigger the inflammatory response, and then changed to fresh media for another $18 \mathrm{~h}$ to ensure that the CM would not contain any leftover LPSs (Fig. 12A). We found that NPC cultures treated with LPSs or CM microLPS produced a majority of stellate cells and a small proportion of ramified cells, although there were no differences between the two treatments in terms of cell-type proportion and numbers (Fig. 12B,C). CM microLPS treatments did not trigger bipolar cells, strongly suggesting that cytokines were unrelated to the effect of the phagocytosis secretome on NPCs.

Unexpectedly, neither LPSs nor CM microLPS reduced the number of neuroblasts compared to CM microC (Fig. 12 B, C). These were surprising results because proinflammatory cytokines are well documented to exert detrimental consequences for neurogenesis (Ekdahl et al., 2003; Monje et al., 2003). To disregard that this discrepancy resulted from different LPS concentration or exposure time compared with prior publications, we performed a series of LPS-based experiments in which we used first, a lower LPS dosage (150 ng/ml for 18 h; Fraser et al., 2010) that produced a very similar cytokine expression as phagocytosis in microglia (Fig. 12D-F); second, the exact LPS dosage and time (1 $\mu \mathrm{g} / \mathrm{ml}, 24 \mathrm{~h}$ ) described by Monje et al. (2003), where they found a reduction in $\mathrm{DCX}^{+}$cells after CM microLPS treatment (Fig. $12 G, H)$; and third, the paradigm described by Monje et al. (2003), who used the BV2 cell line instead of primary microglia (Fig. 12I,J), although they used hippocampal NPC cultures derived from adult rats. None of the LPS or CM LPS treatments gave rise to bipolar cells, strongly suggesting that cytokines are highly unlikely to drive the bipolar phenotype triggered by the phagocytic microglia secretome.

\section{The phagocytosis secretome reduces neuronal differentiation} We next characterized the effect of the CMs at later stages of neurogenesis using a late survival/differentiation assay in which NPCs were allowed to differentiate for $10 \mathrm{~d}$ into neuroblasts and astrocytes using DMEM/F12 without trophic factors. At this stage $(t=0)$, the cultures exhibited a high percentage of cell death $(65.8 \pm 2.4 \%)$ and the majority of the cells had a stellate morphology. These differentiated cultures were then treated for 3 and $5 \mathrm{~d}$ with CM microC and microPH as well as DMEM for positive control (Fig. 13 A, B). Importantly, treatment with microPH did not result in higher levels of apoptosis than microC or DMEM (Fig. 13B). Cultures treated with CM microC presented a vast majority of stellate cells and few ramified cells. In contrast, CM microPH-treated cultures showed no $\mathrm{DCX}^{+}$cells, a small percentage of stellate cells and a majority of stellate cells with a more mature morphology (more complex ramifications; Fig. 13C,D). Nonetheless, the gene array data did not support a direct induction of astrogenesis. The functions "gliogenesis" and "glial cell differentiation" were significantly upregulated in the ClueGo analysis (Fig. 5), but the majority of the genes found under those categories were autologous, and therefore, their overexpression would only modulate the microglial cells expressing them. As the astrocytic lineage is the default differentiation mode of neural 
A

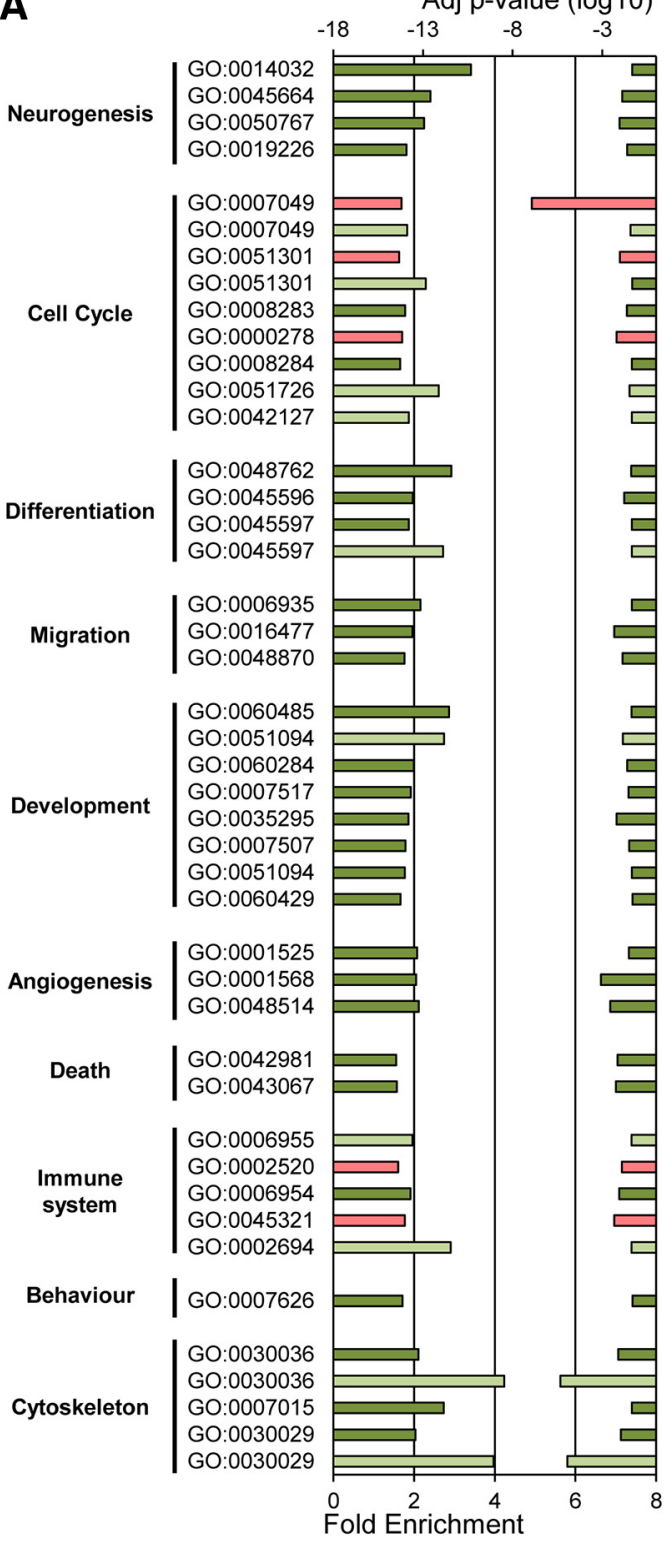

Adj p-value $(\log 10)$

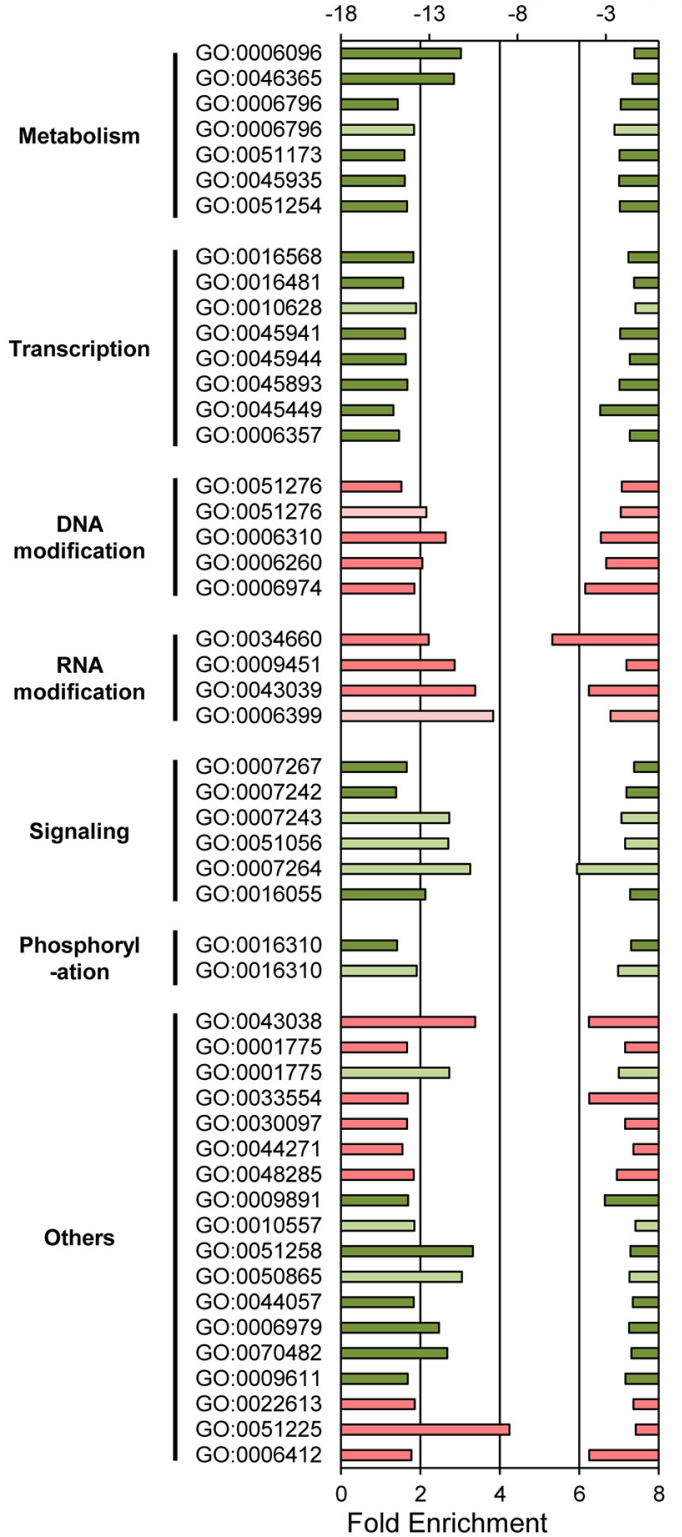

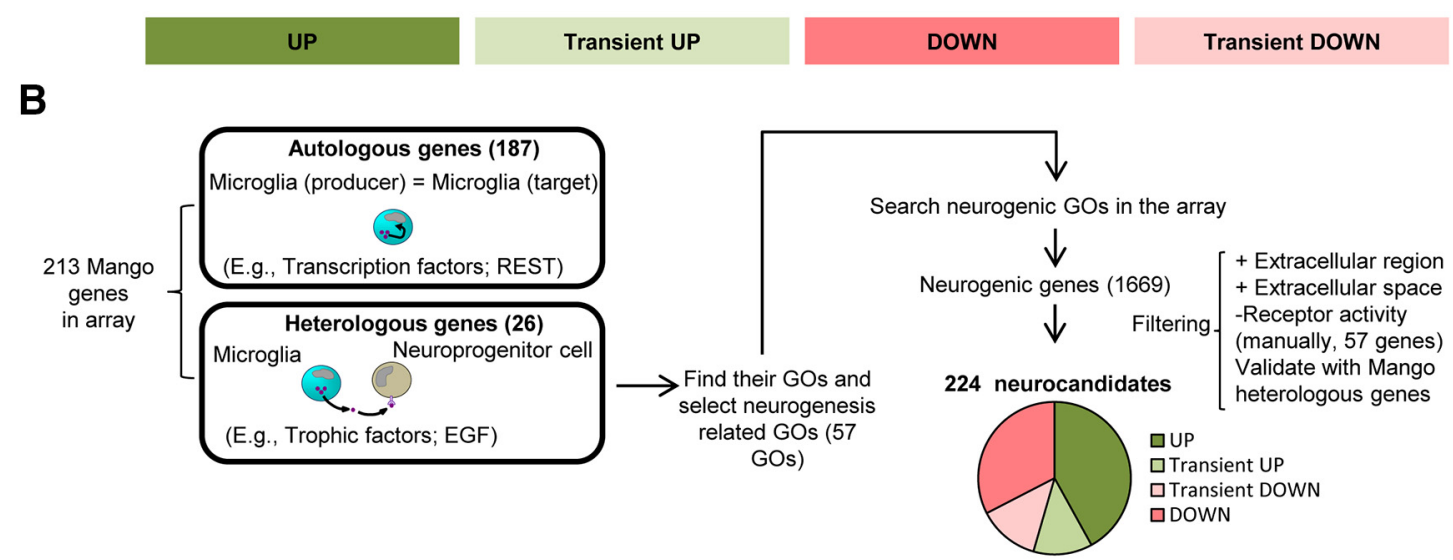

Figure 6. Functional analysis of phagocytic microglia using DAVID and MANGO. A, Functional analysis of phagocytic microglia using DAVID software. Left axis represents the fold enrichment of each biological function and right axis represents the adjusted $p$ value of each $G 0$ term. Key for the $G 0$ terms: $G 0: 0014032$, neural crest cell development; $G 0: 0045664$, regulation of neuron differentiation; G0:0050767, regulation of neurogenesis; G0:0019226, transmission of nerve impulse; G0:0007049, cell cycle; G0:0051301, cell division; G0:0008283, cell proliferation; G0:0000278, mitotic cell cycle; $\mathrm{G0}: 0008284$, positive regulation of cell proliferation; $\mathrm{GO}: 0051726$, regulation of cell cycle; $\mathrm{G0}: 0042127$, regulation of cell proliferation; $\mathrm{G0}: 0048762$, mesenchymal cell differentiation; G0:0045596, negative regulation of cell differentiation; G0:0045597, positive regulation of cell differentiation; G0:0006935, chemotaxis; G0:0016477, cell migration; G0:0048870, cell motility; G0:0060485, mesenchyme development; G0:0051094, positive regulation of developmental process; G0:0060284, regulation of cell development; G0:0007517, muscle organ development; G0:0035295, tube development; G0:0007507, heart development; G0:0051094, positive regulation of developmental process; G0:0060429, epithelium (Figure legend continues.) 
stem cells (Bonaguidi et al., 2011; Encinas et al., 2011), these data suggest that the phagocytosis secretome inhibited neuronal differentiation, indirectly promoting astrocyte differentiation.

\section{Neurogenic modulatory factors secreted by phagocytic microglia in vitro alter neurogenesis in vivo}

To then confirm the neurogenic modulatory role of the phagocytosis secretome on adult hippocampal neurogenesis in vivo, we injected $\mathrm{CM}$ microC and microPH into the hippocampus of 2-month-old fms-EGFP mice for $6 \mathrm{~d}$ using osmotic minipumps. After this period, BrdU was administered to track proliferating cells and mice were killed $2 \mathrm{~h}$ later (Fig. 14A).

We observed no differences in the density of total $\mathrm{BrdU}^{+}$ proliferative cells in $\mathrm{CM}$ microPH treated mice compared to $\mathrm{CM}$ microC treatment (Fig. 14B,C). Importantly, CM microPH did not induce apoptosis in vivo (Fig. 14D). In addition, there was a trend toward decreased density of proliferating $\mathrm{BrdU}^{+}$rNSCs in mice treated with $\mathrm{CM}$ microPH compared to $\mathrm{CM}$ microC $(p=$ 0.0649 ; Fig. $14 E-G)$. Moreover, the density of $\mathrm{DCX}^{+}$neuroblasts, the proportion of the different neuroblast subpopulations $(\mathrm{AB}, \mathrm{CD}$, and $\mathrm{EF})$, and neuroblast proliferation did not differ between $\mathrm{CM}$ microC and microPH (Fig. $14 H-J$ ).

Because we observed a declining trend for rNSCs in the presence of $\mathrm{CM}$ microPH after $6 \mathrm{~d}$, we hypothesized that the induced alterations would accumulate over time. Therefore, we per-

$\leftarrow$

(Figure legend continued.) development; G0:0001525, angiogenesis; G0:0001568, blood vessel development; G0:0048514, blood vessel morphogenesis; $G 0: 0042981$, regulation of apoptosis; G0:0043067, regulation of programmed cell death; G0:0006955, immune response; G0:0002520, immune system development; G0:0006954, inflammatory response; G0: 0045321, leukocyte activation; G0:0002694, regulation of leukocyte activation; G0:0007626,

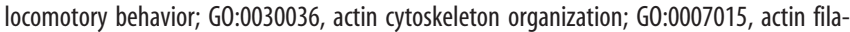
ment organization; G0:0030029, actin filament-based process; G0:0006096, glycolysis; G0: 0046365, monosaccharide catabolic process; G0:0006796, phosphate metabolic process; $\mathrm{GO}$ : 0006796, phosphate metabolic process; G0:0051173, positive regulation of nitrogen compound metabolic process; $60: 0045935$, positive regulation of nucleobase, nucleoside, nucleotide and nucleic acid metabolic process; $60: 0051254$, positive regulation of RNA metabolic

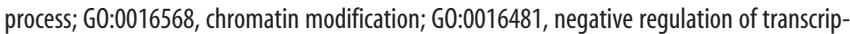
tion; G0:0010628, positive regulation of gene expression; $60: 0045941$, positive regulation of transcription; G0:0045944, positive regulation of transcription from RNA polymerase II promoter; G0:0045893, positive regulation of transcription, DNA-dependent; G0:0045449, regulation of transcription; G0:0006357, regulation of transcription from RNA polymerase II promoter; G0:0051276, chromosome organization; G0:0006310, DNA recombination; G0: 0006260, DNA replication; G0:0006974, response to DNA damage stimulus; G0:0034660, ncRNA metabolic process; G0:0009451, RNA modification; G0:0043039, tRNA aminoacylation; G0:0006399 tRNA metabolic process; G0:0007267, cell-cell signaling; G0:0007242, intracellu-

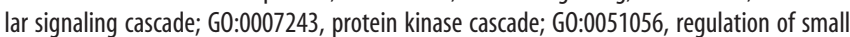
GTPase-mediated signal transduction; G0:0007264, small GTPase-mediated signal transduction; G0:0016055, Wnt receptor signaling pathway; G0:0016310, phosphorylation; G0: 0043038, amino acid activation; G0:0001775, cell activation; G0:0033554, cellular response to stress; G0:0030097, hemopoiesis; $\mathrm{G0}: 0044271$, nitrogen compound biosynthetic process; $\mathrm{GO}$ : 0048285, organelle fission; G0:0009891, positive regulation of biosynthetic process; $\mathrm{GO}$ : 0010557, positive regulation of macromolecule biosynthetic process; G0:0051258, protein

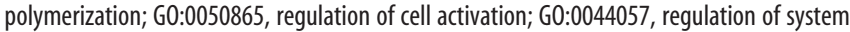
process; $\mathrm{G0}: 0006979$, response to oxidative stress; $\mathrm{G0}: 0070482$, response to oxygen levels; $\mathrm{G0}: 0009611$, response to wounding; $\mathrm{G0}: 0022613$, ribonucleoprotein complex biogenesis; $\mathrm{GO}$ : 0051225, spindle assembly; G0:0006412, translation. Left axis represents the fold enrichment of each biological function and right axis represents the adjusted $p$ value of each $\mathrm{GO}$ term. Only statistically significant changes are shown. $\boldsymbol{B}$, Diagram depicting the strategy followed to search for potential modulators of neurogenesis produced by phagocytic microglia in the arrays. The filtering started by differentiating the heterologous and autologous genes in the MANGO database. Then, $\mathrm{GO}$ terms related to neurogenesis were selected for the heterologous MANGO genes. Afterward, the molecules that presented the neurogenic $\mathrm{GO}$ terms were searched in the array. Finally, the candidate genes were filtered only to select those that appeared extracellularly (heterologous genes), and genes with receptor activity were manually discarded. formed a long-term experiment in which mice were treated with $\mathrm{CM}$ microC and microPH through osmotic minipumps for $6 \mathrm{~d}$, followed by BrdU administration, and killed $28 \mathrm{~d}$ later to allow differentiation of the labeled cells (Fig. 14K). The density of $\mathrm{BrdU}^{+}$cells in mice treated with $\mathrm{CM}$ microPH showed a significant decrease compared to $\mathrm{CM}$ microC (Fig. 14L,M). Importantly, CM microPH did not induce apoptosis in vivo (Fig. 14N). We then quantified neuroblasts and newborn neurons $\left(\mathrm{NeuN}^{+}\right.$, $\mathrm{BrdU}^{+}$; Fig. 14O-S). In all experiments in Figure 14, because the conditioned media diffused over the $6 \mathrm{~d}$ infusion period, we found a stronger effect closer to the injection site (Fig. 14P). Thus, for this set of experiments, only the three tissue slices of the sectioning series most proximal to the injection site were quantified. We found a significant reduction in the intermediate $(\mathrm{CD})$ and most mature (EF) neuroblast subpopulations in mice treated with $\mathrm{CM}$ microPH compared to $\mathrm{CM}$ microC (Fig. 14R). Finally, the density of newborn neurons was also reduced in CM microPH compared to CM microC (Fig. 14S). In summary, we found a trend toward fewer proliferative stem cells at $2 \mathrm{~h}$ after BrdU, and reduced number of mature neuroblasts and newborn neurons after $28 \mathrm{~d}$, suggesting that the acute $(24 \mathrm{~h})$ phagocytic microglia secretome limits neurogenesis via the reduction in the production of neuronalcommitted cells.

\section{Discussion}

In this paper, we provide evidence that microglia modulate adult hippocampal neurogenesis through the secretome associated with phagocytosis of apoptotic newborn cells, based on the following major findings. First, adult hippocampal neurogenesis was reduced in two KO models with chronic microglial phagocytosis impairment. Second, neurogenesis was transiently increased in an acute model of phagocytosis impairment. Third, transcriptomic analysis in vitro revealed that phagocytosis triggered an expression change in a panoply of neurogenesisrelated genes in microglia, strongly suggesting a coordinated neurogenic modulatory program that encompasses up to 224 heterologous genes previously shown to modulate neurogenesis, including peptides, trophic factors, matrix metalloproteases, and cytokines. Fourth, the secretome of phagocytic microglia drove NPCs differentiation toward a bipolar phenotype of astrocytic lineage in vitro, characterized by high expression of astrocytic markers such as nestin, GFAP and S100 $\beta$; calcium responses to ATP and other stimuli; and high levels of phosphorylation of SMAD. Finally, the secretome of phagocytic microglia reduced the most mature neuroblast subpopulation at $28 \mathrm{~d}$ in vivo. Hence, we present evidence that microglial phagocytosis is a pivotal mechanism for the maintenance of homeostasis in the adult neurogenic cascade.

\section{Microglia control the long-term homeostasis of the adult hippocampal neurogenic cascade}

The accurate homeostasis of stem cell niches is crucial for their long-term maintenance, as disruption of the equilibrium between quiescence and proliferation leads to early exhaustion (Santos et al., 2018). In the adult hippocampal neurogenic niche, the mechanisms described to maintain homeostasis rely on the quiescence of rNSCs (Encinas et al., 2011), a feature that prevents an early exhaustion of the niche (Sierra et al., 2015). Herein we focus on the unexplored role of resident immune cells, microglia, which engulf newborn cells that undergo apoptosis (Sierra et al., 2010). Immune cells are increasingly recognized to participate in stem cell niches, and macrophages have been recently 
A
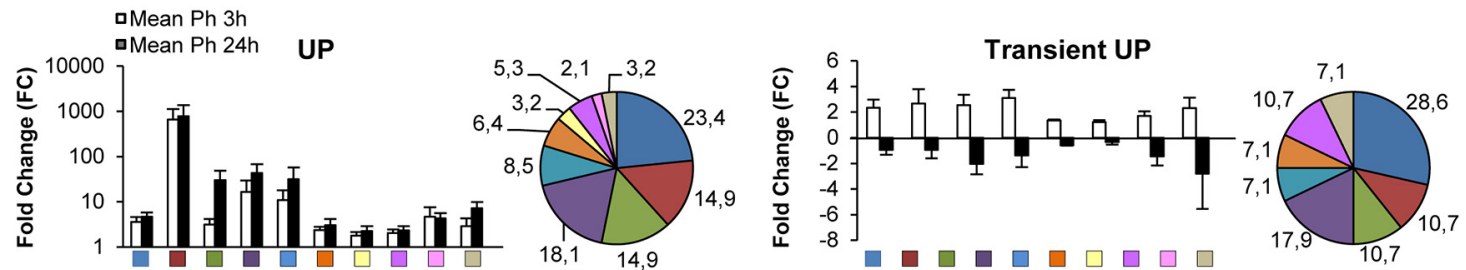

DOWN
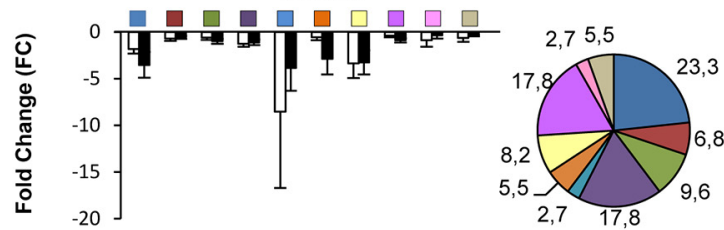

Transient DOWN

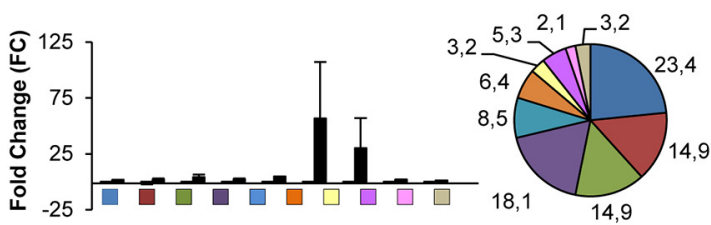

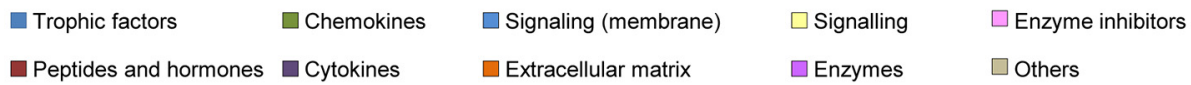

B
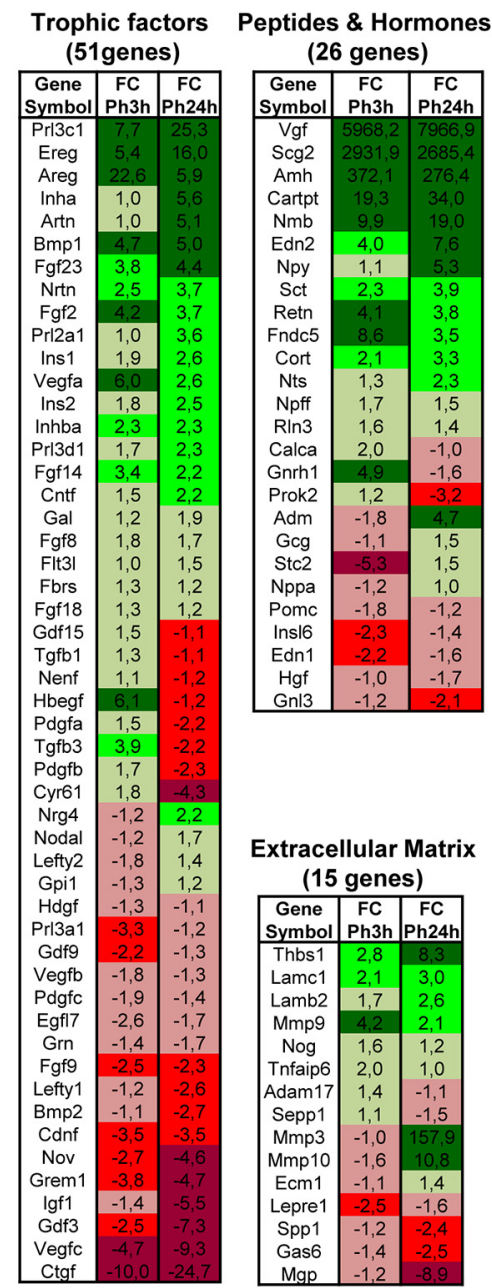

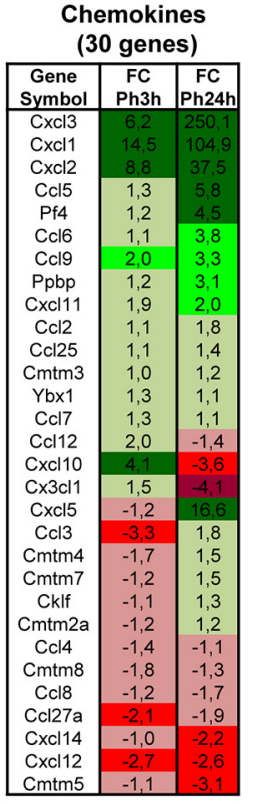

Membrane-bound Signaling molecules

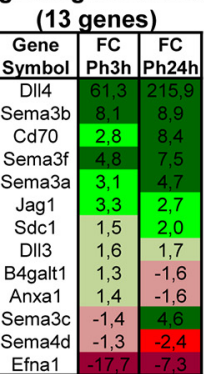

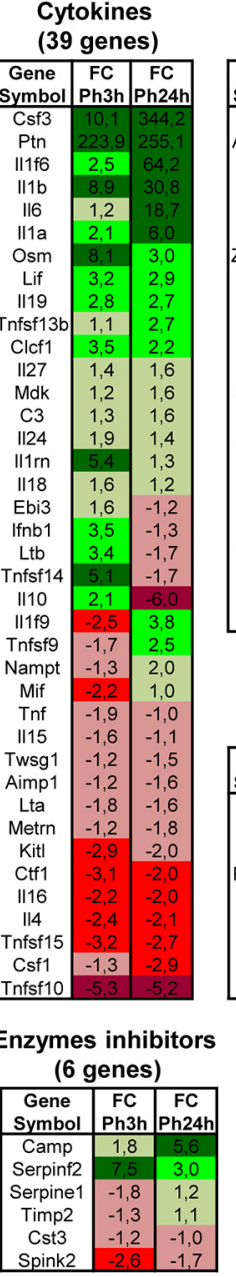

Signaling molecules (12 genes)

\begin{tabular}{|c|c|c|}
\hline $\begin{array}{c}\text { Gene } \\
\text { Symbol }\end{array}$ & $\begin{array}{c}\text { FC } \\
\text { Ph3h }\end{array}$ & $\begin{array}{c}\text { FC } \\
\text { Ph24h }\end{array}$ \\
\hline Wnt1 & 2,5 & 3,5 \\
S100a13 & 1,5 & 1,7 \\
Lgals3 & 1,3 & 1,5 \\
S100a8 & $-1,0$ & 83,7 \\
S100a9 & $-1,2$ & 6,0 \\
Hmgb2 & $-1,2$ & 1,0 \\
Agrp & $-7,5$ & $-1,0$ \\
Tulp3 & $-1,9$ & $-1,3$ \\
Angpt2 & $-1,9$ & $-2,3$ \\
S100b & $-1,9$ & $-5,9$ \\
Angpt13 & $-2,3$ & $-6,4$ \\
Angpt16 & $-10,7$ & $-8,7$ \\
\hline
\end{tabular}

Figure 7. Phagocytosis-related candidates include trophic factors and peptides and hormones. $\boldsymbol{A}$, Classification of the 224 potential modulators of neurogenesis. "Trophic factor" was the category with the highest percentage of genes in every regulatory pattern, however, the category "Peptides and hormones" included genes with the highest FC changes in the UP regulation pattern. $\boldsymbol{B}$, The 224 candidates classified by their identity and FC. 
A

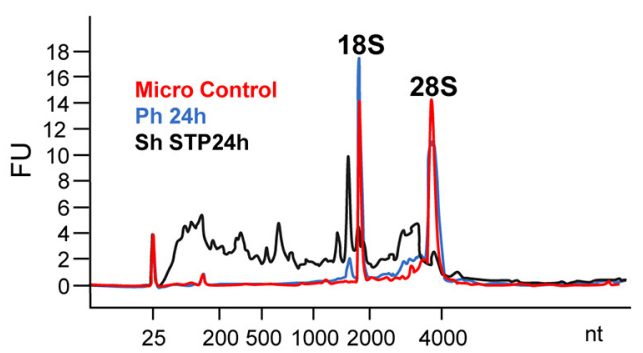

B

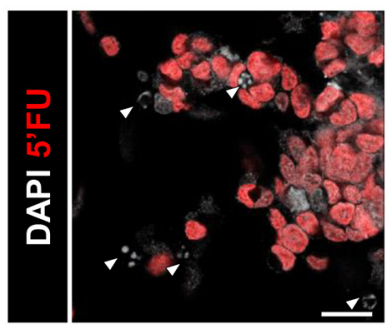

C mRNA expresssion of candidates

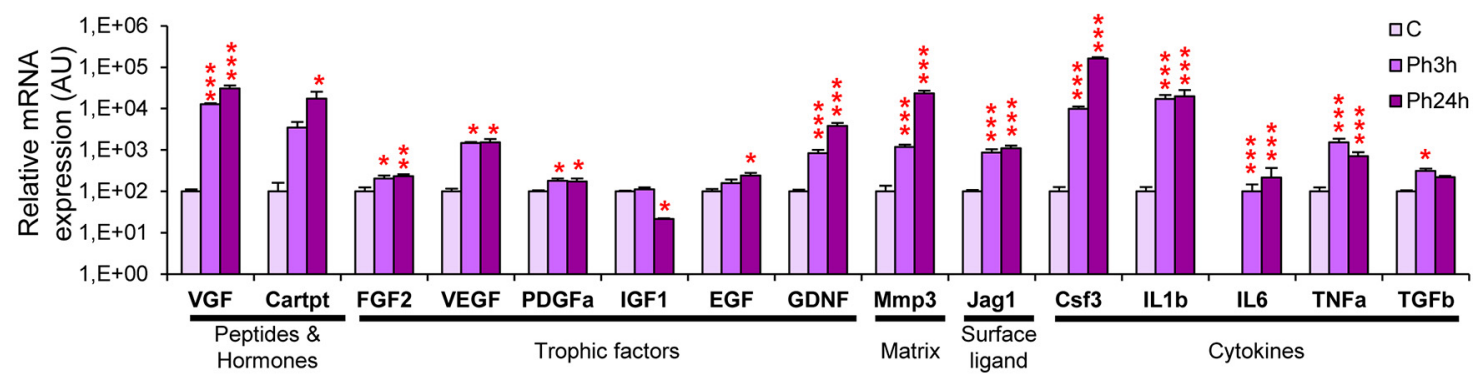

Figure 8. Validation of transcriptional changes induced by phagocytosis. $A$, Electropherogram obtained by a bioanalyzer comparing the RNA profile (nt, nucleotides) of control and phagocytic microglia as well as apoptotic SH-SY5Y (treated with $3 \mu \mathrm{M}$ STP for $24 \mathrm{~h}$ ). B, Representative confocal images of FU ${ }^{+}$active transcription sites of SH-SY5Y cells treated with STP ( $3 \mu \mathrm{M}, 4 \mathrm{~h}$ ) for apoptosis induction. Nuclei were labeled with DAPI (white), cell death was detected by pyknosis/karyorrhexis (white, DAPI; arrowheads), and transcription sites were detected by FU (red). C, $\mathrm{mRNA}$ expression levels of the candidates selected for validation by real-time $\mathrm{qPCR} . N=4$ independent experiments. HPRT was selected as a reference gene. Scale bar, $20 \mu \mathrm{m} . N=4$ independent experiments $(\boldsymbol{F})$. Error bars represent mean \pm SEM. ${ }^{*} p<0.05,{ }^{* *} p<0.01,{ }^{* * *} p<0.001$ by Holm-Sidak post hoc test of (after one-way ANOVA was significant at $p<0.05$ ). Only significant effects are shown. Values of statistics used are shown in Table 4.

shown to promote erythroblast production in the bone marrow (Chow et al., 2013), and to be required for ductal morphogenesis in the mammary gland (Chakrabarti et al., 2018). We found that chronic disruption of microglial phagocytosis impairs neurogenesis using two constitutive $\mathrm{KO}$ mice models for receptors P2Y12, and MerTK/Axl, which participate in different stages of phagocytosis (Scott et al., 2001; Elliott et al., 2009). Nonetheless, it is important to note that these receptors regulate multiple features of microglial physiology, and that MerTK and Axl are also expressed in peripheral macrophages (Rothlin and Lemke, 2010). In addition, microglial phagocytosis impairment leads to the accumulation of nonremoved apoptotic cells, which may also affect neurogenesis directly through the release of toxic intracellular contents. However, the similar reduction in adult neurogenesis in the two models strongly supports the key role of microglial phagocytosis.

In contrast to the effect of constitutive phagocytosis impairment, acute phagocytosis impairment by inducible depletion of MerTK resulted in a transient increase in early neuroblasts that was compensated at later time points. Several effects may explain the differences between the constitutive MerTK/Axl KO and the inducible MerTK KO mice (i.e., double $\mathrm{KO}$ vs single $\mathrm{KO}$; body-wide in all TAM-expressing cells vs microglial-specific; and knock out from embryonic development vs only in selected cells in the adult). Nonetheless, the transient increase in early neuroblasts after acute impairment of phagocytosis in the iKO MerTK model, together with the chronic reduction of neurogenesis in the P2Y12 and MertK/Axl constitutive KO models, and the reduction in neurogenesis in mice treated with the phagocytic microglia conditioned media, suggest that the microglial phagocytosis of newborn cells participates in a feedback loop that maintains the homeostasis of adult hippocampal neurogenesis (Fig. 15).
Microglia regulates neurogenesis through the phagocytosis secretome

We found that phagocytosis of apoptotic cells induced a neurogenic modulatory phenotype in microglia that was mostly related to their secretome, as the majority of the modulatory genes encoded secreted proteins, including neuropeptides such as VGF, and growth factors such as VEGF and FGF2, some of which have already been described to participate in the microglial regulation of neurogenesis (Kreisel et al., 2019). In addition, the microglial secretome may contain metabolites, miRNAs and extracellular vesicles, which may also alter neurogenesis (Rodríguez-Iglesias et al., 2019). When administered in vivo, the acute secretome of phagocytic microglia inhibited hippocampal neurogenesis, as it had an early tendency to decrease rNSCs proliferation that was later followed by a reduction in mature neuroblasts. The effect was similar on isolated NPCs, as we found a decreased production of neuroblasts. However, this effect was unlikely related to an active promotion of apoptosis, which was not detected in vivo. In agreement, the in vitro transcriptomic analysis did not reveal significant increases in heterologous proapoptotic genes, and cell death was not observed in the late survival/differentiation assays. Nonetheless, many early NPCs did die upon culture with the early phagocytic microglia conditioned media, an effect that may be attributed to the lack of key survival factors, possibly metabolites consumed by phagocytic microglia. Apoptosis is common in these early cultures and has been linked to the stress associated with differentiation upon growth factor withdrawal (Babu et al., 2011). Overall, these results suggest that the secretome of phagocytic microglia modulates neurogenesis by acting not on the survival but on the differentiation of neural-committed cells.

The reduced neuronal differentiation induced by the secretome of phagocytic microglia was unlikely related to an enhance- 
A

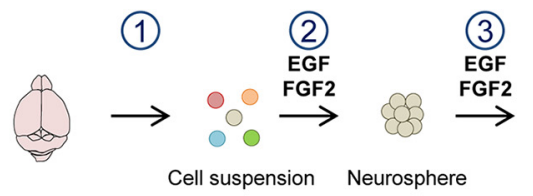

B

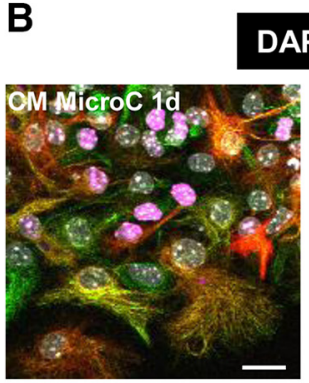

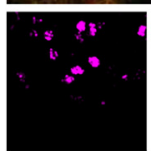
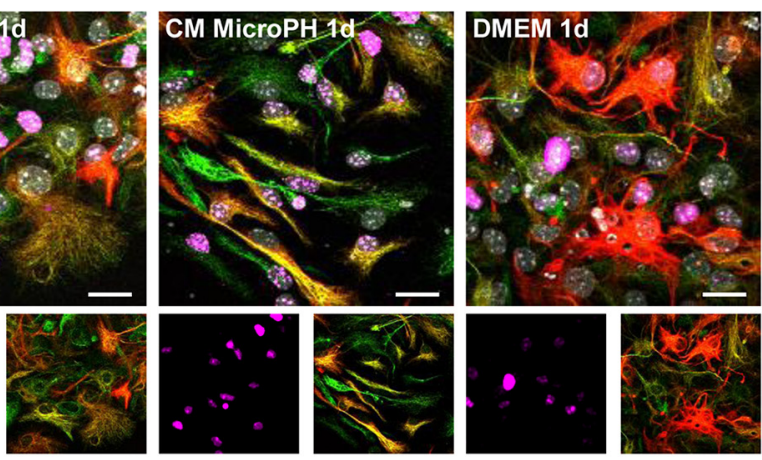

E
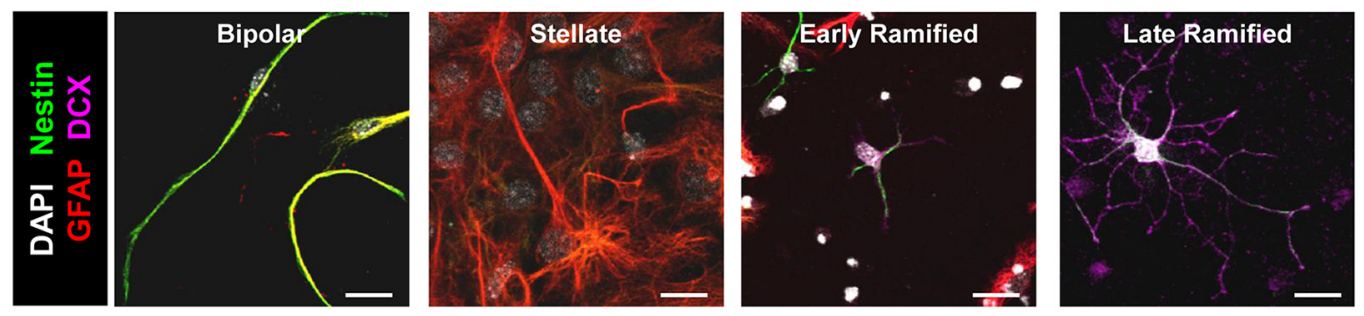

C

Proliferation
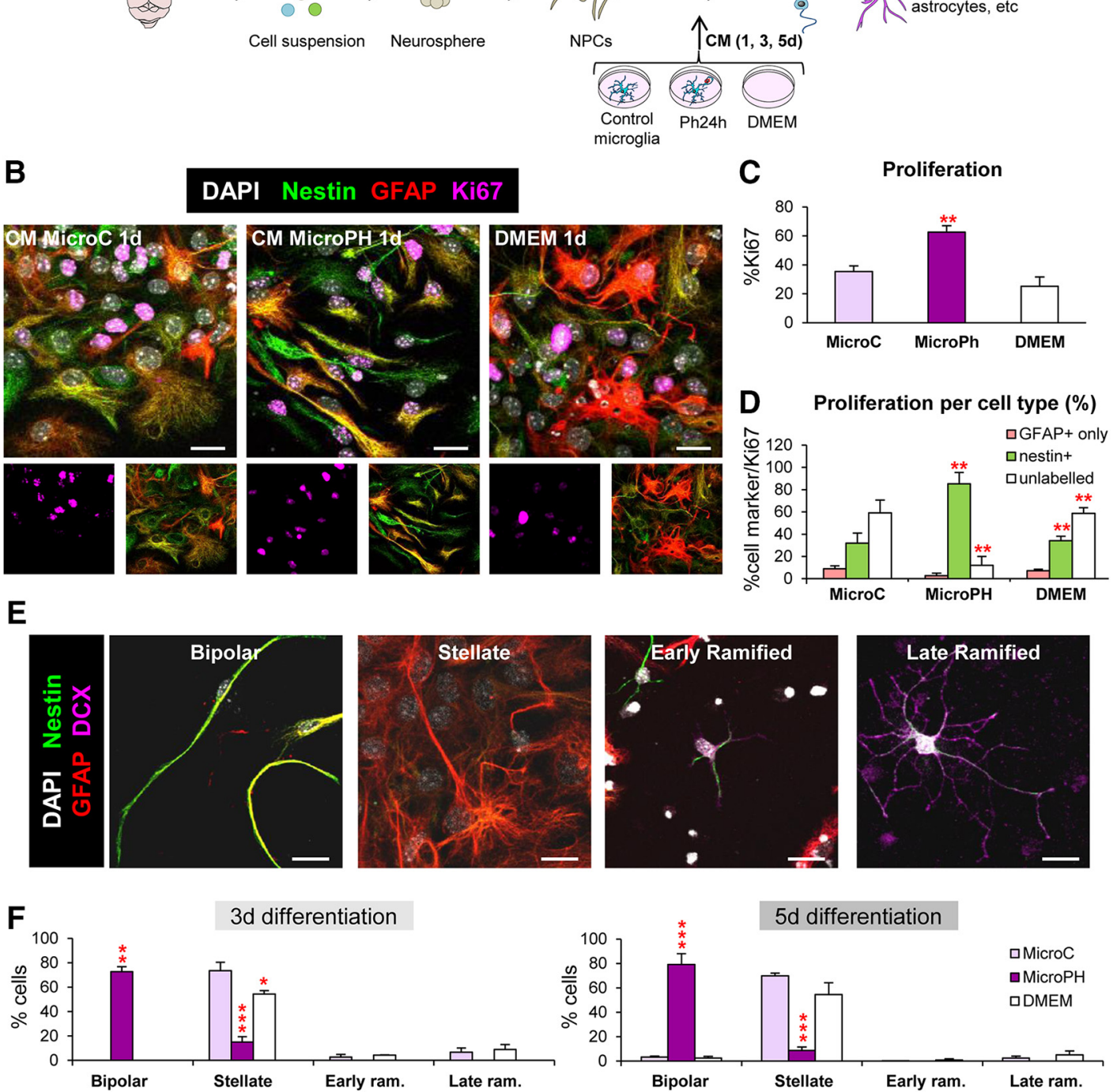

G

H

DAPI Nestin GFAP DCX
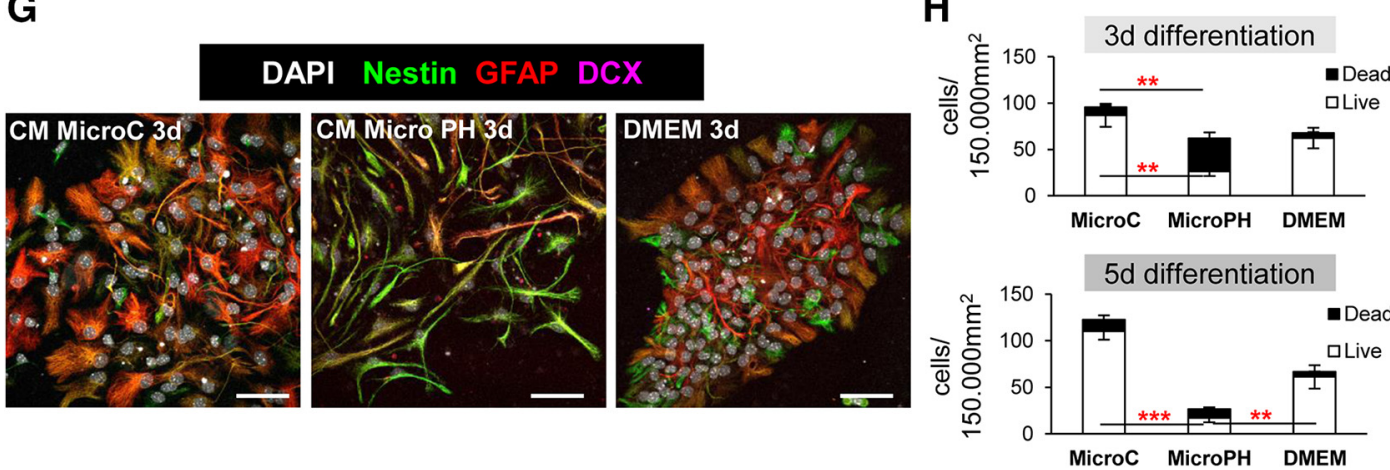

Figure 9. Effect of phagocytic microglia secreted factors on neurogenesis in vitro. $A$, Experimental design of the in vitro neurogenesis assay: (1) brain disaggregation; (2) neurosphere proliferation; (3) dissociation, plating, and proliferation of NPCs for $48 \mathrm{~h}$; (4) differentiation in the presence of conditioned media (CM) from control microglia (microC) or $24 \mathrm{~h}$ phagocytic microglia (microPh). $\boldsymbol{B}$, Representative confocal microscopy images of NPCs treated with CM microC or microPH after $1 \mathrm{~d}$. DMEM was used as control. C, Percentage of cells labeled with Ki67 over total cells labeled with DAPI. D. Percentage of different cell markers over total Ki67 population: nestin ${ }^{+}$(with or without GFAP), GFAP only, or unlabeled. $\boldsymbol{E}$, Representative confocal microscopy images of the different morphologies observed in the neurogenesis assay images. $F$, Percentage of the different cell types found after 3 and $5 \mathrm{~d}$ treatment with CM microC or microPH. Early/late ram refers to early/late ramified cells. $\boldsymbol{G}$, Representative confocal microscopy images of NPCs treated with CM microC or microPH after $3 \mathrm{~d}$. $\boldsymbol{H}$, Density of live and dead cells (determined by pyknosis/karyorrhexis) after $C \mathrm{CM}$ treatment for 3 and 5 d. Scale bars: $\boldsymbol{B}, 50 \mu \mathrm{m} ; \boldsymbol{E}, 9 \mu \mathrm{m} ; \boldsymbol{B}, z=11.9 \mu \mathrm{m} ; \boldsymbol{G}, z=20 \mu \mathrm{m} . \boldsymbol{N}=3$ independent experiments $(\boldsymbol{C}, \boldsymbol{D}, \boldsymbol{F}, \boldsymbol{H})$. Error bars represent mean \pm SEM. Two-way ANOVA (treatment $\times$ cell types, $\boldsymbol{D}$ ) and three-way ANOVA (treatment $\times$ cell types $\times$ time, $\boldsymbol{F}$; and treatment $\times$ life $\times$ time, $\boldsymbol{H}$ ) showed interactions between the different factors and thus the data were split into several one-way ANOVAs. ${ }^{*} p<0.05,{ }^{* *} p<0.01,{ }^{* * *} p<0.001$ by Holm-Sidak post hoc test versus MicroC group (after one-way ANOVA was significant at $p<0.05$ ). Values of statistics used are shown in Table 5. 


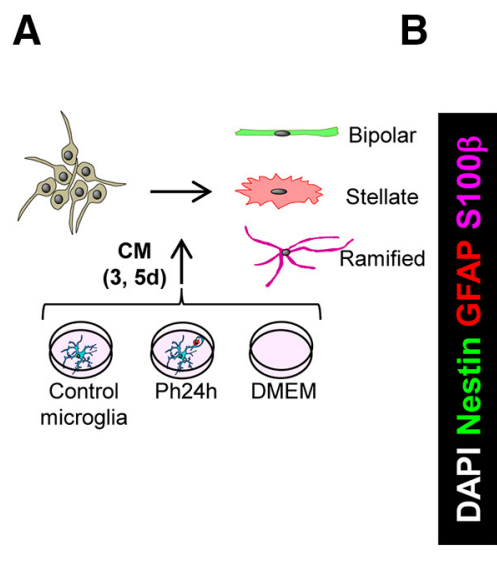

C

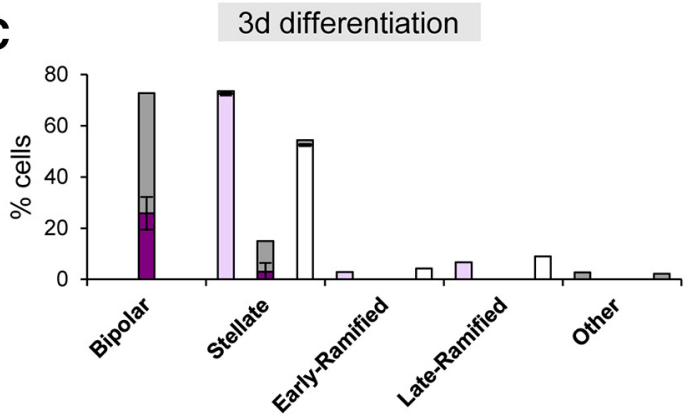

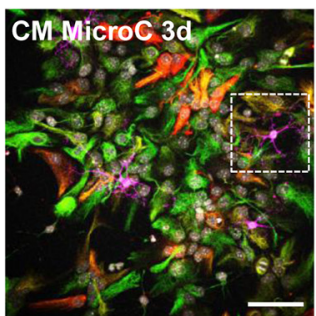
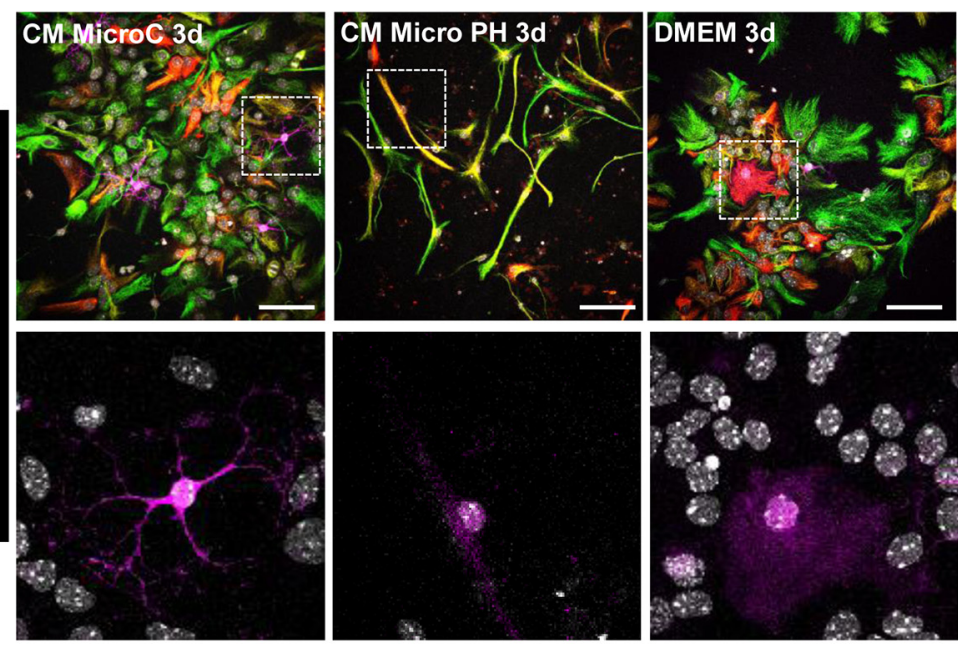

$5 d$ differentiation

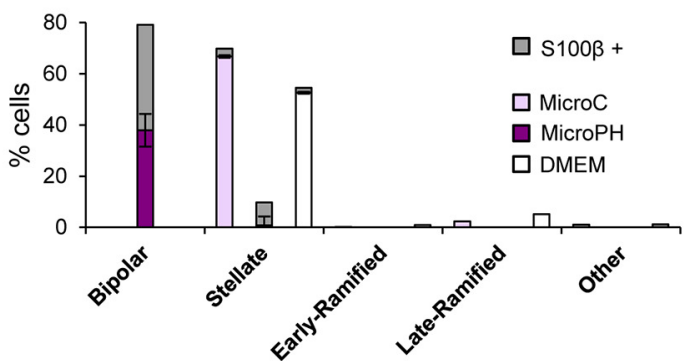

DAPI Nestin GFAP DCX

D

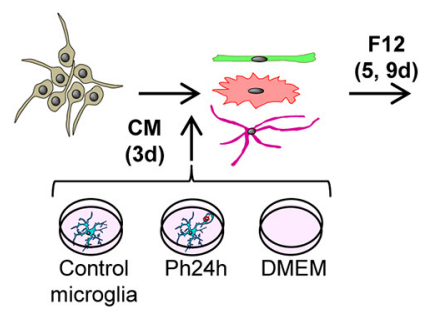

E

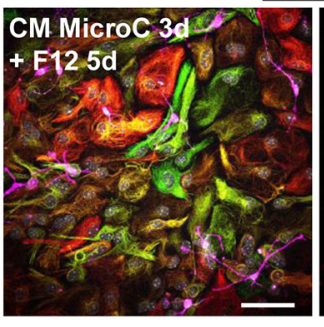

CM MicroPH 3d

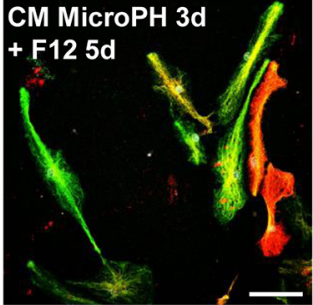

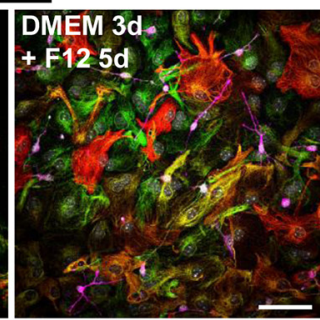

$\mathbf{F}$

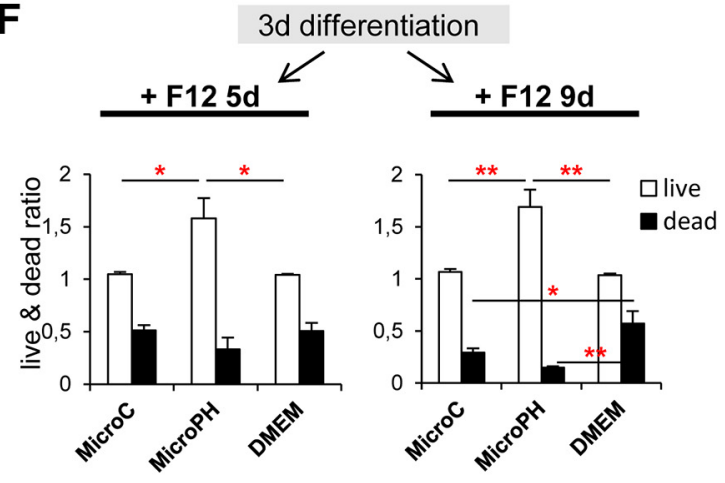

G

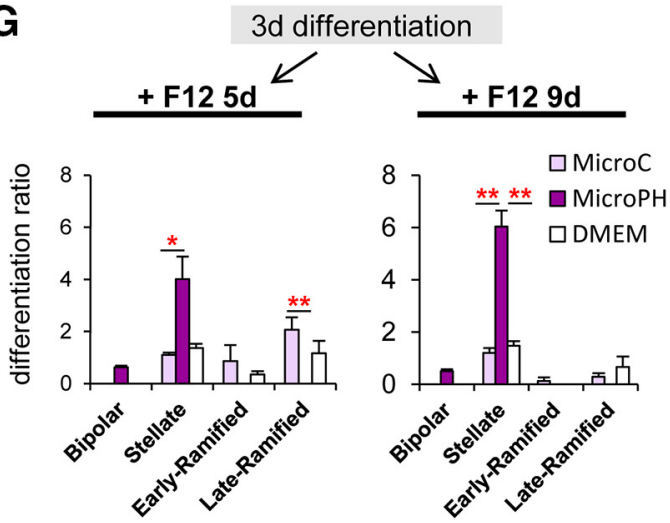

Figure 10. Characterization of $C M$ cell types by $S 100 \beta$ and multipotency assays. $\boldsymbol{A}$, Experimental design of the in vitro neurogenesis assay for $S 100 \beta$ staining. $\boldsymbol{B}$, Representative confocal microscopy images of NPCs treated with CM microC or microPH. DMEM was used as control. C, Percentage of expression of $5100 \beta$ in the different cell types found after 3 and $5 \mathrm{~d}$ treatment with CM microC or microPH. The category "Other" refers to cells with strong S100 $\beta$ expression, no GFAP and a ramified morphology suggest that they may be oligodendrocytes (Hachem et al., 2005). $\boldsymbol{D}$, Experimental design of the in vitro multipotency assay. $\boldsymbol{E}$, Representative confocal microscopy images of NPCs treated with CM microC, microPH or DMEM followed by $5 \mathrm{~d}$ of DMEM/F12.F, Ratio of live/dead cell density over the cells at $3 \mathrm{~d}$ after each treatment. $G$, Differentiation ratio of each phenotype after $3 \mathrm{~d}$ treatment with $\mathrm{CM}$ microC or microPH followed by 5 or $9 \mathrm{~d} D M E M / F 12$. Scale bars: $\boldsymbol{B}, \boldsymbol{E}, 20 \mu \mathrm{m}$ (inserts in $\boldsymbol{B}, 10 \mu \mathrm{m}) ; \boldsymbol{B}, \boldsymbol{F}, \boldsymbol{Z}=9 \mu \mathrm{m} . N=3$ independent experiments $(\boldsymbol{C}, \boldsymbol{F}, \boldsymbol{G})$. Error bars represent mean \pm SEM. ${ }^{*} p<0.05,{ }^{* *} p<0.01$. Values of statistics used are shown in Table 7. 
A

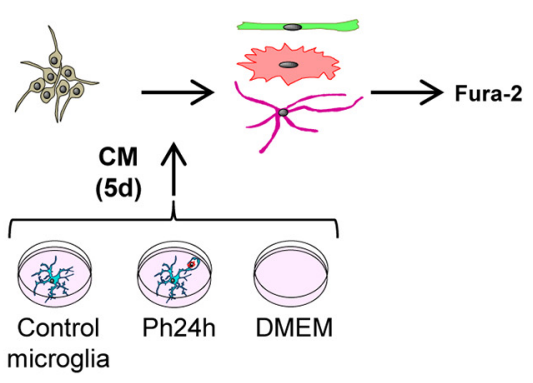

B

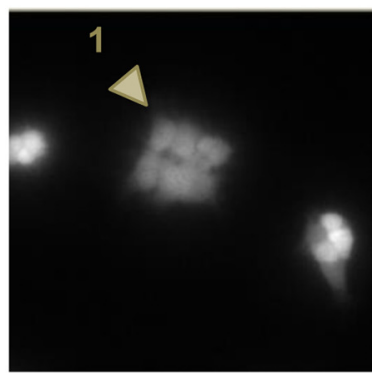

CM micro C

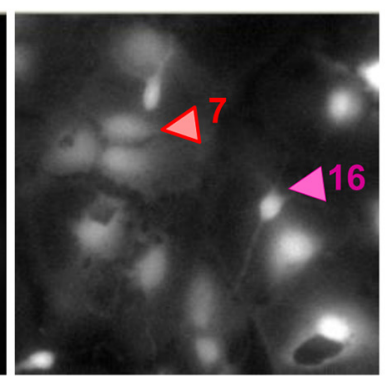

CM microPH

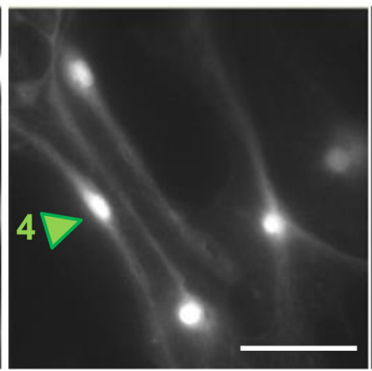

C (1) $\mathrm{kCl}$

(2) AMPA

(3) ATP

(4) Histamine (5) NMDA
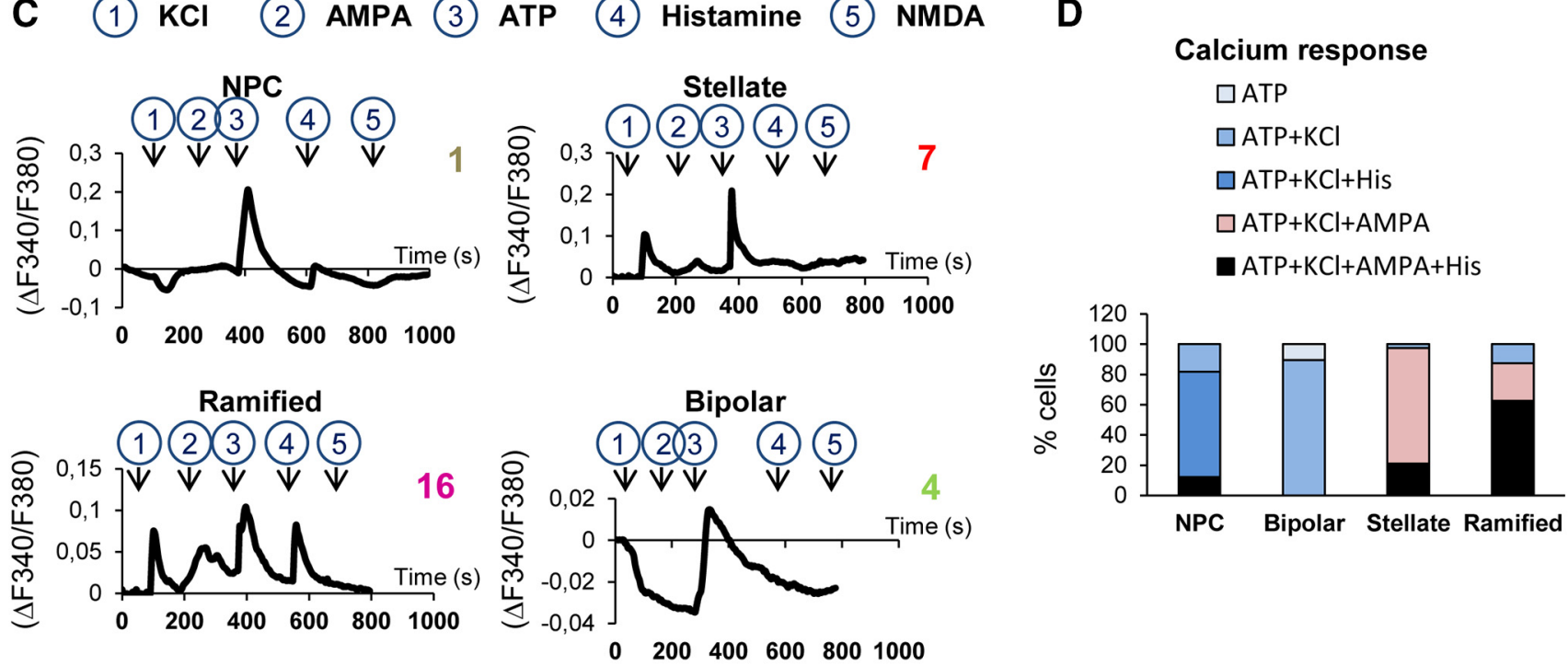

E

Ramified

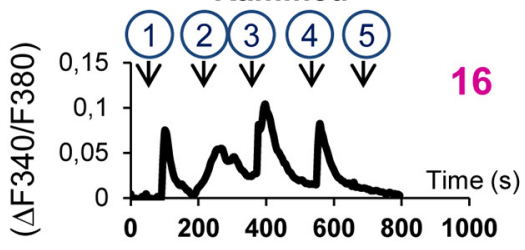

F

REST
Ascl

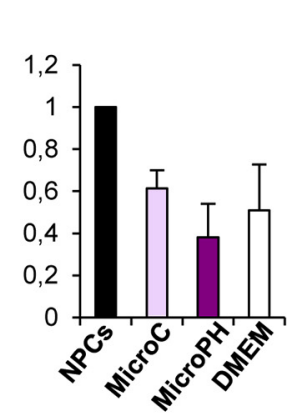

pSMAD/SMAD
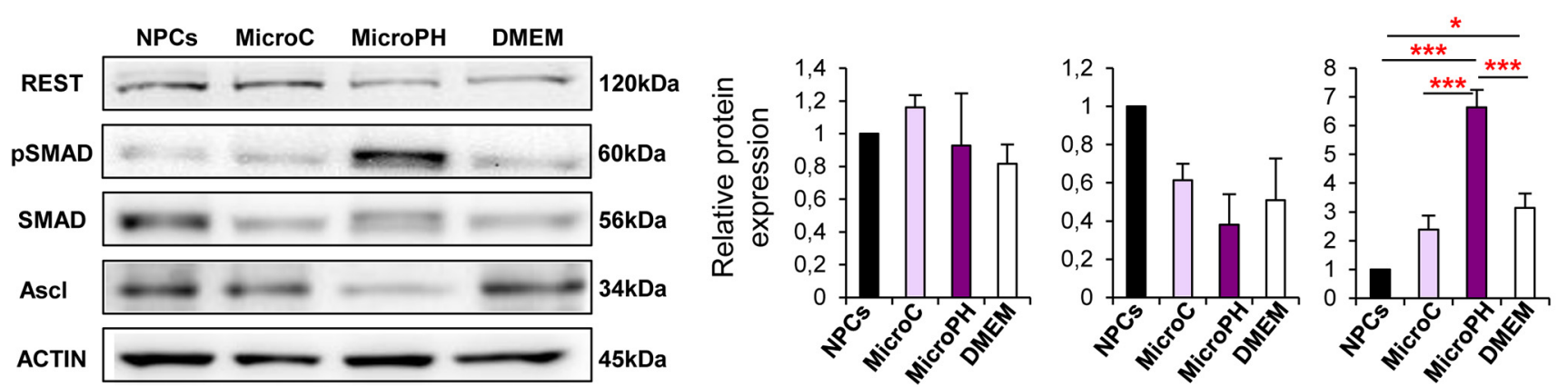

Figure 11. Characterization of CM cell types by calcium imaging and late survival/differentiation assays. $A$, Experimental design of the in vitro calcium imaging assay. NPCs were treated with CM microC or microPH for $5 \mathrm{~d}$ and the resulting stellate, ramified and bipolar cells were incubated and loaded with Fura-2 AM and afterward, cells were challenged with KCl, AMPA, ATP, histamine, and NMDA to measure their $\mathrm{Ca}^{+2}$ response. $\boldsymbol{B}$, Representative epifluorescence microscopy images of neuroprogenitors treated with $\mathrm{CM}$ microC or microPH for $5 \mathrm{~d}$. Freshly dissociated NPCs were used as control. C, Calcium responses to consecutive stimuli (KCl, AMPA, ATP, histamine, NMDA) determined as a ratio of Fura2 fluorescence of cells shown in $\boldsymbol{B}$. D, Percentage of cell phenotypes responding to each stimulus ( 38 stellate cells, 8 ramified cells, 19 bipolar cells, and $33 \mathrm{NPCs}$; pooled from $N=2$ independent experiments). The baseline was calculated as the mean of the first $60 \mathrm{~s}$ of recording for each cell. Only peaks that increase or decrease three times the SEM of the baseline were considered as a positive response. $\boldsymbol{E}$, Representative blots showing relative levels of REST, Ascl, phospho-SMAD1/5/9, and SMAD1 in NPCs treated with CM microC or microPH for $3 \mathrm{~d}$. F, Quantification of the relative expression of REST, Ascl and the ratio phospho-SMAD/total-SMAD in NPCS treated with CM microC or microPH for $3 \mathrm{~d}$. $\beta$-actin was used as a loading control. Scale bar, $20 \mu \mathrm{m} . N=2$ independent experiments (D, pooled cells), $N=3$ independent experiments $(\boldsymbol{F})$. Error bars represent mean \pm SEM. ${ }^{*} p<0.05,{ }^{* * *} p<0.001$ by Holm-Sidak post hoc test (after one-way ANOVA was significant at $p<0.05$ ). Values of statistics used are shown in Table 8.

ment of gliogenesis. In vivo no changes in the production of newborn astrocytes were observed in the neurogenic cascade, although on isolated NPCs the phagocytic microglial secretome gave rise to astrocyte-committed cells with a bipolar phenotype, reminiscent of radial glia (Encinas and Enikolopov, 2008). These cells presented several astrocytic features, including the expression of GFAP and S100 $\beta$ (Raponi et al., 2007; Encinas and Enikolopov, 2008); intracellular calcium response to ATP (De Melo Reis et al., 2011) and high phosphorylation of SMAD, which interacts with TGF $\beta$ to give rise to astrocytes/radial glia (Stipursky and Gomes, 2007). Nonetheless, our transcriptional assay did not show heterologous 'gliogenic' genes in phagocytic microglia, suggesting that rather than actively promoting astrogenesis, the acute phagocytosis secretome indirectly promote the default astrocytic lineage (Miller and Gauthier, 2007) by restricting the neuronal lineage. 
A

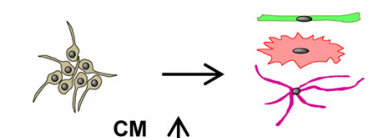

$(3,5 d)$ 个

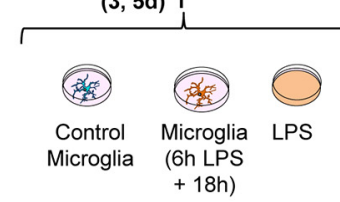

B

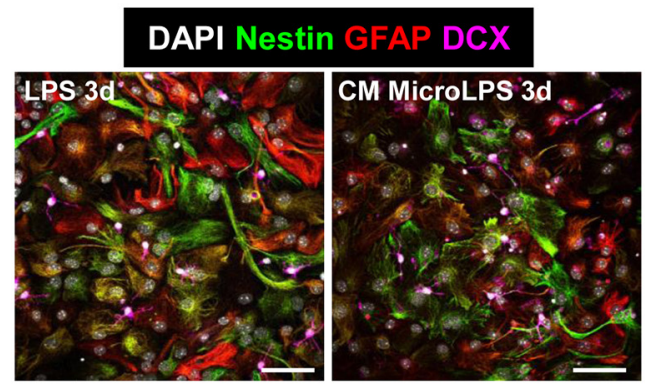

C
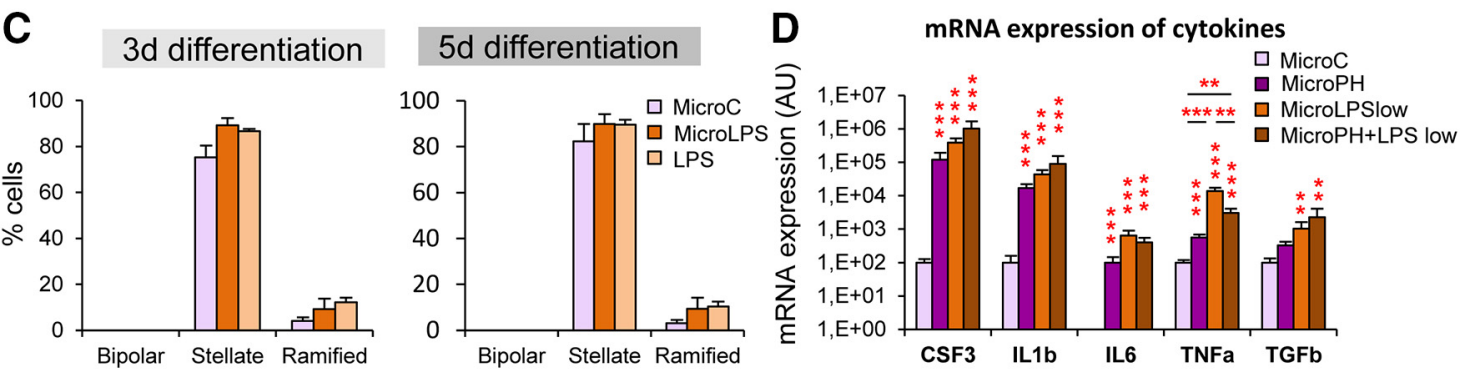

E

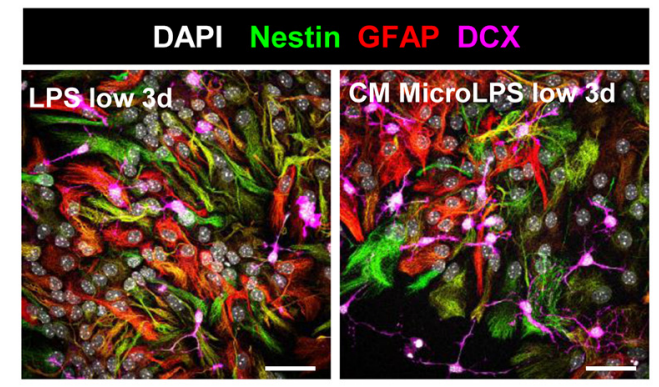

G

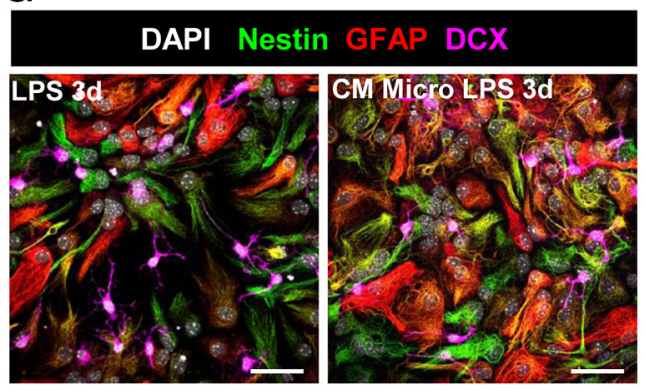

F
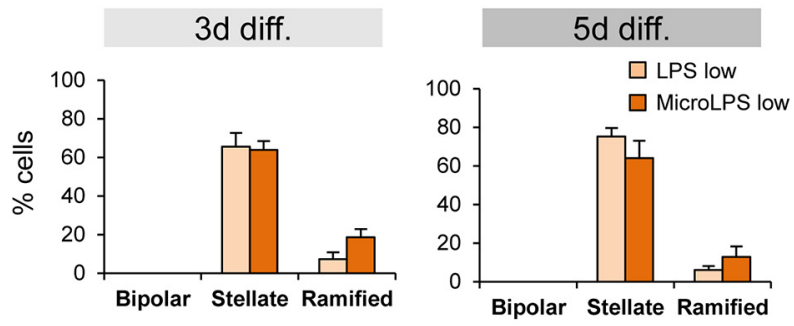

H
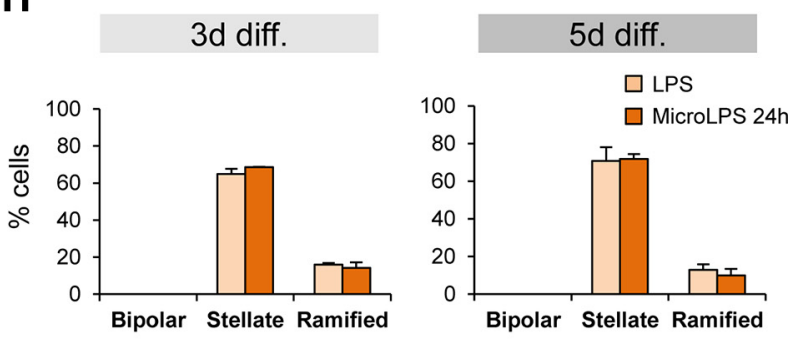

I

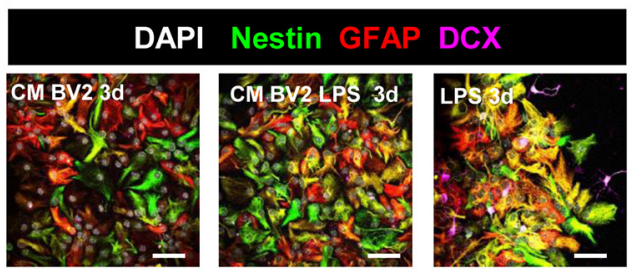

J

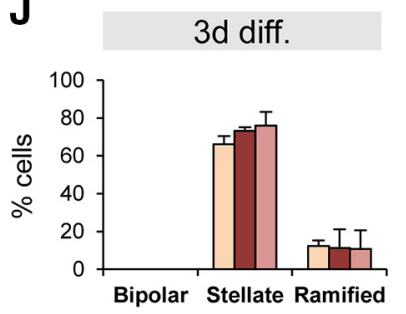

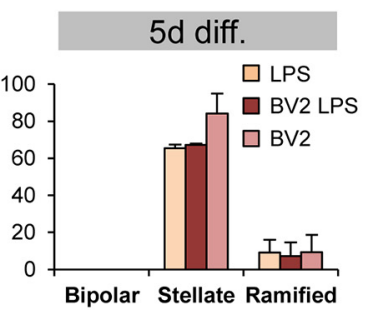

Figure 12. Effect of CM microLPS on neurogenesis in vitro. $\boldsymbol{A}$, Experimental design of the in vitro neurogenesis assay. $\boldsymbol{B}$, Representative confocal microscopy images of neuroprogenitors treated with CM MicroC, CM MicroLPS $6 \mathrm{~h}+18 \mathrm{~h}(1 \mu \mathrm{g} / \mathrm{ml})$ or LPS alone $(1 \mu \mathrm{g} / \mathrm{ml} ; 24 \mathrm{~h})$. C, Percentage of cell types found after 3 or $5 \mathrm{~d}$ treatment with CM MicroC, CM MicroLPS (6h $+18 \mathrm{~h})$, LPS. The group "bipolar cells" is included for visualization purposes, but as this cell type was not found with any of the treatments, it was not included in the statistical analysis. Three-way ANOVA (treatment $X$ life $\times$ time) showed interactions between the different factors and thus the data were split into several one-way ANOVAs, which showed no significant effect of the treatment. $\boldsymbol{D}$, mRNA expression levels of selected cytokines by real-time qPCR in control microglia (microC), $24 \mathrm{~h}$ phagocytic microglia (microPH), as well as control and phagocytic microglia treated with LPS (150 ng/ml, $18 \mathrm{~h}$ ). HPRT was selected as a reference gene. $\boldsymbol{E}$, Representative confocal microscopy images of NPCs treated with CM from LPS treated microglia or LPS alone (low concentration: $150 \mathrm{ng} / \mathrm{ml} ; 18 \mathrm{~h}$ ). $\boldsymbol{F}$, Quantification of the different cell types found after 3 or $5 \mathrm{~d}$ treatment with CM from LPS treated microglia or LPS. G, Representative confocal microscopy images of NPCs treated with CM MicroLPS or LPS (1 $\mu \mathrm{g} / \mathrm{ml} ; 24 \mathrm{~h})$. $\boldsymbol{H}$, Quantification of the different cell types found after 3 or $5 \mathrm{~d}$ treatment with CM MicroLPS or LPS (high concentration: $1 \mu \mathrm{g} / \mathrm{ml} ; 24 \mathrm{~h}) . \boldsymbol{I}$, Representative confocal microscopy images of neuroprogenitors treated with CM BV2, CM BV2 LPS high or LPS high $(1 \mu \mathrm{g} / \mathrm{ml} ; 24 \mathrm{~h})$. J, Quantification of the different cell types found after 3 or $5 \mathrm{~d}$ (Figure legend continues.) 
A

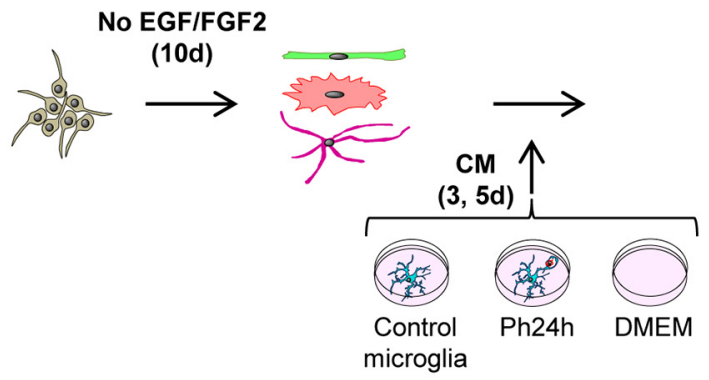

C

\section{DAPI Nestin GFAP DCX}
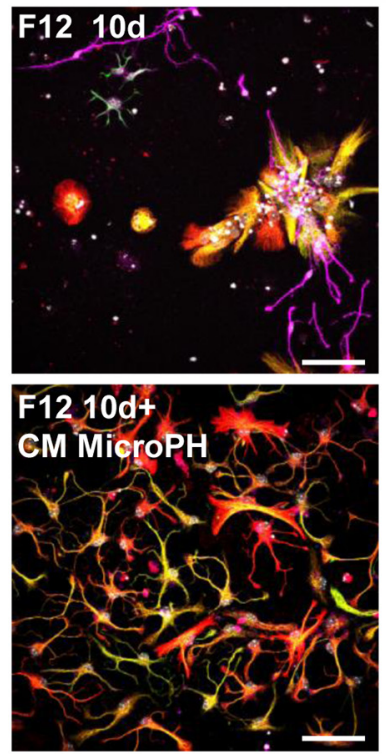

B

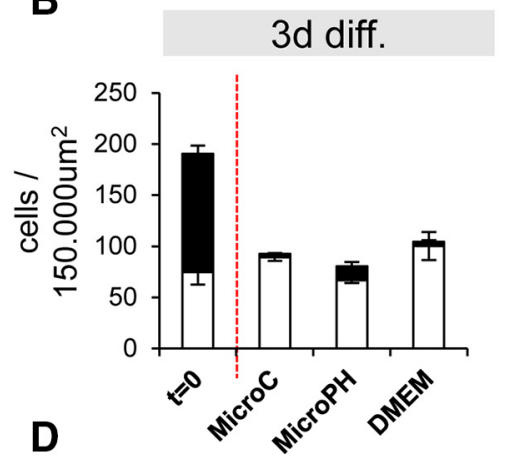

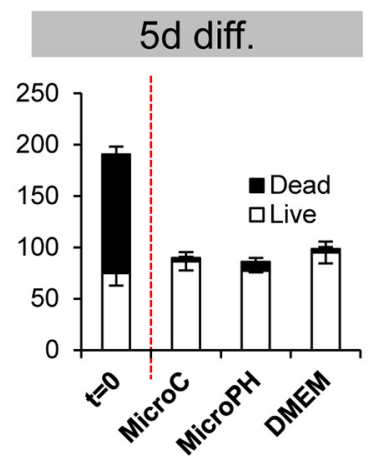

3d differentiation

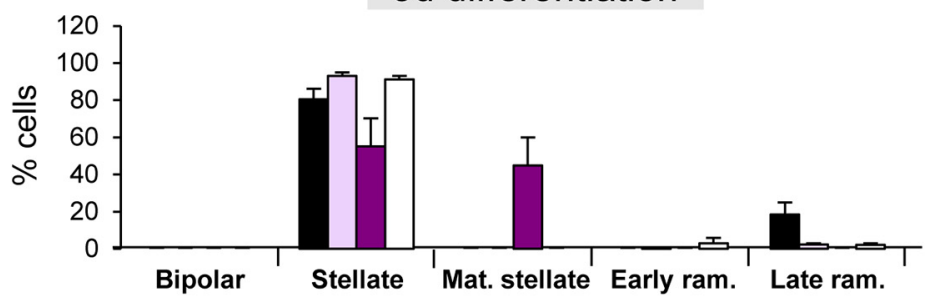

$5 \mathrm{~d}$ differentiation

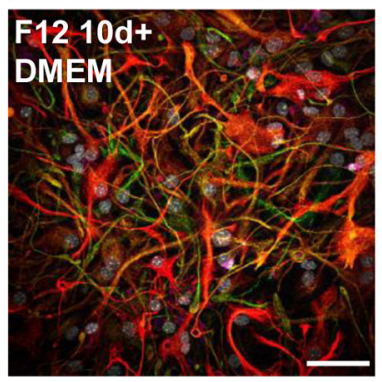

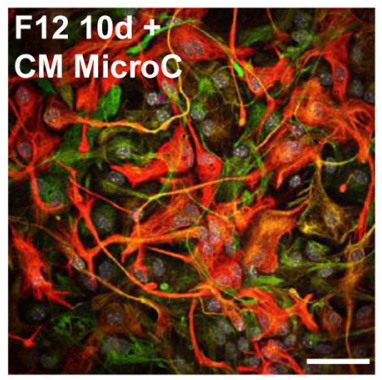

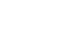

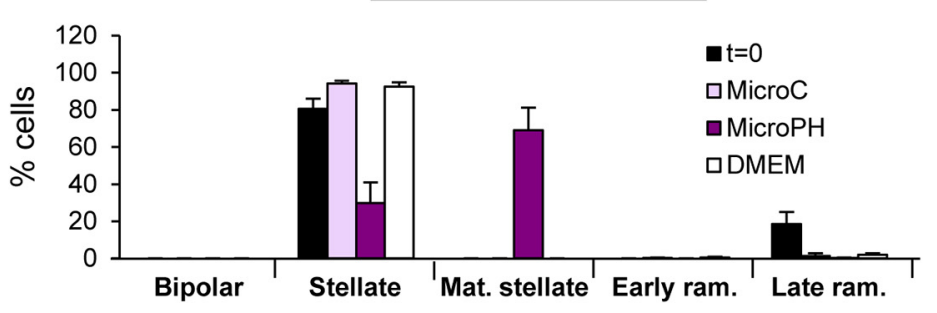

Figure 13. Effect of phagocytic microglia secreted factors on late neurogenesis in vitro. $\boldsymbol{A}$, Experimental design of the in vitro late survival and differentiation assay. $\boldsymbol{B}$, Density of live and dead cells found after $10 \mathrm{~d}$ of DMEM/F12 followed by 3-5 $\mathrm{d}$ of CM microC or microPH and DMEM. The number of cells before adding the $\mathrm{CM}(t=0)$ is shown as a control. $C$, Representative confocal microscopy images of NPCs treated for 10d with DMEM/F12 followed by 3-5 d of CM microC, microPH, or DMEM. Top, Left, DMEM/F12 treatment of $10 \mathrm{~d}$, before adding any CM. D, Percentage of cell types found after $10 \mathrm{~d}$ of DMEM/F12 followed by $3-5 \mathrm{~d}$ of CM microC or microPH and DMEM. The number of cells before adding the $C M(t=0)$ is shown as a control. Mat stellate designates stellate cells with mature (more branched) morphology, and early/late ram designates early/late ramified cells. Scale bars: $20 \mu \mathrm{m}, z=6.3 \mu \mathrm{m}$. $N=3$ independent experiments $(\boldsymbol{B}, \boldsymbol{D})$. Three-way ANOVA (treatment $\times$ life $\times$ time, $F$ ) showed interactions between the different factors and thus the data were split into several one-way ANOVAs, which showed no significant effect of the treatment. Data in $\boldsymbol{D}$ could not be normalized because some cell categories were only present in particular treatments (i.e., the mature stellate phenotype only occurred in MicroPH groups). Error bars represent mean \pm SEM. Values of statistics used are shown in Table 8.

Cytokines are unrelated to the effect of phagocytosis secretome on neurogenesis

Several cytokines were also expressed by phagocytic microglia, such as IL-1 $\beta$, IL-6, and TNF $\alpha$, which have been reported to decrease survival of neuroprogenitors in vitro (IL- $1 \beta$, TNF $\alpha$ ) and in vivo (IL-6; Breton and Mao-Draayer, 2011), inhibiting adult neurogenesis. This cytokine expression profile of phagocytic microglia holds some parallelism to the proinflammatory profile triggered upon inflammation, a process that impairs neurogenesis (Ekdahl et al., 2003; Monje et al., 2003). However, in our hands the inflammatory microglia secretome did not trigger a reduction in the survival of NPCs. Furthermore, we found that treatment with neither LPS nor the secretome of LPS-stimulated

\section{$\leftarrow$}

(Figure legend continued.) treatment with CM BV2, CM BV2 LPS, or LPS. Scale bars: $\boldsymbol{B}, \boldsymbol{E}, \boldsymbol{G}, \boldsymbol{I}$, $20 \mu \mathrm{m}, z=6.3 \mu \mathrm{m} . N=3$ independent experiments $(C), N=4$ independent experiments (D), $N=2$ independent experiments $(\boldsymbol{F}, \boldsymbol{H}, \boldsymbol{J})$. Error bars represent mean \pm SEM. ${ }^{* *} p<0.01$, ${ }^{* * *} p<0.001$ by Holm-Sidak post hoc test (after one-way ANOVA was significant at $p<0.05$ ). Only significant effects are shown. Values of statistics used are shown in Table 8. microglia reduced the production of neuroblasts in vitro, suggesting that inflammation is not as detrimental for neurogenesis as previously stated (Ekdahl et al., 2003; Monje et al., 2003) and that cytokines were not responsible for the effects of phagocytic microglial secretome on neural-committed cells. In addition, the neurogenic modulatory program initiated by phagocytosis encompassed genes involved in matrix remodeling (matrix metalloproteases) and membrane ligands (Jag1, ligand for Notch receptor), suggesting that the observed direct contact between microglia and rNSCs/neuroblasts (Sierra et al., 2010) may also participate in shaping the neurogenic niche through participating in the local control of neuroblast differentiation, survival and synaptic integration (Rodríguez-Iglesias et al., 2019).

Phagocytosis reprograms microglia

Finally, we here show that phagocytosis is not simply a terminal process designed to eliminate debris. In fact, in peripheral macrophages engulfment and degradation result in epigenetic, metabolic and functional reprogramming, a process named 'trained immunity' (Bekkering et al., 2018). Similarly, we here show that 
A

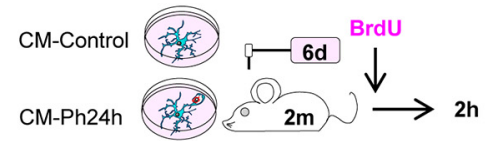

B

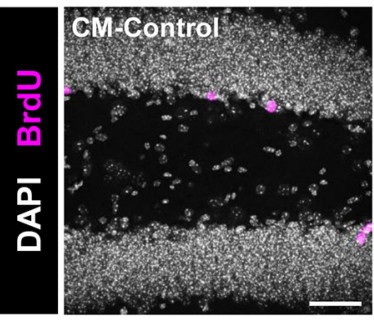

C
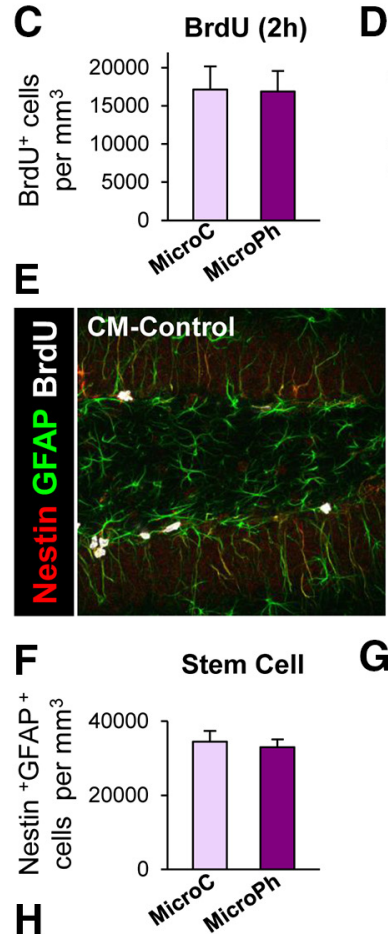

$\mathbf{G}_{+}$
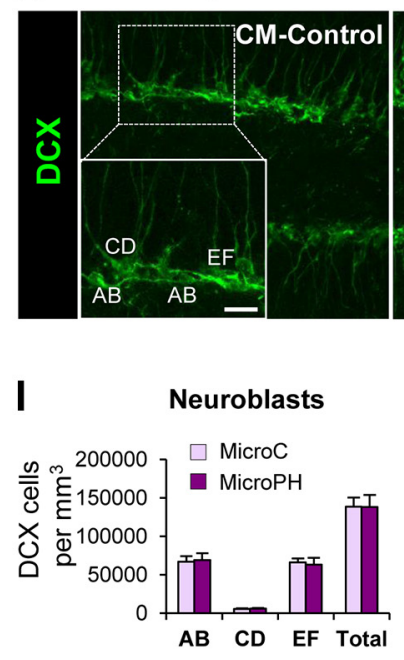
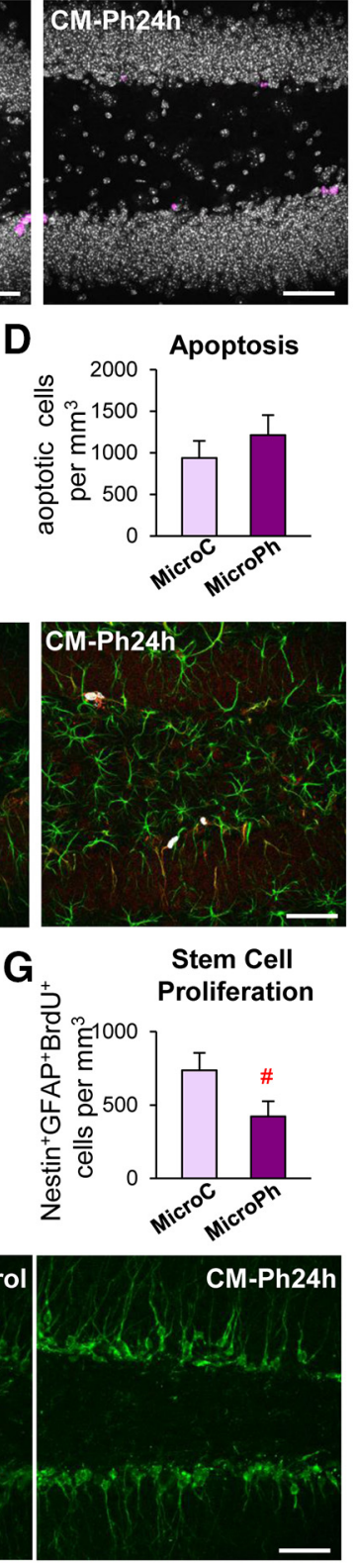

D
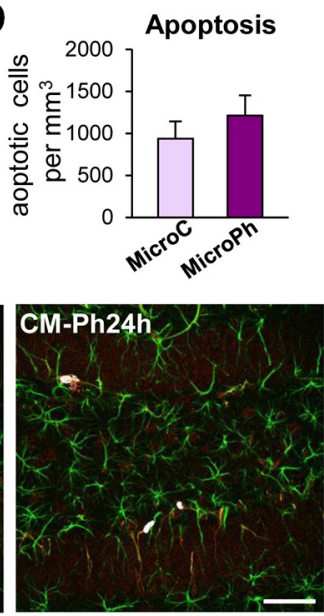

Stem Cell

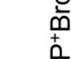

.

$\mathbf{J}$

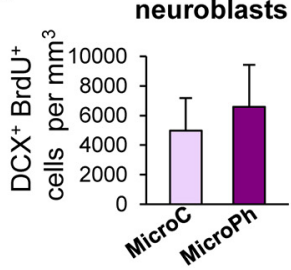

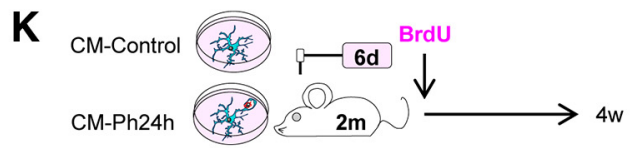

L
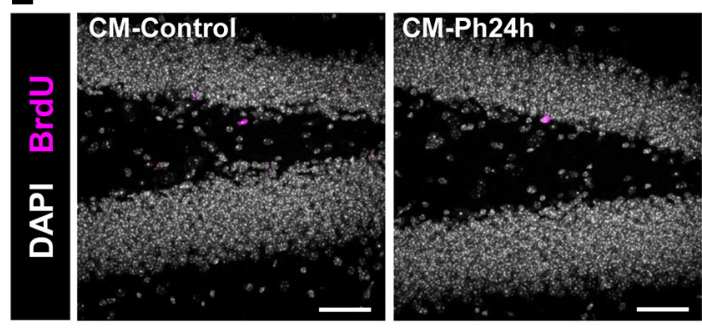

M

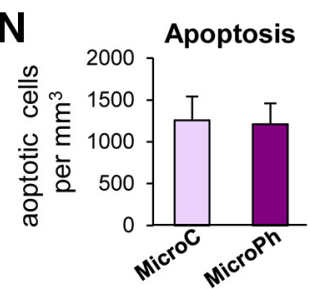

0
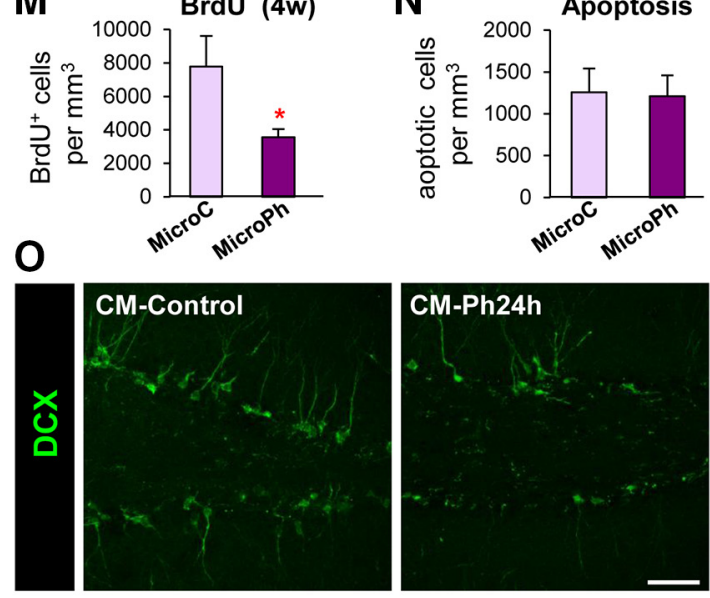

P

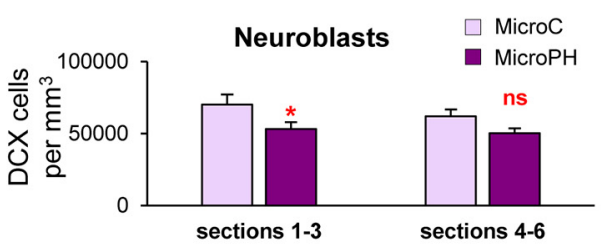

Q
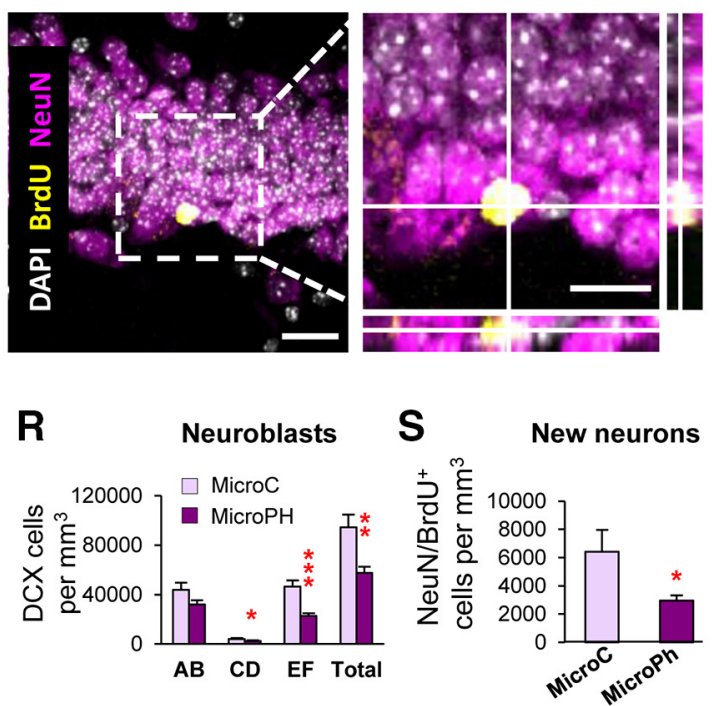

Figure 14. Acute and long-term effects of phagocytic microglia secreted molecules on neurogenesis in vivo. $\boldsymbol{A}$, Experimental design used for the administration of CM micro $\mathrm{C}$ or microPH by osmotic pumps to 2-month-old fms-EGFP mice. B, Representative confocal images of cell proliferation after the CM treatments for $6 \mathrm{~d}$. Cell nuclei were labeled with DAPI (white) and BrdU was used as a proliferative marker (magenta). C, BrdU ${ }^{+}$cell density after CM microC or microPH treatment. D, Apoptotic cell density after CM microC or microPH treatment. $\boldsymbol{E}$, Representative confocal images of stem cells labeled with nestin (red) and GFAP (green). $F$, Stem cell density after CM microC or microPH treatment. $\mathbf{G}$, Proliferating stem cell (nestin ${ }^{+}$, GFAP ${ }^{+}$, BrdU $^{+}$) density after $\mathrm{CM}_{\text {microC }}$ or microPH treatment. $\boldsymbol{H}$, Representative confocal images of neuroblast cell populations $A B, C D, E F$, and total neuroblasts. Neuroblast cells are labeled with DCX (green). $I$, Density of neuroblast types $\mathrm{AB}, \mathrm{CD}$, and EF. J, Proliferating neuroblasts (BrdU ${ }^{+}, \mathrm{DCX}^{+}$) density after treatment with CM microC or microPH. $\boldsymbol{K}$, Experimental design used for the administration of CM microC or microPH by osmotic pumps to 2-month-old fms-EGFP mice. $\mathbf{L}$, Representative confocal images of BrdU ${ }^{+}$cells in the dentate gyrus. $\boldsymbol{M}, \mathrm{BrdU}{ }^{+}{ }^{+}$cell density after $\mathrm{CM}$ microC or (Figure legend continues.) 


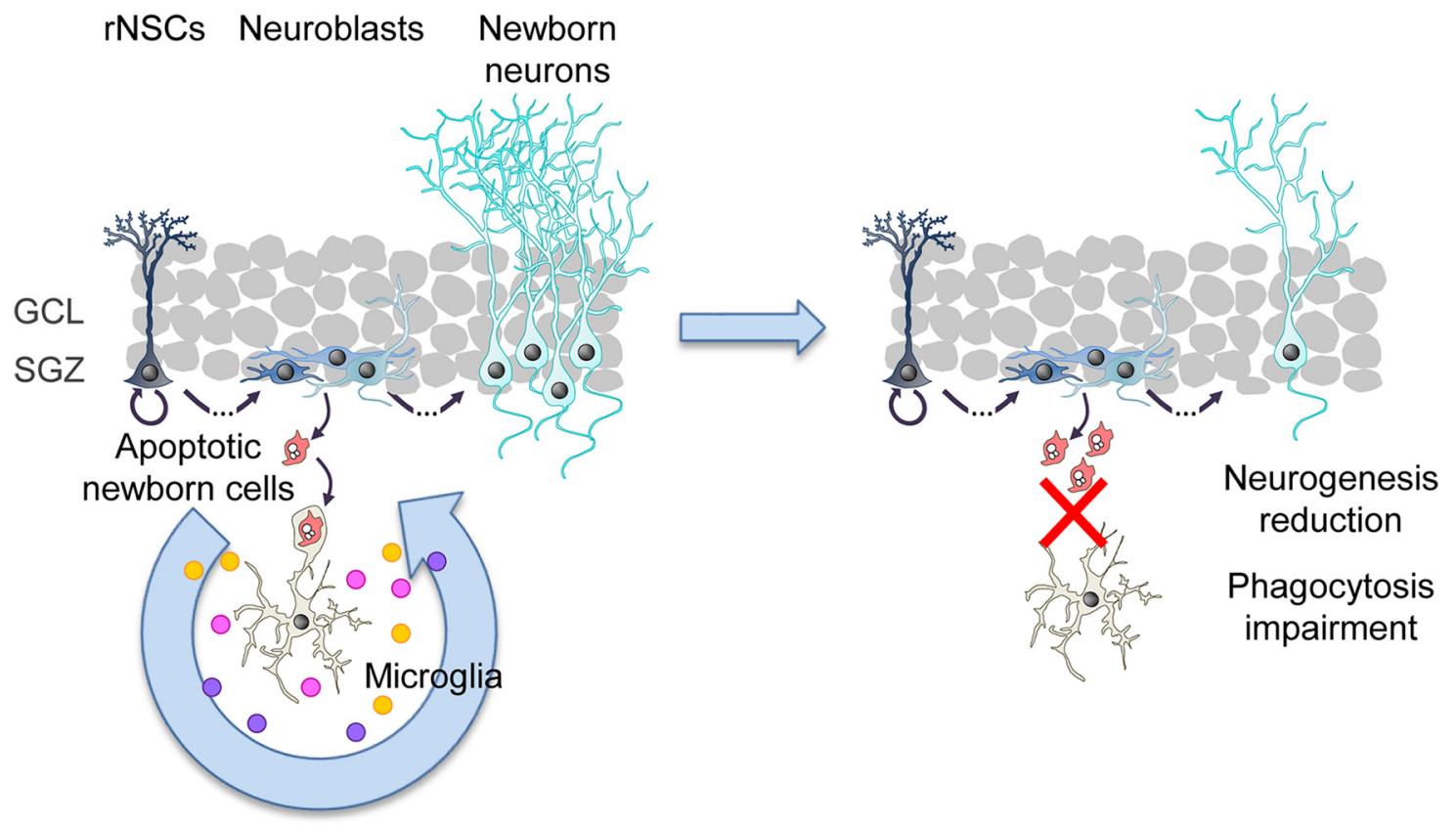

Figure 15. Microglia provides a feedback loop that controls neurogenesis through the phagocytosis-secretome.

in microglia phagocytosis of apoptotic cells triggers a coordinated transcriptional program that involves key chromatin remodeling and metabolic genes, suggesting a long-term reprogramming that may affect multiple microglial functions, from spine surveillance to inflammation. Whether these changes are triggered by the recognition of find-me and "eat-me" surface receptors, or by downstream steps in the phagocytic process of apoptotic cells, remains to be determined. Apoptosis is a widespread phenomenon in neurodegenerative diseases (Abiega et al., 2016) and we speculate that phagocytosis of cell debris and the subsequent alteration of the secretome, as well as other potential functions, may be a key to understanding how microglia impacts surrounding surviving neurons. Similarly, during aging (Pluvinage et al., 2019) or in diseases in which microglial phagocytosis is impaired, such as epilepsy (Abiega et al., 2016), the beneficial effects of promoting engulfment/degradation of cell debris may go beyond merely removing corpses to actively promote regeneration.

In summary, in this paper, we provide strong evidence that phagocytic microglia are a central mechanism to control the homeostasis of the adult hippocampal neurogenic cascade by acutely providing a negative feedback loop via their secretome. This 'brake' is necessary for the long-term maintenance of the neurogenic cascade, since neurogenesis is transiently increased when phagocytosis is acutely blocked, but is disrupted when microglial phagocytosis is chronically impaired, as observed in genetically deficient mice for P2Y12 and MerTK/Axl. Importantly,$$
\leftarrow
$$

(Figure legend continued.) microPH treatment. $\boldsymbol{N}$, Apoptotic cell density after $\mathrm{CM}$ microC or microPH treatment. $\mathbf{0}$, Representative confocal images of neuroblasts labeled with DCX (green). $P$, Density of total number of neuroblasts in Sections $1-3$ closest to the injection site, and $4-6$ further away. $\mathbf{Q}$, Representative confocal images of a newborn neuron labeled with BrdU (yellow) and NeuN (magenta). $\boldsymbol{R}$, Density of neuroblast types $A B, C D, E F$, and total neuroblasts. $S$, New neurons $\left(\mathrm{NeuN}^{+}, \mathrm{BrdU}^{+}\right.$) density after $\mathrm{CM}$ microC or microPH treatment. Scale bars: $\boldsymbol{B}, \boldsymbol{L}$, $\boldsymbol{E}, \mathbf{O}, \boldsymbol{H}, 50 \mu \mathrm{m}$ (insert in $\boldsymbol{H}, 20 \mu \mathrm{m}$ ); $\mathbf{Q}, 20 \mu \mathrm{m}$ (insert, $10 \mu \mathrm{m}$ ); $\boldsymbol{B}, \boldsymbol{L}, \boldsymbol{E}, \mathbf{O}, \boldsymbol{H}, \mathbf{Z}=12 \mu \mathrm{m} ; \mathbf{Q}, \mathbf{Z}=$ $6 \mu \mathrm{m} . N=7-10$ mice $(\boldsymbol{B}-\boldsymbol{J}), N=5-11$ mice $(\boldsymbol{L}-\boldsymbol{S})$. Error bars represent mean \pm SEM. $\# p=$ $0.0649,{ }^{*} p<0.05,{ }^{* *} p<0.01,{ }^{* * *} p<0.001$ by Student's $t$ test. Values of statistics used are shown in Table 9. ns, not significant.
}

the link between the proliferation of newborn cells and apoptosis was already suggested to be necessary for the correct learning and memory of the adult brain (Dupret et al., 2007), and our data here points toward microglial phagocytosis of apoptotic cells as the connecting mechanism. As apoptosis is closely related to neural stem cell proliferation, our data suggest that microglial phagocytosis may also shape other developmental and adult neurogenesis sites, such as the SVZ (Cunningham et al., 2013). In addition, phagocytosis of newborn cells has also been recently shown to play a role in sculpting sex differences in the developing amygdala (VanRyzin et al., 2019). While previous work has suggested a largely detrimental effect of microglia on hippocampal neurogenesis (Valero et al., 2016), our data are in agreement with recent evidences supporting the essential role of macrophages and other immune cells in remodeling stem cells niches (Naik et al., 2018).

\section{References}

Aarum J, Sandberg K, Haeberlein SL, Persson MA (2003) Migration and differentiation of neural precursor cells can be directed by microglia. Proc Natl Acad Sci U S A 100:15983-15988.

Abiega O, Beccari S, Diaz-Aparicio I, Nadjar A, Layé S, Leyrolle Q, GómezNicola D, Domercq M, Pérez-Samartín A, Sánchez-Zafra V, Paris I, Valero J, Savage JC, Hui CW, Tremblay MÈ, Deudero JJ, Brewster AL, Anderson AE, Zaldumbide L, Galbarriatu L, et al. (2016) Neuronal hyperactivity disturbs ATP microgradients, impairs microglial motility, and reduces phagocytic receptor expression triggering apoptosis/microglial phagocytosis uncoupling. PLoS Biol 14:e1002466.

Alberdi E, Wyssenbach A, Alberdi M, Sánchez-Gómez MV, Cavaliere F, Rodríguez JJ, Verkhratsky A, Matute C (2013) $\mathrm{Ca}^{2+}$-dependent endoplasmic reticulum stress correlates with astrogliosis in oligomeric amyloid beta-treated astrocytes and in a model of Alzheimer's disease. Aging Cell 12:292-302.

Babu H, Claasen JH, Kannan S, Rünker AE, Palmer T, Kempermann G (2011) A protocol for isolation and enriched monolayer cultivation of neural precursor cells from mouse dentate gyrus. Front Neurosci 5:89.

Beccari S, Valero J, Maletic-Savatic M, Sierra A (2017) A simulation model of neuroprogenitor proliferation dynamics predicts age-related loss of hippocampal neurogenesis but not astrogenesis. Sci Rep 7:16528.

Beccari S, Diaz-Aparicio I, Sierra A (2018) Quantifying microglial phagocytosis of apoptotic cells in the brain in health and disease. Curr Protoc Immunol 122:e49. 
Bekkering S, Arts RJW, Novakovic B, Kourtzelis I, van der Heijden CD, Li Y, Popa CD, Ter Horst R, van Tuijl J, Netea-Maier RT, van de Veerdonk FL, Chavakis T, Joosten LAB, van der Meer JWM, Stunnenberg H, Riksen NP, Netea MG (2018) Metabolic induction of trained immunity through the mevalonate pathway. Cell 172:135-146.e9.

Bindea G, Galon J, Mlecnik B (2013) CluePedia cytoscape plugin: pathway insights using integrated experimental and in silico data. Bioinformatics 29:661-663.

Bloodgood BL, Sabatini BL (2008) Regulation of synaptic signalling by postsynaptic, non-glutamate receptor ion channels. J Physiol 586:1475-1480.

Bonaguidi MA, Wheeler MA, Shapiro JS, Stadel RP, Sun GJ, Ming GL, Song H (2011) In vivo clonal analysis reveals self-renewing and multipotent adult neural stem cell characteristics. Cell 145:1142-1155.

Brazma A, Hingamp P, Quackenbush J, Sherlock G, Spellman P, Stoeckert C, Aach J, Ansorge W, Ball CA, Causton HC, Gaasterland T, Glenisson P, Holstege FC, Kim IF, Markowitz V, Matese JC, Parkinson H, Robinson A, Sarkans U, Schulze-Kremer S, et al. (2001) Minimum information about a microarray experiment (MIAME)-toward standards for microarray data. Nat Genet 29:365-371.

Breton J, Mao-Draayer Y (2011) Impact of cytokines on neural stem/progenitor cell fate. J Neurol Neurophysiol. S4.

Brown JP, Couillard-Després S, Cooper-Kuhn CM, Winkler J, Aigner L, Kuhn HG (2003) Transient expression of doublecortin during adult neurogenesis. J Comp Neurol 467:1-10.

Bustin SA (2010) Why the need for qPCR publication guidelines? The case for MIQE. Methods 50:217-226.

Chakrabarti R, Celià-Terrassa T, Kumar S, Hang X, Wei Y, Choudhury A, Hwang J, Peng J, Nixon B, Grady JJ, DeCoste C, Gao J, van Es JH, Li MO, Aifantis I, Clevers H, Kang Y (2018) Notch ligand Dll1 mediates crosstalk between mammary stem cells and the macrophageal niche. Science 360:eaan4153.

Chow A, Huggins M, Ahmed J, Hashimoto D, Lucas D, Kunisaki Y, Pinho S, Leboeuf M, Noizat C, van Rooijen N, Tanaka M, Zhao ZJ, Bergman A, Merad M, Frenette PS (2013) CD169(+) macrophages provide a niche promoting erythropoiesis under homeostasis and stress. Nat Med 19: $429-436$.

Conesa A, Nueda MJ, Ferrer A, Talón M (2006) maSigPro: a method to identify significantly differential expression profiles in time-course microarray experiments. Bioinformatics 22:1096-1102.

Cunningham CL, Martínez-Cerdeño V, Noctor SC (2013) Microglia regulate the number of neural precursor cells in the developing cerebral cortex. J Neurosci 33:4216-4233.

De Melo Reis RA, Schitine CS, Köfalvi A, Grade S, Cortes L, Gardino PF, Malva JO, de Mello FG (2011) Functional identification of cell phenotypes differentiating from mice retinal neurospheres using single cell calcium imaging. Cell Mol Neurobiol 31:835-846.

Deng W, Aimone JB, Gage FH (2010) New neurons and new memories: how does adult hippocampal neurogenesis affect learning and memory? Nat Rev Neurosci 11:339-350.

Diaz-Aparicio I, Sierra A (2019) Clq is related to microglial phagocytosis in the hippocampus in physiological conditions. Science Matters.

Dupret D, Fabre A, Döbrössy MD, Panatier A, Rodríguez JJ, Lamarque S, Lemaire V, Oliet SH, Piazza PV, Abrous DN (2007) Spatial learning depends on both the addition and removal of new hippocampal neurons. PLoS Biol 5:e214.

Ehninger D, Kempermann G (2008) Neurogenesis in the adult hippocampus. Cell Tissue Res 331:243-250.

Eiriz MF, Grade S, Rosa A, Xapelli S, Bernardino L, Agasse F, Malva JO (2011) Functional evaluation of neural stem cell differentiation by single cell calcium imaging. Curr Stem Cell Res Ther 6:288-296.

Ekdahl CT, Claasen JH, Bonde S, Kokaia Z, Lindvall O (2003) Inflammation is detrimental for neurogenesis in adult brain. Proc Natl Acad Sci U S A 100:13632-13637.

Elliott MR, Chekeni FB, Trampont PC, Lazarowski ER, Kadl A, Walk SF, Park D, Woodson RI, Ostankovich M, Sharma P, Lysiak JJ, Harden TK, Leitinger N, Ravichandran KS (2009) Nucleotides released by apoptotic cells act as a find-me signal to promote phagocytic clearance. Nature 461:282-286.

Encinas JM, Enikolopov G (2008) Identifying and quantitating neural stem and progenitor cells in the adult brain. Methods Cell Biol 85:243-272.

Encinas JM, Sierra A (2012) Neural stem cell deforestation as the main force driving the age-related decline in adult hippocampal neurogenesis. Behav Brain Res 227:433-439.

Encinas JM, Michurina TV, Peunova N, Park JH, Tordo J, Peterson DA, Fishell G, Koulakov A, Enikolopov G (2011) Division-coupled astrocytic differentiation and age-related depletion of neural stem cells in the adult hippocampus. Cell Stem Cell 8:566-579.

Fourgeaud L, Través PG, Tufail Y, Leal-Bailey H, Lew ED, Burrola PG, Callaway P, Zagórska A, Rothlin CV, Nimmerjahn A, Lemke G (2016) TAM receptors regulate multiple features of microglial physiology. Nature 532:240-244.

Fraser DA, Pisalyaput K, Tenner AJ (2010) C1q enhances microglial clearance of apoptotic neurons and neuronal blebs, and modulates subsequent inflammatory cytokine production. J Neurochem 112:733-743.

Gebara E, Sultan S, Kocher-Braissant J, Toni N (2013) Adult hippocampal neurogenesis inversely correlates with microglia in conditions of voluntary running and aging. Front Neurosci 7:145.

Hachem S, Aguirre A, Vives V, Marks A, Gallo V, Legraverend C (2005) Spatial and temporal expression of S100B in cells of oligodendrocyte lineage. Glia 51:81-97.

Haynes SE, Hollopeter G, Yang G, Kurpius D, Dailey ME, Gan WB, Julius D (2006) The P2Y12 receptor regulates microglial activation by extracellular nucleotides. Nat Neurosci 9:1512-1519.

Kohyama J, Sanosaka T, Tokunaga A, Takatsuka E, Tsujimura K, Okano H, Nakashima K (2010) BMP-induced REST regulates the establishment and maintenance of astrocytic identity. J Cell Biol 189:159-170.

Kreisel T, Wolf B, Keshet E, Licht T (2019) Unique role for dentate gyrus microglia in neuroblast survival and in VEGF-induced activation. Glia 67:594-618.

Kwon MJ, Oh E, Lee S, Roh MR, Kim SE, Lee Y, Choi YL, In YH, Park T, Koh SS, Shin YK (2009) Identification of novel reference genes using multiplatform expression data and their validation for quantitative gene expression analysis. PLoS One 4:e6162.

Liu Y, Miao Q, Yuan J, Han S, Zhang P, Li S, Rao Z, Zhao W, Ye Q, Geng J, Zhang X, Cheng L (2015) Ascll converts dorsal midbrain astrocytes into functional neurons in vivo. J Neurosci 35:9336-9355.

Lopez-Atalaya JP, Askew KE, Sierra A, Gomez-Nicola D (2018) Development and maintenance of the brain's immune toolkit: microglia and nonparenchymal brain macrophages. Dev Neurobiol 78:561-579.

Miller FD, Gauthier AS (2007) Timing is everything: making neurons versus glia in the developing cortex. Neuron 54:357-369.

Mlecnik B, Galon J, Bindea G (2018) Comprehensive functional analysis of large lists of genes and proteins. J Proteomics 171:2-10.

Monje ML, Toda H, Palmer TD (2003) Inflammatory blockade restores adult hippocampal neurogenesis. Science 302:1760-1765.

Moreno-Jiménez EP, Flor-García M, Terreros-Roncal J, Rábano A, Cafini F, Pallas-Bazarra N, Ávila J, Llorens-Martín M (2019) Adult hippocampal neurogenesis is abundant in neurologically healthy subjects and drops sharply in patients with Alzheimer's disease. Nat Med 25:554-560.

Morgan SC, Taylor DL, Pocock JM (2004) Microglia release activators of neuronal proliferation mediated by activation of mitogen-activated protein kinase, phosphatidylinositol-3-kinase/Akt and delta-notch signalling cascades. J Neurochem 90:89-101.

Morioka S, Perry JSA, Raymond MH, Medina CB, Zhu Y, Zhao L, Serbulea V, Onengut-Gumuscu S, Leitinger N, Kucenas S, Rathmell JC, Makowski L, Ravichandran KS (2018) Efferocytosis induces a novel SLC program to promote glucose uptake and lactate release. Nature 563:714-718.

Nagata S, Hanayama R, Kawane K (2010) Autoimmunity and the clearance of dead cells. Cell 140:619-630.

Naik S, Larsen SB, Cowley CJ, Fuchs E (2018) Two to tango: dialog between immunity and stem cells in health and disease. Cell 175:908-920.

Overall RW, Paszkowski-Rogacz M, Kempermann G (2012) The mammalian adult neurogenesis gene ontology (MANGO) provides a structural framework for published information on genes regulating adult hippocampal neurogenesis. PLoS One 7:e48527.

Parkhurst CN, Yang G, Ninan I, Savas JN, Yates JR 3rd, Lafaille JJ, Hempstead BL, Littman DR, Gan WB (2013) Microglia promote learningdependent synapse formation through brain-derived neurotrophic factor. Cell 155:1596-1609.

Plümpe T, Ehninger D, Steiner B, Klempin F, Jessberger S, Brandt M, Römer B, Rodriguez GR, Kronenberg G, Kempermann G (2006) Variability of doublecortin-associated dendrite maturation in adult hippocampal neu- 
rogenesis is independent of the regulation of precursor cell proliferation. BMC Neurosci 7:77.

Pluvinage JV, Haney MS, Smith BAH, Sun J, Iram T, Bonanno L, Li L, Lee DP, Morgens DW, Yang AC, Shuken SR, Gate D, Scott M, Khatri P, Luo J, Bertozzi CR, Bassik MC, Wyss-Coray T (2019) CD22 blockade restores homeostatic microglial phagocytosis in ageing brains. Nature 568:187192.

Ramakers C, Ruijter JM, Deprez RH, Moorman AF (2003) Assumption-free analysis of quantitative real-time polymerase chain reaction (PCR) data. Neurosci Lett 339:62-66.

Raponi E, Agenes F, Delphin C, Assard N, Baudier J, Legraverend C, Deloulme JC (2007) S100B expression defines a state in which GFAPexpressing cells lose their neural stem cell potential and acquire a more mature developmental stage. Glia 55:165-177.

Rodríguez-Iglesias N, Sierra A, Valero J (2019) Rewiring of memory circuits: connecting adult newborn neurons with the help of microglia. Front Cell Dev Biol 7:24.

Rogers JT, Morganti JM, Bachstetter AD, Hudson CE, Peters MM, Grimmig BA, Weeber EJ, Bickford PC, Gemma C (2011) CX3CR1 deficiency leads to impairment of hippocampal cognitive function and synaptic plasticity. J Neurosci 31:16241-16250.

Rotheneichner P, Romanelli P, Bieler L, Pagitsch S, Zaunmair P, Kreutzer C, Konig R, König R, Marschallinger J, Aigner L, Couillard-Després S (2017) Tamoxifen activation of cre-recombinase has no persisting effects on adult neurogenesis or learning and anxiety. Front Neurosci 11:27.

Rothlin CV, Lemke G (2010) TAM receptor signaling and autoimmune disease. Curr Opin Immunol 22:740-746.

Santos AJM, Lo YH, Mah AT, Kuo CJ (2018) The intestinal stem cell niche: homeostasis and adaptations. Trends Cell Biol 28:1062-1078.

Sasmono RT, Oceandy D, Pollard JW, Tong W, Pavli P, Wainwright BJ, Ostrowski MC, Himes SR, Hume DA (2003) A macrophage colonystimulating factor receptor-green fluorescent protein transgene is expressed throughout the mononuclear phagocyte system of the mouse. Blood 101:1155-1163.

Scholzen T, Gerdes J (2000) The ki-67 protein: from the known and the unknown. J Cell Physiol 182:311-322.

Scott RS, McMahon EJ, Pop SM, Reap EA, Caricchio R, Cohen PL, Earp HS, Matsushima GK (2001) Phagocytosis and clearance of apoptotic cells is mediated by MER. Nature 411:207-211.
Sierra A, Gottfried-Blackmore AC, McEwen BS, Bulloch K (2007) Microglia derived from aging mice exhibit an altered inflammatory profile. Glia 55:412-424.

Sierra A, Encinas JM, Deudero JJ, Chancey JH, Enikolopov G, OverstreetWadiche LS, Tsirka SE, Maletic-Savatic M (2010) Microglia shape adult hippocampal neurogenesis through apoptosis-coupled phagocytosis. Cell Stem Cell 7:483-495.

Sierra A, Abiega O, Shahraz A, Neumann H (2013) Janus-faced microglia: beneficial and detrimental consequences of microglial phagocytosis. Front Cell Neurosci 7:6.

Sierra A, Beccari S, Diaz-Aparicio I, Encinas JM, Comeau S, Tremblay MÈ (2014) Surveillance, phagocytosis, and inflammation: how never-resting microglia influence adult hippocampal neurogenesis. Neural Plast 2014:610343.

Sierra A, Martín-Suárez S, Valcárcel-Martin R, Pascual-Brazo J, Aelvoet SA, Abiega O, Deudero JJ, Brewster AL, Bernales I, Anderson AE, Baekelandt V, Maletić-Savatić M, Encinas JM (2015) Neuronal hyperactivity accelerates depletion of neural stem cells and impairs hippocampal neurogenesis. Cell Stem Cell 16:488-503.

Stipursky J, Gomes FC (2007) TGF-betal/SMAD signaling induces astrocyte fate commitment in vitro: implications for radial glia development. Glia 55:1023-1033.

Valero J, Paris I, Sierra A (2016) Lifestyle shapes the dialogue between environment, microglia, and adult neurogenesis. ACS Chem Neurosci 7: 442-453.

van de Moosdijk AA, van Amerongen R (2016) Identification of reliable reference genes for $\mathrm{qRT}$-PCR studies of the developing mouse mammary gland. Sci Rep 6:35595.

VanRyzin JW, Marquardt AE, Argue KJ, Vecchiarelli HA, Ashton SE, Arambula SE, Hill MN, McCarthy MM (2019) Microglial phagocytosis of newborn cells is induced by endocannabinoids and sculpts sex differences in juvenile rat social play. Neuron 102:435-449.e6.

Walton NM, Sutter BM, Laywell ED, Levkoff LH, Kearns SM, Marshall GP 2nd, Scheffler B, Steindler DA (2006) Microglia instruct subventricular zone neurogenesis. Glia 54:815-825.

Xapelli S, Agasse F, Sardà-Arroyo L, Bernardino L, Santos T, Ribeiro FF, Valero J, Bragança J, Schitine C, de Melo Reis RA, Sebastião AM, Malva JO (2013) Activation of type 1 cannabinoid receptor (CB1R) promotes neurogenesis in murine subventricular zone cell cultures. PLoS One 8:e63529. 